\title{
Der Einfluß „normaler” Temperaturen auf Lebensprozesse bei wechselwarmen Tieren unter Ausschluß der Wachstums- und Entwicklungsprozesse
}

\author{
H. PReChT \\ Zoologisches Institut der Universität Kiel, Lebrstubl für vergleichende \\ Pbysiologie und Tierpsychologie, Kiel
}

\begin{abstract}
The influence of "normal" temperatures on life processes in poikilotherm animals exclusive of growth and development processes. This review summarizes especially literature published since 1955. It deals with reactions, regulations and acclimations (adaptations) and does not attempt to exclude overlappings in regard to terminological classifications; acclimatizations (according to the terminology of PrOSSER 1958) are not discussed and the problem of usefulness of a response (in the sense of a selective advantage) is avoided. In order to characterize the dependence of life processes on experimental temperatures, $Q_{10}$ or $\mu$-values are used. These values can differ greatly, e. g. in different organ functions, partial functions of an organ, in case of varying functional states of an organ, equal organ functions in different races or species, etc. Parts of $r-t$ curves of biological importance show sometimes especially low temperature coefficients - a fact not always caused by endogenous reaction norms, but sometimes also by regulations or adaptations. R-t curves can also be influenced in different ways by the size of the test animal; this may be demonstrated both in interracial and interspecific comparisons as well as by comparing different states of growth of one and the same species. In cases of capacity adaptation, temperature coefficients may also depend on the adaptation temperature. Seasonal influences on $r-t$ curves are dealt with only briefly; they can be caused by various factors (adaptation temperature, photoperiod, endogenous rhythm, etc.). Experimental results may be complicated by over- and undershoots, particularly if the test temperature is changed rapidly. Over- and undershoots can be immediate reactions ("Einschwingprozesse"); but also longer lasting after-effects may be observed due to stress phenomena releasing counter-reactions of the body, rendering exact experiments more difficult. Damages which require repair may also occur. Stress phenomena can be observed on the basis of enzyme activities or of changes in RNA-content. Some examples are presented concerning regulations via integrative systems, and the possibilities for separating such regulations from reactions and adaptations are discussed. It is necessary to distinguish between genetic and non-genetic adaptations; the latter have been studied much more intensively. Changes in adaptation temperature can cause quantitative changes in important substances (e. g. contents of water and salt, proteins, fats, RNA, DNA) or in $r$-t curves of which several types can be distinguished; in some cases classifications are very difficult, e. g. in regard to some enzyme activities. The prerequisites concerning exact experimentation in regard to capacity adaptation are described. A non-genetic adaptation may manifest itself at all organismic levels (intact animals, isolated organs, cell metabolism, etc.). General rules for determining the presence of a capacity adaptation are difficult to establish; apparently it is more often to be found in aquatic than in terrestrial animals. Degree and type of adaptation can be different in regard to different functions of one and the same organ, tissues of the same ani-
\end{abstract}


mal, or cell metabolic processes of the same tissue. Furthermore, the metabolic pathway may depend on the adaptation temperature. Though relatively rapid capacity adaptations can be found, acclimations generally compensate for long lasting temperature changes. The mechanism of adaptation often depends on temperature, but may still function at temperatures below zero; it is still insufficiently known; an attempt to analyze the mechanism of adaptation is undertaken using the respiration of the eel Anguilla anguilla as an example. Influences of the central nervous system, body fluids and hormones are discussed.

\section{EINLEITUNG}

Seit dem 1955 erschienenen Buch "Temperatur und Leben" von Precht, ChriSTOPHERSEN \& HENSEL, in dem die ältere Literatur zu finden ist, hat man über den Einfluß „normaler“ Temperaturen auf Lebensprozesse bei poikilothermen Tieren intensiv weitergearbeitet (Zusammenfassungen: FrY 1958, Prosser 1958, 1967, PRECHT 1961a, 1964b, Prosser \& Brown 1961, Hannon \& Viereck 1962, Dill et al. 1964, Kinne 1964b, 1965, Rose 1967, Troshin 1967). Es soll versucht werden, besonders die nach 1955 erarbeiteten wesentlichsten Gesichtspunkte über diesen speziellen Problemkreis ohne Anspruch auf Vollständigkeit zusammenfassend darzustellen.

Nicht behandelt werden die sich in vielem anders verhaltenden sich ändernden Reaktionssysteme (Wachstums- und Entwicklungsprozesse), alle Möglichkeiten der wechselwarmen Tiere, ihre Körpertemperatur zu ändern, sei es durch Anklänge an eine Thermoregulation oder ihr Verhalten, und auch alle Probleme der Resistenz gegenïber extremen Temperaturen. Der im Gegensatz dazu verwendete Ausdrudk „normaler" Temperaturbereich ist natürlich relativ zu werten, da dieser Bereich für verschiedene Arten unterschiedlich sein kann. Es interessieren nur die Fälle, bei denen die wechselwarmen Tiere ihre Körpertemperatur mehr oder weniger vollkommen der Außentemperatur angleichen. Die Temperatur ist natürlich nur einer der Faktoren, die das Leben der Organismen beeinflussen, wenn auch ein sehr wichtiger. Den Okologen interessiert, welchen Einfluß gerade das Zusammenwirken mehrerer Faktoren hat, doch bringen polyfaktorielle Untersuchungen für den Physiologen eine wesentliche, oftmals kaum zu bewältigende Komplikation mit sich. Eine Berücksichtigung mehrerer Faktoren würde den Rahmen dieser Abhandlung sprengen; hier soll nur der Einfluß der Temperatur berüdssichtigt werden.

Zur Nomenklatur: Bei Anderungen der Versuchstemperatur (VT) verhalten sich die meisten Lebensprozesse der poikilothermen Organismen wie chemische Reaktionen, andere auch wie physikalische Prozesse. Sich anschließende Gleichgewichtseinstellungen (overshoots etc.) rechnet man sinnvollerweise ebenfalls zu den $\mathrm{R} \mathrm{e} \mathrm{a} \mathrm{k}$ tion en. Durch eine typische $R$ e gulat i o n wird die Körpertemperatur der Vögel und Säugetiere konstant gehalten. Regulationen kommen im Hinblick auf unser Thema auch schon bei den wechselwarmen Tieren vor. Von den Ad a p tation en unterscheiden sie sich (trotz mancher Übergänge) dadurch, daß diese "echte funktionelle und strukturelle Veränderungen im Organismus verursachen, Zeit zu ihrer ,Entwicklung' benötigen und sich vielfach nicht auf spezifische Organe beschränken, sondern mehr oder minder alle Ebenen der organismischen. Organisation betreffen. Regulationen dagegen haben im allgemeinen keine echten Veränderungen des Status quo ante zur 
Folge; sie verlaufen meist recht schnell und sind das Ergebnis der routinemäßigen Aktivität spezifischer, präexistierender Reaktionssysteme" (KINNE 1965, p. 147, vgl. Wieser 1964, Precht \& Lindner 1966). Bei den Adaptationen unterscheidet KinNe (a) Simultanreaktionen, (b) die Stabilisierungsphase und (c) den neuen stationären $\mathrm{Zu}$ stand. Prosser (1958, p. 169) trennt $z$ wischen a $\mathrm{cclim}$ a tion und a $\mathrm{ccl}$ im a $\mathrm{ti}$ $z$ a tio n; im ersten Fall handelt es sich um eine Anpassung an einen Faktor unter kontrollietten Bedingungen, im zweiten um eine Anpassung an einen Komplex von Umweltfaktoren, sowohl jahreszeitliche als auch klimatische; uns interessieren in diesem Zusammenhang acclimations.

Die Worte Adaptation und Akklimatisation (im Sinne von acclimation) werden im allgemeinen als Synonyme gebraucht. Die Sinnesphysiologen verwenden das Wort Adaptation für Mechanismen, die nach der Definition von KINNE eher Regulationen sind und für die das Wort Akklimation unpassend wäre, zumal man dabei an Klimafaktoren denkt; insofern sollte man für die hier behandelten Phänomene dem Wort Akklimatisation den Vorrang geben, sofern Verwechslungen möglich sind. Diese Adaptationen oder Akklimatisationen können durch Außenfaktoren, wie die Vorbehandlungstemperatur vor den Versuchen (Adaptationstemperatur $=\mathrm{AT}$ ), ausgelöst werden oder durch eine Selektion, sei es in länger dauernden Experimenten oder im Laufe der Phylogenie, wobei es sich dann nicht wie im ersten Fall um funktionelle feedbadkSysteme handelt (vgl. Rozhaja 1963, LeAke in Dill et al. 1964). Bei den nichtgenetischen und genetischen Adaptationen unterscheidet man eine Leistungsadaptation (Leistungsakklimatisation) im "normalen" Temperaturbereich von einer Resistenzadaptation als Anpassung an extreme Temperaturen (Hitze- und Kälteadaptation).

Die Worte Adaptation und Akklimatisation beinhalten eigentlich einen Nutzen für die Art im Sinne eines Selektionsvorteils, dessen Feststellung jedoch viele zusätzliche Untersuchungen erfordern würde; kaum ein Autor hat derartige Versuche bisher durchgeführt. Im allgemeinen dürfte bei den nichtgenetischen Adaptationen der intakten Organismen ein derartiger Nutzen vorhanden sein, doch können „Begleitumstände" das Bild komplizieren (z. B. die gesteigerte Hitzeresistenz frostabgehärteter Pflanzen). Es ist deshalb ratsam, das Problem des Nutzens ganz auszuklammern und von nichtgenetischen Adaptationen zu sprechen, wenn ein Wechsel der AT irgendwelche Folgeerscheinungen hat, die nicht nur als Reaktionen verstanden werden können und auch keine Regulationen sind (Precht \& Christophersen 1965, Precht \& LINDNER 1966).

Es ist zweckmäßig, eine Unterteilung in sich ä $\mathrm{ndernde} \mathrm{und} \mathrm{sich} \mathrm{n}$ icht ä nd e rnd e (konstante) Reaktionssysteme vorzunehmen. Mißt man z. B. die Temperaturabhängigkeit eines Betriebsstoffwechselprozesses (Sauerstoffyerbrauch, Fermentaktivität), so verändert sich das Versuchsobjekt während des Versuchs nicht entscheidend, im Gegensatz zu Wachstums- und Entwicklungsvorgängen, bei denen die Zeit der Änderung des Systems direkt als Maß dient (z. B. Entwicklung rom Ei bis zur Imago). 


\title{
REAKTIONEN
}

\author{
Abhängigkeit der Lebensprozesse von der \\ Versuchstemperatur
}

Es soll zunächst die Erörterung der Reaktionen im Vordergrund stehen, wobei ihre Beeinflussung durch die AT berücksichtigt werden muß; die Besprechung der Adaptationsvorgänge selbst erfolgt später (p. 516).

\section{Versuchsausfübrung}

Besonders bei Tierversuchen sind verschiedene Vorsichtsmaßregeln $z u$ beachten. Will man z. B. die Abhängigkeit des Sauerstoffverbrauchs eines Tieres von der VTT messen, so können schon die Haltungsbedingungen vor dem Versuch für die Höhe der Meßwerte sowie für das ganze Kurvenbild entscheidend sein. Dies kann für die AT gelten, die lange genug eingewirkt haben muß, für die Photoperiode, den Sättigungszustand der Tiere etc. Während der Messungen sind natürlich alle Faktoren bis auf den $\mathrm{zu}$ untersuchenden (hier die VT) konstant zu halten; bei längeren Versuchen kann nach KasbohM (1967) sogar die Einhaltung einer bestimmten Tageslänge wichtig sein.

Man geht am besten von einer VT aus, die der AT entspricht. Störungen durch Uberführung der Versuchstiere in die Meßapparatur muß man erst abklingen lassen (Precht, Christophersen \& Hensel 1955, p. 17, Saunders 1963). Nach der Konstanz der Meßwerte ändert man die VT zunächst in einem einmaligen Schritt. Die Schnelligkeit der Änderung und die Größe des Sprungs sind so zu wählen, daß overshoots etc. das Bild möglichst wenig verfälschen; wieder ist bis zur Konstanz der Werte zu messen. Zur Kontrolle kann man anschließend auf die Ausgangstemperatur zurückgehen und nochmals Messungen durchführen, doch ist zu berücksichtigen, daß sich Temperatursenkungen und -erhöhungen auch im gleichen Bereich unterschiedlich auswirken können. Vor der nächsten Messung bei einer anderen VT müssen die Tiere wieder genügend lange in die AT überfürt werden, wenn Gefahr besteht, daß bereits durch den Versuch eine gewisse Umadaptation eingeleitet worden ist. Das geschilderte Meßverfahren bei jeweils zwei VTs ist natürlich umständlich und wohl auch nicht in jedem Fall notwendig. Wenn die Temperatur sehr langsam verändert wird und nur kleine Temperatursprünge angewandt werden, können Messungen eventuell in einem Versuch bei mehreren VT's durchgeführt werden, wobei man wieder mit einer VT beginnt, die der AT entspricht. Tageszeitliche Schwankungen der Werte sind zu berücksichtigen.

Will man einen zwischen- oder innerartlichen Vergleich von Bewohnern unterschiedlich temperierter Wohngebiete durchführen, so sollte man (wenn möglich) die Versuchsobjekte vor den Messungen bei derselben AT (bzw. mehreren ATs) halten und auch unter gleichen Versuchsbedingungen messen, da nur so entschieden werden kann, ob Unterschiede in der Höhe der Meßswerte oder der $Q_{10}$-Werte erblich bedingt sind oder durch die unterschiedliche A'T der Wohngebiete.

Man kann die Abhängigkeit der Lebensprozesse von der V'T messen (bei konstanter AT), oder die von der AT (bei konstanter VT), oder jeweils VT=AT wählen, oder 
unterschiedlich adaptierte Tiere bei verschiedenen VTs untersuchen, wie dies bei den Versuchen der Abbildung 1 z. B. geschehen ist. Es wurde schon früher erwähnt (PRECHT, Christophersen \& Hensel 1955, p. 21), daß es auch auf die Darstellung der Kurven ankommt.
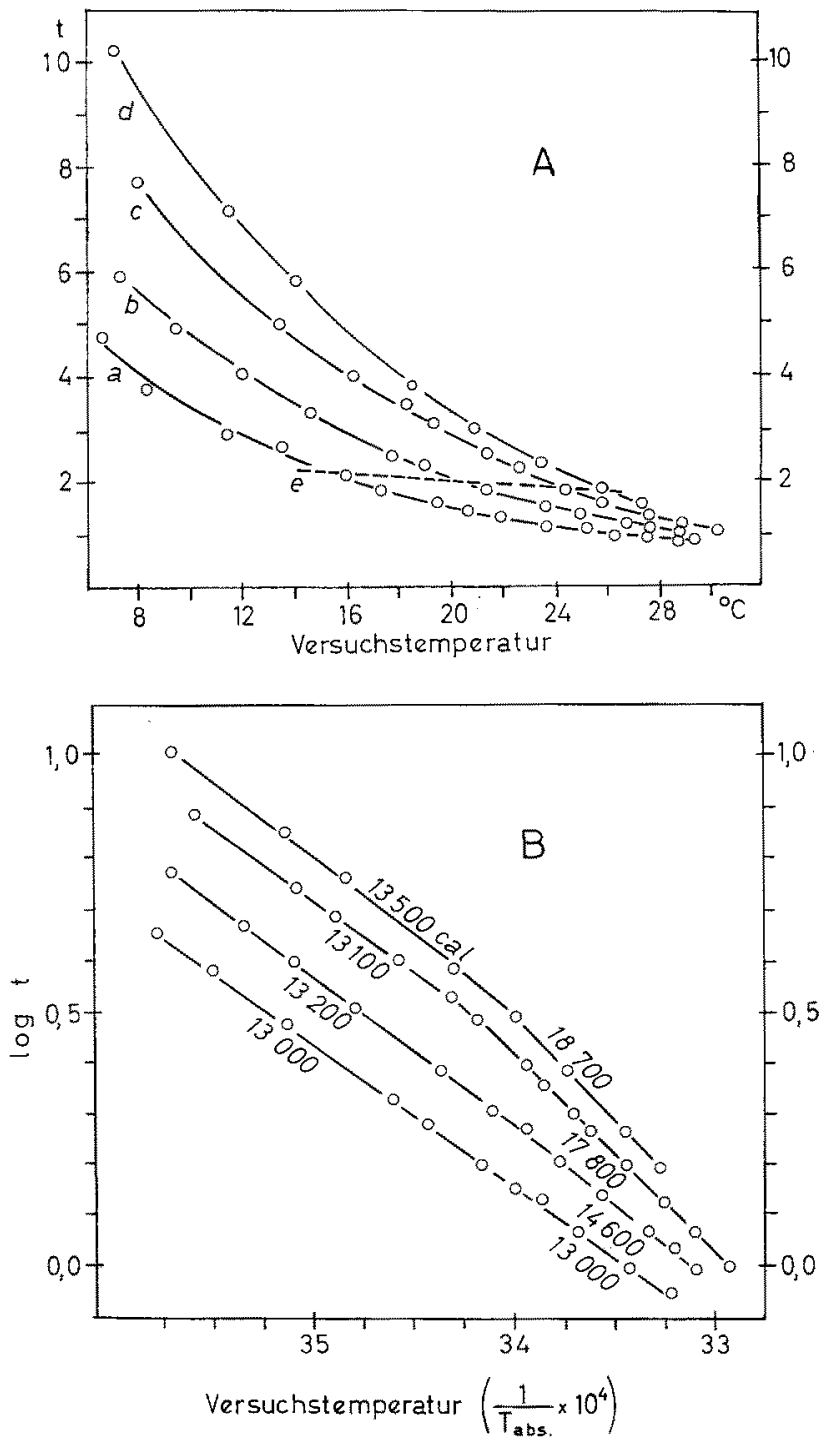

Abb. 1: (A) Pleopodenschlag von Gammarus pulex. $t=$ Dauer von 10 Schlägen (in sec). Adaptationstemperatur bei a $15,5^{\circ} \mathrm{C}$, bei $b 20^{\circ} \mathrm{C}$, bei $c 25^{\circ} \mathrm{C}$, bei $d 26,3^{\circ} \mathrm{C}$, $e$ nach Adaptation $(\mathrm{VT}=\mathrm{AT})$. In (B) sind die $\mu$-Werte semilogarithmisch eingezeichnet. (Nach PRECHT 1949)

Vom biologisch-ökologischen Standpunkt mag die Messung volladaptierter Tiere bei einer VT, die der AT entspricht, besonders wichtig sein. Wir engen aber bei dieser Beschränkung auf VT $=$ AT-Werte die physiologischen Deutungsmöglichkeiten ein. Auch 
bei der Messung bei mehreren VTs beginnt man - wie erwähnt - am besten mit einer $\mathrm{VT}$, die der AT entspricht; damit erfaßt man auch die VT=AT-Kurve (in Abb. 1 als Kurve e eingezeichnet). Allerdings können durch die sich anschließende Änderung der VT noch zu schildernde vorübergehende, aber doch langanhaltende Störeffekte verursacht werden; man sollte dieselben Versuchstiere erst nach deren Abklingen wieder verwenden. Mit Beeinträchtigungen dieser Art während des Versuchs und längeren Nachwirkungen hat man besonders bei raschen Temperaturänderungen zu rechnen.

Die erwähnte Einengung wird z. B. bei folgendem Problem deutlich. Bereiche mit niedrigen $\mathrm{Q}_{10}$-Werten, die oftmals beobachtet wurden, können erblich bedingt, also Reaktionen sein, durch Regulationen zustande kommen oder durch eine Leistungsadaptation im Sinne einer Kompensation. Eine Unterscheidung zwischen der dritten und den erstgenannten beiden Möglichkeiten ist allein mit Hilfe von VT=AT-Kurven nicht möglich. (Eine Trennung der ersten beiden Möglichkeiten ist nur auf Grund weiterer Untersuchungen durchzuführen.)

Auf all diese Gesichtspunkte sei deshalb so eindringlich hingewiesen, weil durch deren Außerachtlassung die Befunde vieler Autoren gar nicht vergleichbar sind. Dies führt leider auch dazu, daß man in den seltensten Fällen wirklich gültige Regeln aufstellen kann, ganz abgesehen davon, daß zur Aufstellung von Regeln die Zahl der untersuchten Arten meist ohnehin zu gering ist.

\section{Die Angabe von $\mathrm{Q}_{10}$ - und $\mu$-Werten}

Die Angabe von Temperaturkoeffizienten ( $Q_{10}$-Werten) hat sich zur Charakterisierung der Temperaturabhängigkeit von Lebensprozessen bewährt, obwohl diese Werte nicht wie die Aktivierungsenergien ( $\mu$-Werte, vgl. Precht, Christophersen \& Hensel 1955, p. 4) in dem in Frage kommenden Temperaturbereich unabhängig von der VT sind, sondern im allgemeinen meist mit steigender VT abnehmen; seltener bleiben sie konstant (vgl. Roberts 1957, Dawson in MrLstead 1967). Die Q10-Werte der Atmung von Plerocercoiden von Schistocephalus solidus nehmen bis $30^{\circ} \mathrm{C}$ ab, darüber hinaus zu (Davies \& WaLKeY 1966). Auch die mehrfach gefundenen geradlinigen Abhängigkeitskurven von der VT (Precht, Christophersen \& HeNsel 1955, p. 23, Richards 1963, Kanehisa 1965) weisen mit steigender Temperatur abnehmende $\mathrm{Q}_{10}$-Werte auf. Diese sind beim Vergleich mehrerer Reaktionen für den gleichen Temperatursprung für diejenigen größer, welche die größeren $\mu$-Werte haben.

Die Angabe von $\mu$-Werten lohnt sich dann, wenn diese zumindest über größere $\mathrm{VT}$-Bereiche konstant sind. Es mag überraschen, daß man auch für komplexere biologische Vorgänge oftmals konstante $\mu$-Werte angeben kann, doch gilt dies auch für kinetisch komplexe chemische Reaktionen, soweit es sich um Reaktionsfolgen und nicht um Simultanreaktionen handelt, z. B. für den $\mathrm{N}_{2} \mathrm{O}_{5}$-Zerfall $\left(2 \mathrm{~N}_{2} \mathrm{O}_{3} \rightarrow 4 \mathrm{NO}_{2}+\mathrm{O}_{2}\right.$ ), der über drei Stufen verläuft; die Aktivierungsenergie der Gesamtreaktion ( $\mu_{\text {beob }}$ ) beträgt: $\mu_{\text {beob }}=\mu_{1}-\mu_{2}+\mu_{3} . \mu_{\text {beob }}(\simeq 25 \mathrm{kcal})$ ist von der 'Temperatur ebensowenig abhängig wie die Aktivierungsenergien $\left(\mu_{1} \simeq 21, \mu_{2} \simeq \mathrm{O}, \mu_{3} \simeq 4 \mathrm{kcal}\right)$ der Teilreaktionen. 
Daß aus der Größe der $\mu$-Werte nicht ohne weiteres auf eine master reaction geschlossen werden kann, wie ältere Autoren annahmen (PRECHT, CHRISTOPHeRsen \& HeNsel 1955, p. 21), geht außerdem aus der offenbar manchmal stetigen Anderung der Werte mit der AT hervor (Abb. 1, vgl. Precht 1949, Benthe 1954). Wenn man ferner bei einem Versuch die VT laufend steigert, erhält man für denselben Lebensprozeß und VT-Bereich unter Umständen andere $\mathrm{Q}_{10}$ - und damit auch $\mu$-Werte als bei einer laufenden Senkung der VT; dabei können nicht abgeklungene overshoots etc. eine Rolle mitspielen. NopP \& Farahat (1967) erhielten z. B. für den Sauerstoffverbrauch von Heliciden-Geweben für den gleichen VT-Bereich bei Abkühlung stets höhere $Q_{10}$-Werte als bei einer Erwärmung (vgl. MonowsKa \& ZaLESKA 1958, LAGET et al. 1955, Zerbst 1966). Für die Herzfrequenz von Periplaneta gilt dies nicht (Richards 1963, vgl. BurkhardT 1959).

Chemische Reaktionen haben meist $Q_{10}$-Werte von 2 bis 4 , physikalische Vorgänge (Diffusion, Osmose, Leitfähigkeit usw.), niedrigere (1,1 bis 1,4); photochemische Reaktionen sind von der Temperatur unabhängig. Es ist aber nicht obne weiteres möglich, aus der Größe der Q10-Werte auf die Art eines Lebensprozesses zu schließen. Höhere Temperaturkoeffizienten beweisen nicht unbedingt das Vorliegen von chemischen Reaktionen (vgl. Danielli 1954, Vogel et al. 1958), niedrige Q $_{10}$-Werte schließen diese nicht aus. Der Biologe stößt bisweilen sogar auf $\mathrm{Q}_{10}$-Werte $<1$. Oft liegen in solchen Fällen zwei sich überschneidende Reaktionen vor, die jede für sich betrachtet $Q_{10^{-}}$ Werte $>1$ aufweisen (Beispiel bei PReCht, Christophersen \& Hensel 1955, p. 23). Auch Hemmwirkungen nehmen mit steigender VT zu, was zu niedrigen $\mathrm{Q}_{10}$-Werten führen kann, z. B. die Hemmung des Herzschlags durch den Vagus oder die Hemmung bei der Krebsschere (Precht, Christophersen \& Hensel 1955, p. 24, Schenck et al. 1956). Nach Wieser \& Nopp-PAmmer (1968) kann eine Temperaturunabhängigkeit (z. B. der Melaninsynthese bei Triturus cristatus) dadurch zustande kommen, daß ein beteiligtes Ferment ein Reaktionsoptimum bei niedriger VT hat, und damit seine Aktivität bei darüberliegenden VTs abnimmt. Die Aktivität eines anderen Fermentes wächst jedoch wie üblich mit steigender VT an, so daß die Addition beider Aktivitäten zu einem $Q_{10}$-Wert $\approx 1$ führt. Nach OHNesorge \& Schmitz (1968) nimmt die Kontraktionshöhe der quergestreiften Darmmuskulatur vom Tinca tinca nach Acetylcholinzusatz mit steigender VT zu, bei der glatten Muskulatur ab.

Als charakteristisch für die Abhängigkeit der Lebensprozesse von der VT hat man lange Zeit die sogenannte Kroghsche Normalkurve (Precht, Christophersen \& HeNSEL 1955, p. 22, Abb. 6) angesehen; sie gilt für den Ruhestoffwechsel verschiedener Tiere. Wie üblich nehmen die Q10-Werte dieser Kurve mit steigender VT ab; es lassen sich zwei größere Temperaturbereiche mit konstanten $\mu$-Werten angeben. Die Kurve gehorcht auch der von F. KRüGer $(1963,1966)$ angegebenen Formel. (Auf weitere Versuche, die Kurven mathematisch auszudrüicken, soll nicht eingegangen werden.) Es hat sich später herausgestellt, daß der Stoffwechsel vieler Tiere auch unter den angegebenen Normalbedingungen nicht dieser Kurve von KroGH entspricht, was erblich bedingt sein kann (BERG et al. 1962) oder auch durch Außenfaktoren wie z. B. die Vorbehandlung der Tiere. KROGH weist schon selbst auf den sich abweichend verhaltenden Sauerstoffverbrauch von T'enebrio-Puppen hin. Gerade die Verschiedenheit der Abhängigkeitskurven von der VT ist Gegenstand zahlreicher Untersuchungen gewesen. 
Auch die zu einer Organfunktion gehörenden Teilreaktionen können unterschiedliche $\mathrm{Q}_{10}$-Werte aufweisen. An der Erregung der Sehzellen im Eupagurus-Auge sind z. B. photochemische Reaktionen, Membran- und Stoffwechselvorgänge beteiligt. Außer der photochemischen Primärreaktion sind diese Prozesse in verschiedenem Maße von der VT abhängig. Im Gegensatz zu den Aktionspotentialen von Nerv und Muskel, deren Amplituden über einen großen Temperaturbereich kaum von der VT abhängen, gibt es für die Amplitude des untersuchten Belichtungspotentials ein Temperaturoptimum (Streve 1963, vgl. auch Krkuchi et al. 1961, WAlther 1965). Bei Carausins morosus ist unter den von SCHNEIDER (1964) angewandten Versuchsbedingungen die Dunkeladaptation von der VT unabhängig, nicht jedoch die Helladaptation. Die Dunkeladaptation des Bienenauges hängt im Verhaltensversuch nicht von der VT $a b$, bei elektrophysiologischen Messungen zeigte sich bei den drei Retinogrammtypen jedoch Abhängigkeit (SErBT 1967, vgl. Autrum \& HAMDorF 1964. Ruhepotentialmessungen ergaben beim Frosch und bei Carcinus unterschiedliche $\mathrm{Q}_{10-}$ Werte für individuelle Muskelfasern derselben Tiere (KerkuT \& RIDGE 1961). Bei Ableitungen von Geschmacksnerven von Rana nigromaculata waren die $\mathrm{Q}_{10}$-Werte für die Antwortgröße für verschiedene Geschmacksstoffe unterschiedlich (Y AMASHITA 1964).

Bei den Dehnungsrezeptoren von Astacus ist nach Burkhardt (1959) der Temperaturkoeffizient der stationären Entladung eine Funktion des Dehnungszustandes des Muskels. Die Entladungsfrequenz stark gedehnter Rezeptoren hat einen $\mathrm{Q}_{10}$-Wert von etwa 2, bei schwacher Streckung kann der $Q_{10}$-Wert gleich 1 sein und bei völliger Entspannung sogar $<1$. Der $Q_{10}$-Wert für die Adaptationsgeschwindigkeit des Rezeptors nach Reizung liegt bei allen Streckzuständen zwischen 3 und 5. WrESER (1965a) schließt aus der Untersuchung der Temperaturabhängigkeit, daß bei Porcellio scaber die Nahrungsaufnahme in keiner einfachen Beziehung zum Sauerstoffverbrauch zu stehen braucht; dieser ist auch von der Jahreszeit abhängig, nicht jedoch der Laubverzehr etc.

Gleiche Organfunktionen verschiedener Arten können unterschiedliche $Q_{10}$-Werte aufweisen. Die Entladungsfrequenz der Muskelrezeptoren (stationärer Zustand) ist z. B. bei Raja von der VT unabhängig, bei Astacus abhängig. Bei Rana temporaria nimmt die stationäre Entladungsfrequenz zunächst mit steigender VT linear zu; von $20^{\circ}$ bis $26^{\circ} \mathrm{C}$ ändert sich die Frequenz kaum und kann bei schwacher Dehnung sogar abnehmen (vgl. WINTER 1967, ferner DaLton \& HENDRIX 1962).

Genetisch bedingte Rassenunterschiede von Drosophila melanogaster, die von einer Wildpopulation stammten, fanden Vernberg \& Merrney (1957). Die Qi0-Werte betragen für den VT-Bereich von $13^{\circ}$ bis $18^{\circ} \mathrm{C}$ für die dunkle Rasse 4,71 , für die hellere 4,32 und für die Heterozygoten 8,98 (für den Bereich von $22^{\circ}$ bis $27^{\circ} \mathrm{C}: 3,39,5,14$ und 1,67). Die Abhängigkeitskurven weisen Plateaus auf, was natirlich die $\mathrm{Q}_{10}$-Werte stark beeinflussen kann. Nach ScHmid T (1968) unterscheiden sich die $\mathrm{Q}_{10^{-}}$Werte für den Sauerstoff verbrauch von $\hat{\delta}, \phi 9$ und $\$ \notin$ (Puppen) von Formica polyctena und die verschiedenen Puppenstadien.

Trägt man die $\mathrm{Q}_{10}$-Werte für den Sauerstoffverbrauch von Herzmuskel und Supraösophagealganglion von $3 U_{c a}$-Arten gegen die VT auf, so ergeben sich bei derselben Art für unterschiedliche Gewebe und für gleiche Gewebe bei unterschiedlichen Arten verschiedene Kurven, die ausgesprochene Minima und Maxima aufweisen können. Die $Q_{10}$ Werte für das Nervengewebe entsprechen noch am ehesten den für die 
Ganztieratmung (W. B. Vernberg \& F. J. Vernberg 1966). Kennedy \& Richards (1955) fanden, daß die Apyraseaktivität in den Flugmuskeln von Lethocerus americanus geringer war und niedrigere Temperaturkoeffizienten aufwies als die in den Schwimmuskeln.

\section{Bereiche mit niedrigen Temperaturkoeffizienten und andere Besonderbeiten}

Der Bereich der im Biotop üblicherweise herrschenden Temperaturen kann sich durch besonders niedrige $\mathrm{Q}_{10}$-Werte auszeichnen, wodurch gerade für diesen wichtigen Bereich eine mehr oder weniger ausgeprägte Unabhängigkeit der Lebensprozesse von der Außentemperatur gewährleistet wird, was besonders wichtig ist, wenn diese stark schwankt. Hier interessieren nur Plateaus im Kurvenverlauf, die Reaktionsnormen, also genetisch bedingt sind. Es ist aber nicht ohne weitere Untersuchungen auszuschließen, daß Regulationen durch übergeordnete Systeme vorliegen, was auch für die genannten Beispiele gilt. Plateaus durch eine Leistungsadaptation können leichter erkannt werden (p. 522).

Im biologisch allein wichtigen unteren Temperaturbereich zeigt der Sauerstoffverbrauch winterschlafender Melasoma populi auffallend niedrige $\mu$-Werte. Die Käfer, die im Ruhestadium mit ihren Reservestoffen auskommen müssen, verhindern (neben einer Leistungsadaptation) auch auf diese Weise eine zu starke Ankurbelung des Stoffwechsels. Winterschlafende Kartoffelkäfer, die sich tiefer eingraben und somit Temperaturschwankungen weniger ausgesetzt sind, zeigen diese Erscheinung nicht (Precht, Christophersen \& Hensel 1955, p. 24). Unter $15^{\circ} \mathrm{C}$ mißt man bei thermophilen Eidechsen höhere $Q_{10}$-Werte für den Ruhestoffwechsel als bei weniger hitzeresistenten Arten; die $\mathrm{Q}_{10^{-}}$Werte für die Herzschlagfrequenz steigen in der ersten Gruppe unter VT $=20^{\circ} \mathrm{C}$ merklich an, in der zweiten Gruppe erst unter $10^{\circ} \mathrm{C}$ (vgl. Dawson in Milstead 1967, Dawson \& Templeton $1966^{1}$ u. a.). Der Sauerstoffverbrauch von Embryonal- und Jugendstadien fällt nach WoYNárovich (1963) bei solchen Fischen (Silurus glanis, Cyprinus carpio), die warmes Wasser vorziehen, bei tiefen VT's weit stärker zurück als bei jenen Arten (Esox lucius, Lucioperca lucioperca), die sich auch im kalten Wasser gut entwickeln. Auch bei Parasiten kann man nach Vernberg \& Hunter (1961) beobachten, daß die Q ${ }_{10}$-Werte bei den normalerweise vorherrschenden Temperaturen relativ klein sind; die untersuchten Trematoden lebten in einem Fisch, einer Schildkröte bzw. einem Vogel (vgl. auch VERNBerg 1961).

NEWELL \& NORTHCROFT (1967) beobachteten (bei Messungen in geschlossenen Behältern) größere Konstanzintervalle für den "maintenance metabolism", während der "active metabolism" Q $10^{-}$Werte von etwa 2 aufwies (Actinia equina: 7,50 bis $20^{\circ} \mathrm{C}$, Nephtbys bombergi: $3^{\circ}$ bis $20^{\circ} \mathrm{C}$, Littorina littorea: $10^{\circ}$ bis $23^{\circ} \mathrm{C}$ ). Daßs auch isolierte Mitochondrien derartige Konstanzintervalle zeigen sollen, würde auf eine erbliche Reaktionsnorm hindeuten. Diese Intervalle sollen Beziehungen zu dem Temperaturbereich haben, in dem die Tiere normalerweise leben. Diese Ergebnisse erwecken den

1 Es ist zu berücksichtigen, daß die Körpertemperatur bei den Reptilien tags oft durch eine Verhaltensregulierung erhöht wird, so daß sie bei der Vorbehandlung nicht genau der AT entspricht. 
Eindruck, als wenn solche ausgedehnten Bereiche der Temperaturunabhängigkeit sehr verbreitet sind, doch widerspricht dies den Befunden vieler anderer Autoren (vgl. VAlen 1958, Tribe \& Bowler. 1968). Bei Crassostrea virginica sollen sogar 5 Temperaturintervalle der Pumprate mit mehr oder weniger großer Homogenität vorhanden sein (LOOSANOFF 1958).

Weitere Besonderheiten der Abhängigkeitskurven der Lebensprozesse von der V'T seien nur kurz erwähnt. Es gibt Fälle, wo die Kurven im oberen VT-Bereich fast waagerecht verlaufen; die Leistung gebt über einen Höchstwert nicht hinaus; dies gilt z. B. für den Schlag der Rankenfüße von Balanus improvisus (PRECHT 1949).

Unregelmäßigkeiten im Kurvenverlauf fand $O^{\prime}$ CoNNoR $(1960,1964)$ bei der Atmung von Säugetier- und auch Froschgeweben; es zeigten sich verschiedene Maxima ... "these maxima result from a surface action of fatty acids in molecular order". Besonderheiten der Insektenatmung können dadurch auftreten, daß die periodische Atmung bei tieferen VT's in eine reine Diffusionsatmung (ohne Stigmenöffnung) übergeht (KANWISHER 1966).

\section{Grundstoffwechsel und Bewegung}

KROGHS „Normalbedingungen“ betreffen sich nicht bewegende Tiere. Zur Erfassung des Grundstoff wechsels, die recht schwierig sein kann (vgl. LEgAY \& Coulon 1965, SMIT 1965), hat man oftmals die Bewegungen der Tiere ausgeschaltet, z. B. durch Großhirnexstirpation oder Narkose, wobei allerdings berücksichtigt werden muß, daß die Narkosetiefe von der AT abhängen kann (v. BudDenBrock 1960). Man arbeitet am besten mit Tieren, die sich von Natur aus nicht bewegen. Vielfach begnügt man sich damit, die Bewegungen durch eine Verdunkelung der Meßapparatur einzuschränken. Den Ökologen kann gerade der Stoffwechsel eines sich natürlich bewegenden Tieres interessieren, den Physiologen stört jedoch die damit verbundene große Variabilität der Meßwerte. Darum hat man versucht, den Sauerstoffverbrauch (z. B. von Fischen) bei konstanten Bewegungsgeschwindigkeiten zu messen, wobei man dem Tier (z. B. durch entgegenströmendes Wasser) eine bestimmte oder maximale Bewegung (cruising speed) aufnötigt; oder man mißt den Sauerstoffverbrauch und die Aktivität gleichzeitig (vgl. z. B. Kanungo \& Prosser 1959, Ruhland \& Heussner 1959, Brett 1964, 1965, 1967, BeAmish \& MoOKHERjI 1964). Insekten hat man an einem Flugkarussell im Warburgapparat untersucht (YURKIEWICZ \& SMYTH 1966). FRY (in Rose 1967) unterscheidet (1) den Standardstoffwechsel, den man auch durch Extrapolation bestimmen kann, wenn man die Beziehungen zwischen der Aktivität und dem Sauerstoffverbrauch kennt, oder - wie erwähnt - nach Narkose oder Operation der Tiere, (2) den Routinestoffwechsel (ohne Störung der Tiere) und (3) den aktiven Stoffwechsel ("the maximum steady rate of oxygen consumption under continous forced activity").

KEISTER \& BUCK (1961) maßen den Sauerstoffverbrauch von Larven und Imagines von Phormia regina, wobei die Abhängigkeit der Bewegung von der VT miterfaßt oder die Aktivität durch Operation ausgeschaltet wurde. Ein Vergleich zwischen normalen Larven und solchen ohne Ganglien ergab, daß der absolute Beitrag der Bewegung zum gesamten Stoffwechsel für den VT-Bereich von $15^{\circ}$ bis etwa $35^{\circ} \mathrm{C}$ konstant war. Ein Versuch mit intakten und geköpften Imagines zeigte dagegen, daß der 
Beitrag der Aktivität zwar schwankte, aber doch deutlich mit steigender VT zunahm. McFarland \& Pickens (1965) maßen den Standardstauerstoffverbrauch von Palaemonetes vulgaris und den von Tieren bei maximaler Bewegungsgeschwindigkeit. Die $Q_{10^{-}}$Werte betrugen z. B. für den VT-Bereich $10^{\circ}$ bis $20^{\circ} \mathrm{C}: 1,77 \mathrm{bzw} \cdot 1,62\left(\mathrm{AT}=10^{\circ} \mathrm{C}\right)$ und 2,08 bzw. $2,07\left(\mathrm{AT}=20^{\circ} \mathrm{C}\right)$; für den VT-Bereich $20^{\circ}$ bis $30^{\circ} \mathrm{C}$ erhielten sie die Werte: 1,59 bzw. 1,42 (AT $\left.=10^{\circ} \mathrm{C}\right)$ und 1,52 bzw. 1,25 $\left(\mathrm{AT}=20^{\circ} \mathrm{C}\right)$. Die $\mathrm{Q}_{10}$-Werte für den Stoffwechsel von Eidechsen können bei aktiven Tieren niedriger sein

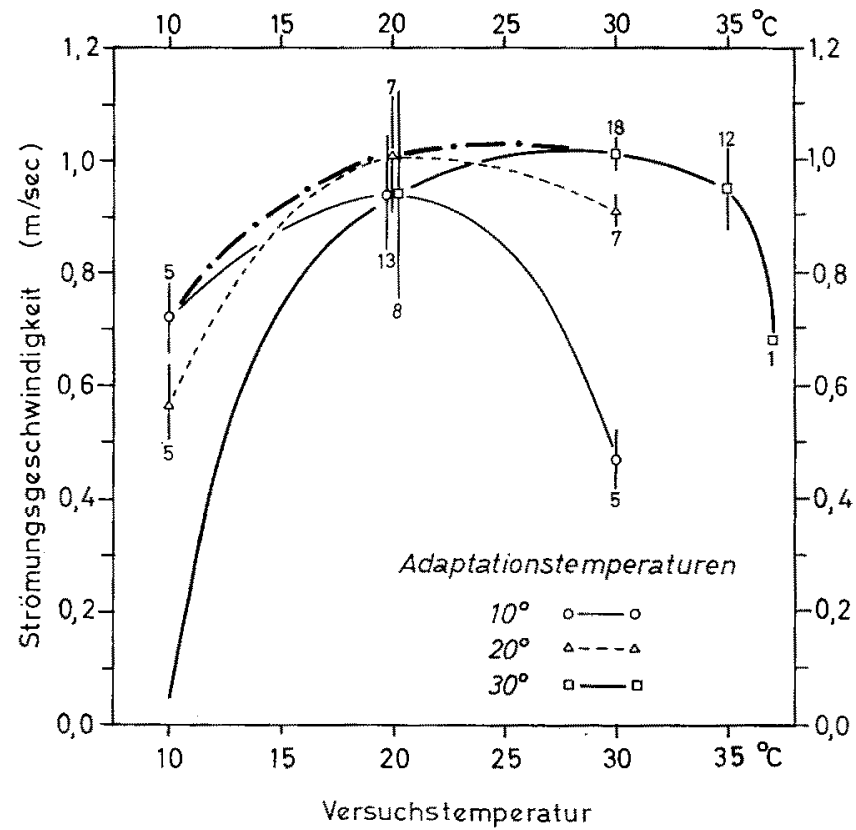

Abb. 2: Darstellung der Strömungsgeschwindigkeiten $(\mathrm{m} / \mathrm{sec})$, die eine maximale Bewegung von Palaemonetes vulgaris verursachen. Die VT-AT-Kurve (-.-) ist nachträglich eingezeichnet worden. Die Zahlen unter bzw. uber den Symbolen geben die Anzahl der Messungen an. (Verändert nach McFarLand \& PICKENS 1965)

als bei solchen in Ruhe (Varanus sp., Tiliqua scincoides) oder höher (Iguana iguana, VT-Bereich $15^{\circ}$ bis $30^{\circ} \mathrm{C}$; vgl. Dawson in Milstead 1967). Auf die speziell bei Fischen oftmals ausschließlich aufgenommenen $\mathrm{AT}=\mathrm{VT}$-Kurven sei nur hingewiesen; bei groBen Geschwindigkeiten kommt es bei höheren Temperaturen zum Abfall des Sauerstoffverbrauchs, was mit dem eintretenden Sauerstoffmangel zusammenhängen soll (vgl. FRY in Rose 1967 u. a.).

Des öfteren ist bei unterschiedlich adaptierten Fischen die Abhängigkeit der maximalen Schwimmgeschwindigkeit von der VT gemessen worden (vgl. FRY in Rose 1967). Wie in Abbildung 2 für Palaemonetes vulgaris liegt die VT=AT-Kurve bei relativ hohen Werten.

Die Abhängigkeit der freiwillig vom Tier ausgeführten Aktivität von der VT ist eigentlich schon ein Problem des Verhaltens. Die Kurve für die Häufigkeit der Spontan- 
bewegungen von Forellen zeigt z. B. zwei Maxima; eines davon liegt bei mittleren VTs, das andere kurz unter der Letaltemperatur. Die Lage des ersten Maximums hängt von der AT ab (Fisher in Prosser 1958, Fisher \& Sullivan 1958).

\section{Körpergröße und Abhängigkeit von der Versuchstemperatur}

Man kann verwandte verschieden große Arten oder Rassen vergleichen oder unterschiedliche Wachstumsstadien derselben Art, wobei natürlich besonders dann mit Verschiedenheiten zu rechnen ist, wenn sehr unterschiedliche Stadien (z. B. bei holometabolen Insekten) verglichen werden.

RAO \& BULLOCK (1954) gelangen nach einer Literaturübersicht (trotz gegenteiliger Ansicht einiger Autoren) zu der Meinung, daß die $Q_{10}$-Werte der Abhängigkeitskurven von der VT im allgemeinen mit zunehmender Körpergröße steigen. Man kann jedoch kaum von einer Regel sprechen, obwohl einige spätere Befunde diese bestätigen, z. B. der Sauerstoffverbrauch von Stadien des Fisches Aequidens portalegrensis (MoRrus 1962). Andere Autoren fanden umgekehrt eine Abnahme, z. B. für den Herzschlag von Asellus aquaticus im VT-Bereich von $9^{\circ}$ bis $22^{\circ} \mathrm{C}$ (Schwarzkopfo 1955), den Sauerstoffverbrauch des Skorpions Heterometrus fulvipes (vgl. Rao 1966), den Herzschlag des Fisches Ophicephalus punctatus (HASAN \& QASIM 1961, vgl. auch JoB 1957, ARmitage 1962).

Verwandte Arten können sich unterschiedlich verhalten. Bei Salmo irideus, S. fario, Scyliorbinus canicula und Pristiurus melanostomus steigen die Herzfrequenzen mit fortschreitender Entwicklung an; die $Q_{10}$-Werte nehmen gleichzeitig ab (S. irideus) oder bleiben annähernd konstant (Hugger 1959, 1961), wie dies auch Pickens (1965) für den Herzschlag von Mytilus californicus fand, wenn er auf das innere Schalenvolumen bezog (vgl, auch Davies 1966,1967, Davies \& Walkey 1966).

Man fand sogar Unterschiede bei den einzelnen VT-Bereichen. Nach RoBERTs (1957) bleiben die $Q_{10}$-Werte für den Sauerstoffverbraud von Pachygrapsus crassipes von $8,5^{\circ}$ bis $16^{\circ} \mathrm{C}$ mit steigender Körpergröße konstant; sie ändern sich von $16^{\circ}$ bis $23,5^{\circ} \mathrm{C}$ jedoch direkt mit dem Gewicht, was mit einer Streßwirkung der höheren Temperaturen zusammenhängen soll $\left(\mathrm{AT}=16^{\circ} \mathrm{C}\right.$ ). Bei im Laboratorium adaptierten Palaemonetes varians ändern sich die $\mathrm{Q}_{10}$-Werte für den Sauerstoffverbrauch nur wenig mit dem Körpergewicht, bei Frischfängen mehr, bei Sommertieren nicht (VT $=10^{\circ}$ und $30^{\circ} \mathrm{C}$, McFarland u. Pickens 1965). 12 Tage alte Larven eines holometabolen Insekts (Calandra oryzae) verbrauchen weit mehr Sauerstoff und weisen niedrigere $\mathrm{Q}_{10^{-}}$Werte auf als 7 Tage alte adulte Tiere $\left(\mathrm{AT}=29^{\circ} \mathrm{C}\right)\left(\mathrm{B}_{\mathrm{IRCH}} 1947\right)$.

Unterschiede kommen auch bei geographischen Rassen vor, z. B. nach TASHIAN (1956) bei Uca pugnax. Individuen von New York, North Carolina und Florida zeigen eine Abnahme der $Q_{10}$-Werte für den Sauerstoffverbrauch mit steigender Körpergröße, das Umgekehrte ist bei Tieren aus Trinidad der Fall (vgl. TASHIAN \& VERNBERG 1958).

In den bisher erwähnten Fällen wurden verschieden große Wachstumsstadien untersucht. MinamoRI (1957) maß die Abhängigkeit des Sauerstoffverbrauchs bestimmter Embryonalstadien verschieden großer Rassen von Cobitis taenia striata von der VT. 
Die $\mathrm{Q}_{10}$-Werte nehmen beim Vergleich dreier Rassen mit abnehmender Größe zu; die Höhe des Sauerstoffverbrauchs verhält sich umgekehrt (vgl. Tab. 16 des Autors). Ein zwischenartlicher Vergleich bei Winkerkrabben zeigt, daß kleinere Arten höhere $\mathrm{Q}_{10^{-}}$ Werte für den Sauerstoffverbrauch im VT-Bereich von $12^{\circ}$ bis $28^{\circ}$ oder $30^{\circ} \mathrm{C}$ aufweisen als größere (VERNBERG 1959).

Nach Locker (1958a, b, 1959) nehmen die $\mu$-Werte der Atmung von Leber und Haut von Rana esculenta mit einer Zunahme der Körpergröße ab. Die Größenabhängigkeit hängt von der Jahreszeit ab. Die $\mu$-Werte der Gewebsatmung lassen sich allerdings leicht beeinflussen (z. B. durch Substrate).

\section{Abhängigkeit der Temperaturkoeffizienten der VT-Kurven von der Adaptationstemperatur}

Die Frage nach der Abhängigkeit der $\mathrm{Q}_{10}$-Werte der VT-Kurven von der AT kann nur dort gestellt werden, wo eine Leistungsadaptation vorhanden ist, auf deren Problematik erst später eingegangen wird.

Adaptation im Sinne einer Kompensation (Typen 1 b is 3): In einigen Fällen hat die AT keinen nennenswerten oder zumindest keinen systematischen Einfluß auf die Q10-Werte (Sauerstoffverbrauch von Karauschen nach Suhrmann 1955, von Porcellio laevis und Armadillidium nach Edney 1964, der Fische Carassiops compressus und Ictalurus natalis nach Morris $1965 \mathrm{a}, \mathrm{b}$ ) (ATs $17^{\circ}$ und $22^{\circ} \mathrm{C}$ ) und auch bei Fermentaktivitäten (Cholinesterase des Gehirns von Fundulus beteroclitus nach Baslow \& Nigrelli 1964, vgl. hierzu Lüdtke \& Ohnesorge 1966, Cytochromoxydase beim Goldfisch nach FrEED 1965).

Die Q 10 -Werte können auch mit fallender AT zunehmen (Sauerstoffverbrauch von Pachygrapsus crassipes nach RoBERTs 1957, des Goldfisches ${ }^{2}$ nur im unteren VT-Bereich nach KLIcKa 1965, von Männchen von Calliphora erytbrocephala nach TRIBE \& Bowler 1968). Kaltadaptierte Ictalurus haben im unteren VT-Bereich auffallend hohe $Q_{10}$-Werte (MORRIs 1965a).

Oftmals nehmen die $\mathrm{Q}_{10}$-Werte mit steigender AT zu: der Sauerstoffverbrauch vom $\mathrm{Aal}^{2}$ (Precht 1951), Herzschlag von Gammarus pulex² (SchwarzkopfF 1955), Standard-und aktiver Sauerstoffverbrauch vom Goldfisch (KANUNgo \& Prosser 1959) (ATs $10^{\circ}$ und $30^{\circ} \mathrm{C}$ ), Sauerstoffverbraud von Aequidens portalegrensis (MorRIs 1962), von Strongylocentrotus purpuratus (FarmanfarmaIAN \& GIFSE 1965), von Neoceratodus forsteri (GRIGG 1965), von Chironomus strenzkei (PLATZER 1967), Leitungsgeschwindigkeit und absolute Refraktärperiode der Neurochorde von Lumbricus terrestris (LAgerspetz \& TAlo 1967, TAlo \& Lagerspetz 1967), Kontraktionshöhe der quergestreiften Darmmuskulatur von Tinca tinca (OHNEsorge \& Schmitz 1968),

2 Diese Beispiele gehören zu den seltenen Fällen, wo sich die Kurven der unterschiedlich adaptierten Tiere in einem VT-Bereid, schneiden, der innerhalb der beiden ATs liegt. Beim Aal kommt eine Oberschneidung der Kurven nur vor, wenn man bei den Messungen des Sauerstoffverbrauchs die VT zu schnell ändert und den Zeitfaktor außer acht läßt (PRECHT 1951). In solchen Fällen versagt die Typeneinteilung der Leistungsadaptation nach Precur (p. 517), nicht die nach Prosser (p. 500). 
ATPase-Aktivität von Musca domestica und Periplaneta americana (Mutcrmor in Prosser 1967; vgl. auch Rao \& Bullock 1954).

Inverse Kompensation (Typ 5): Bei unter Landtagsbedingungen gehaltenen Carassius carassius nehmen die $Q_{10}$-Werte für den Sauerstoffverbrauch mit steigender AT ab (Roberts 1961). Die Peroxydaseaktivität der Hefe Torulopsis kefyr zeigt nach PRECHT (1956) Entsprechendes. FLökKE et al. (1954) fanden für den Sauerstoffverbrauch des Kiemengewebes folgende Werte: Trutta trutta, $\mathrm{Q}_{10}$ bei AT $=5^{\circ} \mathrm{C}$ : 2,18 , bei $\mathrm{AT}=15^{\circ} \mathrm{C}: 2,25$; Squalus cepbalus, $\mathrm{Q}_{10}$ bei $\mathrm{AT}=5^{\circ} \mathrm{C}: 2,14$, bei $\mathrm{AT}=$ $15^{\circ} \mathrm{C}: 2,23$.

Es können weitere Komplikationen hinzukommen. Nach Kirberger (1953) entsprechen sich die $\mathrm{Q}_{10}$-Werte für den Sauerstoffverbrauch von Lumbriculus variegatus bei ATs von $1^{\circ}$ und $16^{\circ} \mathrm{C}$, ferner wenn die AT in 12stiindigem Wedsel $15^{\circ}$ und $23^{\circ} \mathrm{C}$ beträgt; erst bei einer konstanten $A T$ von $23^{\circ} \mathrm{C}$ nehmen die $\mathrm{Q}_{10}$-Werte $\mathrm{ab}$. Die Temperaturkoeffizienten für die Einbaugeschwindigkeit von markiertem Leucin in die Eiweiße von Kiemen und Leber des Goldfisches sind bei den an $25^{\circ} \mathrm{C}$ adaptierten Fischen größer als bei den 50-Tieren, doch gilt dies nur für den unteren VT-Bereich; der obere Bereich verhält sich umgekehrt (DAs \& Prosser 1967). Für den Pleopodenschlag von Gammarus pulex ergeben sich für jede Kurve zwei konstante $\mu$-Werte (Abb. 1); hier besteht bei niedrigen VTs Unabhängigkeit, bei höheren Abhängigkeit von der AT. Für die $\mathrm{CO}_{2}$-Abgabe von Tinca tinca ergibt sich für die $\mathrm{Q}_{10}$-Werte ein Maximum, das sich mit der AT verschiebt (PuNr 1945).

Komplikationen können auch für den Zellstoffwechsel auftreten. So kann bei den schon erwähnten Kurven für die $Q_{10}$-Werte der Gewebeatmung von Uca-Arten (p. 494) die Höhe und die Lage der Minima und Maxima von der AT abhängen, die Höhe besonders auffällig beim Herzgewebe von $U$. pugilator. LOCKER \& WEISH (1965) fanden für den Sauerstoffverbrauch einzelner Gewebe von Rana esculanta eine Steigerung $\operatorname{der} \mu$-Werte mit fallender AT, für andere nicht. Eine Zugabe von stoffwechselsteigernden (entkoppelnden) Substanzen kann die Abhängigkeit umkehren (jahreszeitliche Einflüsse können eine Rolle mitgespielt haben, vgl. RaO \& BuLlock 1954).

All diese Daten zeigen, daß man kaum allgemeinguiltige, einfache Regeln aufstellen kann. Eine Änderung der Temperaturkoeffizienten von einzelnen Fermentreaktionen mit der AT hat eine Bedeutung für die Frage, ob das Ferment selbst mit der AT verändert wird, doch sind nie reine Fermente untersucht worden, so daß die AT lediglich auf das Zellmilieu eingewirkt haben kann und nicht auf die Struktur des Fermentes selbst.

Prosser (1958) spricht in den Fällen einer Änderung der Temperaturkoeffizienten mit der AT von einer "rotation"; er benutzt das Verhalten dieser Koeffizienten zu einer Charakterisierung der Leistungsadaptation (I, No adaptation. II. Translation, [a] up or to left with cold, [b] down or to right with cold. III. Rotation, [a] clockwise, $\mathrm{Q}_{10}$ reduced in cold, [b] counterclockwise, $\mathrm{Q}_{10}$ increased in cold. IV. Translation combined with rotation). Prosser (in Hannon \& Viereck 1962, p. 10) gibt Beispiele für diese Typen an (vgl. auch Prosser \& Brown 1961).

Wenn die unterschiedlichen Abhängigkeitskurven von der VT konstante, aber verschiedene $\mathrm{Q}_{10}$-Werte aufweisen, so muß es zu einer Überschneidung kommen. $\mathrm{Zu}$ meist nehmen die $\mathrm{Q}_{10}$-Werte mit steigender VT ab, so daß man nur bestimmte VT- 
Bereiche der Kurven unterschiedlich adaptierter Tiere vergleichen kann. Es findet deshalb zumeist keine Überschneidung dieser Kurven statt, weil die Anderung der $\mathrm{Q}_{10^{-}}$ Werte innerhalb der Kurven mit der VT unterschiedlich ist (Prechr in Prosser 1958, p. 56).

Man kann auch die $Q_{10}$-Werte von Organismen aus konstanten ATs mit solchen vergleichen, die während der Vorbehandlung wechselnden Temperaturen ausgesetzt werden. BERKHOLZ (1966) führte derartige Messungen für den Sauerstoffverbrauch des Muskelgewebes von Idus idus durch; systematische Veränderungen der $Q_{10}$-Werte treten nicht auf.

\section{Sinnesgrenzen, Verständigung}

Bei Elritzen steigt die obere Frequenzgrenze, bis zu der nach der Tonhöhe unterschieden werden kann, mit der VT an. Nach vaN HeEL (1956) ist dies nach Wevers "volley theory" $z u$ verstehen: "arise in temperature will shorten the refractory period of nerve fibres and therefore increase certain sensory abilities in cold-blooded animals".

Bei der Notwendigkeit einer Verständigung ergeben sich besondere Probleme. Nach WALKER (1957) können die einzelnen Elemente des Grillengesangs unterschiedlich durch die VT beeinflußt werden, so daß es zu Verständigungsschwierigkeiten kommen kann, wenn die Gesangspartner sich bei verschiedenen Temperaturen befinden. Männliche Culiciden benutzen das große Johnstonsche Organ zum Auffinden der Weibchen; es hat seine höchste Empfindlichkeit im Tonbereich des weiblichen Fluggeräusches. Mit der Temperatur ändern sich Fluggeräusch und Gehöroptimum gleichsinnig (KEPPLER 1958 u. a.). Auch bei Feldheuschrecken muß die innerartliche Verständigung gewährleistet bleiben, obwohl z. B. bei Neoconocephalus ensiger die Silbenzahl mit der Temperatur ansteigt $\left(Q_{10}=2, z . T . V T=A T\right)$ und auch das Verhältnis zwischen Verslänge und Ruheintervall sich ändert (bei $14^{\circ} \mathrm{C} 1: 1$, bei $25^{\circ} \mathrm{C} 1: 2$; FrIngs \& Frings 1957, vgl. Busnel 1953 u. a.). Bei Photinus und Pboturis nimmt die Latenzzeit bis zur Antwort mit abnehmender Temperatur zu; die $\mathrm{Q}_{10^{-}}$Werte betragen für den Bereich von $10^{\circ}$ bis $30^{\circ} \mathrm{C}: 2,4$ bis 1,4 . In dem Bereich von $15^{\circ}$ bis $30^{\circ} \mathrm{C}$ bleibt die Form des Lichtsignals relativ konstant, nicht außerhalb dieses Bereichs (BUCK \& CAsE 1961, vgl. EDMUNDS 1963, LÖRCHER 1966).

\section{Jabreszeitliche Unterschiede}

Durch eine Leistungsadaptation können sich die Organismen auch an die jahreszeitlichen Temperaturunterschiede anpassen; dies wird später erörtert. Außerdem gibt es temperaturunabhängige Anderungen. Ein besserer Zeitgeber für die Jahreszeit als die Temperatur ist die Tageslänge, welche die Jahresrhythmik weitgehend bestimmen kann, doch wird oftmals auch eine endogene Komponente, ein circaannualer Rhythmus, deutlich (vgl. Precht 1964a, Remmert 1965).

Etliche Organismen überbrücken die ungünstige Jahreszeit durch besondere Ruhephasen, während welcher der Stoffwechsel meist herabgesetzt ist. Im Winter aktive Tiere zeigen zu dieser Jahreszeit oftmals einen relativ hohen Stoffwechsel, so daß 
durch die niedrige Außentemperatur nicht eine zu starke Abdrosselung erfolgt. Weitere Komplikationen können hinzukommen. Obwohl z. B. bei zwei Hemigrapsus-Arten der Sauerstoffverbrauch bei den meisten Gewichtsklassen mit fallender AT ansteigt, sind die Sommerwerte bei gleichen VTs höher als die Winterwerte, was mit dem unterschiedlichen Salzgehalt zu beiden Jahreszeiten zusammenhängt (Dennez 1960). Die Atmung des Kiemengewebes dieser Krebse zeigt jedoch auch bei gleichem Salzgehalt höhere Sommerwerte (DeHnel \& McCAUghran 1964).

Solche von der AT ganz oder zumindest teilweise unabhängigen jahreszeitlichen Unterschiede in der Höhe des Stoff wechsels und auch unterschiedliche $\mathrm{Q}_{10}$-Werte für die Abhängigkeitskurven von der VT sind mehrfach beobachtet worden, doch kann auf diese Probleme nicht eingegangen werden, da sie ja nicht direkt mit der Temperatur zusammenhängen und somit nicht in den Rahmen dieser Abhandlung gehören, wenn sie auch zumeist indirekt als Anpassungen an die unterschiedlichen Temperaturen der Jahreszeiten zu werten sind.

\section{Folgen einer Temperaturänderung}

\section{Overshoots und andere Reaktionen}

In den Angaben zur Versuchsausführung wurde vorgeschlagen, zunächst bei einer VT zu messen, die der AT entspricht, und die VT dann in einem einmaligen Schritt zu ändern. Eine solche Anderung hat, wic erwähnt, besonders dann, wenn sie relativ rasch erfolgt, oftmals unerwünschte Folgen, die natürlich vermieden werden, wenn man sich damit begnügt, nur eine VT $=\mathrm{AT}-\mathrm{Kurve}$ aufzustellen; dies hat jedoch wieder andere Nachteile.

Eine Temperaturerhöhung wirkt auf viele Tiere beunruhigend. Die dadurch bedingte Erhöhung des Stoffwechsels muß man vor den endgültigen Messungen erst abklingen lassen. Auch Temperatursenkungen können zunächst Störeffekte auslösen. Nicht derartige Erscheinungen sollen hier interessieren, sondern andere, die nicht mit einer veränderten Bewegung der Tiere zusammenhängen und auch bei unbeweglichen Organismen bei relativ raschen Temperaturänderungen auftreten.

Die Leistungswerte können anfänglich über das endgültige Maß hinausschießen, also bei Temperatursteigerungen zu hoch und bei Senkungen zu niedrig sein (overshoots), oder die Endwerte werden erst nach einer gewissen Verzögerung und nicht sofort erreicht, sobald der Organismus die veränderte Temperatur angenommen hat. Es gibt auch Fälle, wo die Leistungswerte bei Temperaturerhöhungen zunächst ab- und nach Senkungen zuerst zunehmen (undershoots; diese werden auch als false start bezeichnet, vgl. hierzu GraINGer 1960; einige Autoren nennen undershoot einen overshoot bei abnehmender Temperatur). In manchen Fällen stellt sich der neue Wert erst nach oszillierenden Schwankungen ein (vgl. Grainger in Prosser 1958, Karger 1962).

Grainger (in Prosser 1958, 1960) fand overshoots nach einem Temperaturwechsel von $5^{\circ} \mathrm{C}$ in den ersten $5 \mathrm{~min}$ bei der Atmung von Chilomonas paramecium, Astasia longa, Euglena gracilis, Bacillus subtilis und Bäckerhefe. In dieser Übergangsphase ist auch der respiratorische Quotient anders als im steady state-Stadium der beiden Tem- 
peraturen. Bei einem Temperatursprung von $30^{\circ}$ auf $20^{\circ} \mathrm{C}$ zeigt die $\mathrm{CO}_{2}$-Abgabe der Hefe einen krättigen overshoot mit anschließenden oszillierenden Schwankungen (die Anderungen beim Sauerstoffverbrauch sind geringer); der overshoot verschwindet, wenn $\mathrm{Mg}$-Ionen zugesetzt werden, die bekanntlich die Plasmaviskosität beeinflussen.

Neuerdings sind diese Phänomene eingehend von ZERBST (1966, vgl. auch HüLSEN \& ZERBST 1964) bearbeitet worden, der wie bei der Leistungsadaptation 5 Typen unterscheidet, die er an einem elektrischen Modell nachahmen konnte. Es handelt sich nach ZERBST um Einschwingprozesse, also Reaktionen, die sich zwanglos aus den Eigenschaften des lebenden Systems ergeben und keine übergeordnete Regulation notwendig machen. Er arbeitete mit isolierten Herzen von Rana esculenta und solchen in situ. Bei einer raschen Temperatursteigerung $\left(10^{\circ} \rightarrow 25^{\circ} \mathrm{C}\right)$ nimmt die Frequenz des Herzschlags in situ zunächst überschießend $\mathrm{zu}$, bis nach $6 \mathrm{~min}$ ein steady-state-Wert erreicht ist; nach einem folgenden Senken der Temperatur um $10^{\circ} \mathrm{C}$ nimmt die Frequenz zunächst wieder überschießend $a b$, um nach etwa 90 min den Ausgangswert zu erreichen. Bei langsamer Temperatursteigerung stellt sich die Frequenz nicht überschießend, sondern graduell auf einen neuen Wert ein. Bei Herzen warmadaptierter Frösche werden die neuen steady state-Werte nach Temperatursprüngen schneller erreicht als bei solchen von kaltadaptierten Tieren. SEgal (1962) fand overshoots als erste Antwort auf plötzliche Änderungen der Temperatur bei der Herzfrequenz von Acmaea limatula. Gleiche Temperaturerhöhungen führen zu um so ausgeprägteren overshoots, bei desto höheren Temperaturen der Sprung ausgeführt wird (vgl. BLAžKa 1955).

Overshoots findet man auch bei der Bewegungsgeschwindigkeit von Insekten (vgl. KENNEDY 1939). Undershoots beobachtete GäRDEFORs (1964) bei der Aktivität von Chortippus albomarginatus nach Temperatursprüngen auf- und abwärts; die Endaktivität war in einem mittleren Bereich unabhängig von der VT. Auch bei elektrophysiologischen Messungen treten oftmals typische undershoots auf. Wird die Temperatur sprungartig erhöht, so sinkt die Entladungsfrequenz eines mäßig bis stark gedehnten Dehnungsrezeptors von Astacus ruckartig ab; anschließend kehrt sie im Verlauf einiger Minuten auf den Ausgangswert zurïck, steigt stetig weiter an und erreicht schließlich (etwa nach 1 Std.) einen höheren Endwert. Wird die Temperatur sprungartig gesenkt, so steigt die Entladungsfrequenz zuerst rasch an, nimmt dann stark und schließlich immer langsamer ab. Weniger untersuchte langsame Temperaturänderungen wirken sich anders aus. Auch intrazelluläre Ableitungen zeigen bei Astacus deutliche Unterschiede bei langsamen und raschen Temperaturänderungen (BURKHARdT 1959, vgl. Kerkut \& Taylor 1958, Winter 1967, Larimer 1967). Schließlich sei daran erinnert, daß entsprechende Phänomene die Funktion der Thermorezeptoren auszeichnen (Precht, Christophersen \& Hensel 1955, p. 145). Bei einer schnellen Abkühlung auf eine konstante tiefere Temperatur erhöht sich z. B. die Frequenz der einzelnen Kältefasern zunächst, um sich dann auf einen niedrigeren Endwert einzustellen, welcher der neuen konstanten Temperatur entspricht.

Undershoots können bei Protozoen (Suctorien) sogar zu Volumenänderungen führen. "A sudden increase of temperature from below $15^{\circ} \mathrm{C}$ by $5^{\circ} \mathrm{C}$ or more causes a temporary fall in the rate of output, followed by a rise to a new level higher than the original. During the depression in activity the body swells slightly. The vacuolar frequency increases immediately but briefly when the temperature is raised, falls 
steeply when the depression sets in and when secretion is re-established rises again to a level above the original" (KITCHING 1954, p. 75).

SchLIEPER und seine Schüler fanden, daß der Sauerstoff verbrauch (z. B. bei Astacus und Planarien) sich nach einer Veränderung der Temperatur manchmal nicht sofort, sondern erst verzögert ändert (Precht, Christophersen \& Hensel 1955, p. 38, vgl. jedoch auch VALEN 1958). Im Gegensatz zu einem großen Temperatursprung $\left(15^{\circ}\right.$ $\rightarrow 25^{\circ} \mathrm{C}$ ) steigt der Sauerstoffverbrauch bei Planaria gonocephala und $P$. alpina bei einer Anderung von $5^{\circ} \rightarrow 10^{\circ} \mathrm{C}$ in $3 \mathrm{Std}$. noch gar nicht an und erst später langsam bis zum Endwert (in etwa 12 Std.). Nach WIESER (1965b) steigt bei Porcellio scaber der Sauerstoffverbrauch nach einer Anderung der AT von $8,6^{\circ}$ auf $20^{\circ} \mathrm{C}$ nicht sofort an, sondern erst allmählich bis zum Endwert. WIESER vermutet, daß zunächst neue Enzyme synthetisiert werden müssen, doch müßte die Temperaturänderung wie in anderen Fällen auch gleich zu einer Erhöhung der Reaktionsgeschwindigkeit führen. Es ist nicht sicher, daß es sich in derartigen Fällen noch um bloße Reaktionen handelt.

\section{Vorübergehende Nachwirkungen}

Bei vielen Erscheinungen, die im Folgenden erörtert werden, handelt es sich nicht mehr nur um Reaktionen, jedoch zumeist auch nicht um Regulationen bzw. Akklimatisationen, wie sie in den weiteren Kapiteln besprochen werden. Da es sich $z$. T. wahrscheinlich um vom Körper vorgenommene Reparationen nach Störungen handelt und wir außerdem über die geschilderten Phänomene so wenig wissen, daß eine exakte Zuordnung noch nicht möglich ist, sollen sie hier behandelt werden.

Es wurde erwähnt, daß die $\mathrm{Q}_{10}$-Werte der einzelnen Lebensprozesse recht unterschiedlich sein können, was bei Änderungen der Temperatur zu Veränderungen im Zusammenspiel der Prozesse führen muß, die als Störungen z. T. wieder beseitigt werden müssen. Bei Süßwassertieren mit wasserdurchlässiger Haut müssen z. B. Wassereinstrom und -ausstrom aufeinander abgestimmt sein. Schon RAFry (1954) berichtet über vorübergehende Gewichtsveränderungen bei Fischen nach einer Änderung der Temperatur (die Untersuchung von KITCHING 1954 wurde erwähnt). Dies erinnert an Umsetzversuche von Süßwasser- und Meerestieren in Brackwasser. Die Regulation setzt dabei oft erst ein, nachdem anfangs sehr wohl das Volumen verändert wird (vgl. REMANE \& SCHLIEPER 1958, p. 245 ff.). Sicherlich beruht der Wassereinstrom nicht nur auf einer Osmose mit niedrigem $\mathrm{Q}_{10}$-Wert. Die gebildete Harnmenge und die Wasserpermeabilität hatten nach WIKGREN (1953) bei Petromyzon fluviatilis z. B. etwa gleich hohe Temperaturkoeffizienten, wenn er die Tiere von Zimmertemperatur in tiefe Temperaturen überführte (vgl. Remane \& Schlieper 1958, p. 297 ff.). Das Verhältnis von Chlorid-Ausscheidung zur-Absorption ist jedoch zunächst gestört; innerhalb von 10 bis 20 Std. findet ein gewisser Ausgleich statt, auch die Wasserpermeabilität ändert sich in dieser Zeit.

KINNE (Diskussionsbeitrag zu SCHLIEPER 1966) weist mit Recht darauf hin, daß nicht nur eine Uberführung der Organismen in subletale Temperaturen als Streß wirken kann, sondern eventuell auch eine Temperaturänderung im "normalen“ Bereich, vor allem dann, wenn der Temperaturwechsel rasch erfolgt. Diese Probleme müssen 
viel mehr beachtet werden als dies bisher geschehen ist. Heinicke \& Houston (1965) untersuchten den Salz- und Wassergehalt von Blut und Gewebe des Goldfisches (ATs $20^{\circ}$ und $30^{\circ} \mathrm{C}$ ). Langangepaßte Fische unterscheiden sich kaum im Na-Gehalt des Blutplasmas und im Chlorid-, K- und Wassergehalt des Gewebes. Der Chloridgehalt des Plasmas und der Na-Gehalt des Gewebes nehmen mit steigender AT ab, der K-Gehalt im Plasma etwas zu. Eine rasche Überführung der Fische von $20^{\circ}$ in $30^{\circ} \mathrm{C}$ hat zur Folge, daß der Chloridgehalt im Plasma plötzlich nach 48 Std. ansteigt, dann folgt ein scharfer Abfall, bis sich schließlich der Endwert einstellt (ähnlich verhält sich der Na-Gehalt). Im Gewebe ändert sich der Na- und Chloridgehalt in 24 Std. nur unwesentlich. Nach einem Wärme- oder auch Kältestreß zeigen die Konzentrationen an Glutaminsäure und $\gamma$-Aminobuttersäure im Gehirn des Goldfisches nach 24 bis 48 Std. ein Maximum, um innerhalb von 2 Wochen auf den Ausgangswert zurückzugehen (BAsLow in Prosser 1967).

Auch Hickman et al. (1964), die Salmo gairdnerii von einer AT von $16^{\circ}$ in $6^{\circ} \mathrm{C}$ (in $17 \mathrm{Std}$.) überführten, unterscheiden zwischen vorübergehenden und bleibenden Veränderungen. „Plasma, muscle, and brain tissue showed a transient but significant drop in water content during the first days of cold exposure... Significant reciprocal changes in brain $\mathrm{Na}$ and $\mathrm{K}$ concentration were measured shortly after transfer to $6^{\circ} \mathrm{C}$ and large $(61 \%)$ increase in brain $\mathrm{Cl}$ concentration occured after 3 weeks of cold adaptation. Large, rapid but mostly transient shifts in muscle $\mathrm{Na}$ and $\mathrm{K}$ occured. During the first 3 days of cold exposure muscle lost $61 \%$ of the $\mathrm{Na}$ and $30 \%$ of the $\mathrm{K}$ present before transfer. This loss is reflected in a rise in plasma $\mathrm{Na}$ and $\mathrm{K}^{\text {" }}$ (p. 577 , vgl. auch Munday \& Blane 1961). Nach Heitmann (unveröffentlicht) ist bei kaltadaptierten Ameiurus nebulosus (AT $=8,5^{\circ} \mathrm{C}$ ) der Blutplasmagehalt an Na gegenüber 25,50-Tieren erhöht, an K gesenkt, ebenfalls der K-Gehalt im Muskel (Na-Gehalt nicht verändert). Nach einer plötzlichen Steigerung der AT $\left(8,5^{\circ} \rightarrow 25,5^{\circ} \mathrm{C}\right)$ nimmt im Plasma der Na-Gehalt zunächst stetig zu (Maximum nach 4 Tagen), während der KGehalt gleich übermäßig stark ansteigt (Maximum bei täglichen Messungen am 1. Tag). Der K-Gehalt im Muskel steigt in der Versuchszeit (3 Wochen nach dem Umsetzen) langsam an, dessen Na-Gehalt ändert sich nicht wesentlich. Huggel et al. (1963) zeigten, daß schon ein bloßes Umsetzen der Fische in die Apparatur als "Streß" wirken kann und den $\mathrm{Na}$ - und $\mathrm{Cl}-\mathrm{Gehalt}$ des Blutes ansteigen läßt.

LeHmanN (1968b) untersuchte die Folgen einer abrupten Anderung der AT $\left(15^{0} \rightarrow 5^{\circ} \mathrm{C}\right)$ auf zahleiche Fermente der Goldfischmuskulatur; zumeist treten Verminderungen der Aktivität ein, doch verläuft die Kurve anfangs oft zickzackförmig, um später gleichförmiger zu werden. Selbst die beobachtete Proportionskonstanz von Fermentgruppen (PETTE 1965) kann vorübergehend verlorengehen. Nach einer Woche sind die Endwerte oft noch nicht erreicht. Eine kurzfristige Senkung der AT $\left(15^{\circ} \rightarrow\right.$ $0,5^{\circ} \rightarrow 15^{\circ} \mathrm{C}$ ) führt $\mathrm{zu}$ ähnlichen Anderungen. Der RNS-Gehalt der Goldfischmuskulatur wird nach einer Senkung und auch Erhöhung der AT vorübergehend erheblich gesteigert. Es handelt sich hierbei sicherlich um Gegenmaßnahme des Körpers zur Beseitigung der Schockfolgen. - Bei Elasmobranchiern hatten Temperaturschocks kaum eine Wirkung auf Fermente im Gegensatz zu anderen Arten eines Streß (RAsmussen \& RASMUSSEN 1967).

Eine Erklärung oder auch nur Zuordnung all dieser Phänomene ist kaum möglich. 
Bemerkenswert ist das so unterschiedliche Verhalten der einzelnen Ionen, das auch anders sein kann, als man üblicherweise an tierischen Geweben gefunden hat (Verlust der Zellen an $\mathrm{K}$ und Gewinn an Na bei einer Temperatursenkung; vgl. die Diskussion von Hrckman et al. 1964). Auch der so verschiedene zeitliche Verlauf der Kurven nach dem Temperaturwechsel ist schwer deutbar. Vielleicht treten sogar Störungen einzelner Transportsysteme in den Membranen auf, die repariert werden müssen. Schließlich ist mit Gegenmaßnahmen des Körpers zu rechnen, die sich ganz allgemein an einen Streß anschließen und bei Säugetieren zu vermehrter Corticotropinausschüttung und damit zu einer gesteigerten Hormonausschüttung der Nebennierenrinde (vor allem an Glucocorticoiden) führt. Bei 'Teleostiern kann durch ACTH ein Anstieg des Kaliums im Blut

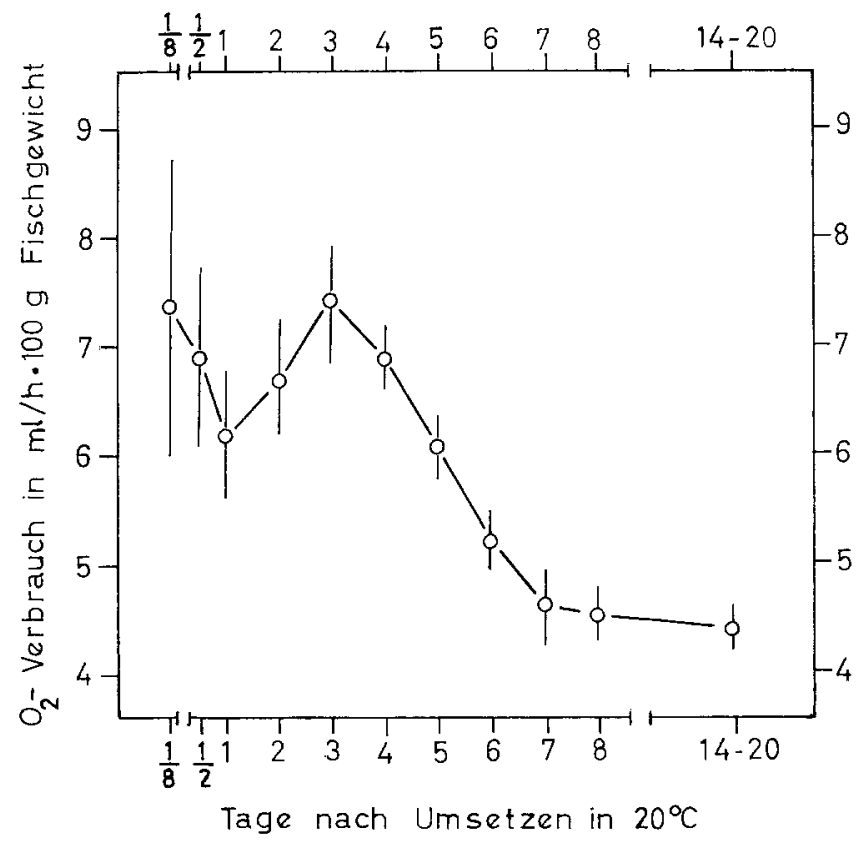

Abb. 3: Der zeitliche Verlauf einer Umadaptation (AT $10^{\circ} \rightarrow 20^{\circ} \mathrm{C}, \mathrm{VT}=20^{\circ} \mathrm{C}$ ), gemessen am Sauerstoffverbrauch von Tinca tinca (Gewicht 204 bis $275 \mathrm{~g}$ ). Eingetragen sind die mittleren Fehler des Mittelwertes (je 7 Tiere, nach unveröffentlichten Daten von JankowsKY)

und ein Abfall des Natriumgehaltes erzielt werden (vgl. PARRY 1966, p. 427); über die hormonale Seite eines Streß bei Fischen siehe MaHon et al. (1962), WEATHERLEy (1963), Hane et al. (1966) und Fagerlund (1967). Die Befunde von Lehmann deuten auf eine vermehrte Proteinsynthese nach dem Temperaturwechsel hin; die Schwankungen der Fermentaktivitäten, die wir inzwischen für die weiße Seitenrumpfmuskulatur von Idus idus bestätigen konnten, sind schwer deutbar. Überlagern können sich die bleibenden Phänomene, die später als Leistungsadaptation beschrieben werden.

Nach SMITH \& Morris (1966) ist eine vorübergehende Vermehrung der Einbaurate von Aminosäuren in die Mucosa des Goldfischdarmes nach einer Änderung der 
AT $\left(8^{0} \rightarrow 25^{\circ} \mathrm{C}\right)$ auf eine verstärkte Proteinsynthese zurückzuführen, die gehemmt werden kann.

Hier seien noch einige Beobachtungen geschildert, die kaum als bloße Reaktionen gedeutet werden können, somit eigentlich auch nicht mehr zu diesem Kapitel gehören. PRECHT (1962, p. 72) fand bei Messungen des Sauerstoffverbrauchs von Xiphopborus belleri und JANKOWSKX (unveröffentlicht) bei Tinca tinca zeitlich ausgedehnte Phänomene (Abb. 3). Nach einem Senken der AT $\left(20^{\circ} \rightarrow 8,6^{\circ} \mathrm{C}\right)$ wird der Sauerstoffverbrauch von Porcellio scaber (Wintertiere) für einige Tage gesteigert, um dann wieder auf den alten Wert abzufallen (VT stets $20^{\circ} \mathrm{C}$ ). Sommertiere zeigen diese Erscheinung nicht (WIESER 1965b). LANGE (in PRECHT et al. 1966) überführte langfristig an $8^{0} \mathrm{bzw} .25^{\circ} \mathrm{C}$ angepaßte Idus idus stufenweise in die mittlere Temperatur von $16,5^{\circ}$ und beließ sie darin. Der $\mathrm{Q}_{10}$-Wert für die Kiemendeckelbewegungen der Fische beträgt nach der Senkung der AT zunächst 2,9; der Abfall der Frequenz hält jedoch auch am nächsten Tage an; der viel höher liegende Endwert wird erst langsam erreicht. Es handelt sich somit um einen ausgedehnten "overshoot" (man könnte dies Wort nur für echte Reaktionen reservieren, doch ist die Entscheidung, ob nur solche vorliegen, oft kaum zu fällen). Bei einer Temperatursteigerung ist ein entsprechender Effekt bei den natürlich sehr schwankenden Werten weniger deutlich. Auch in diesen Fällen werden anscheinend anfängliche Störungen im Laufe von Tagen ausgeglichen.

\section{REGULATIONEN DURCH UBERGEORDNETE SYSTEME}

Es ist damit zu rechnen, daß Besonderheiten des Reagierens, die man zunächst für eine angeborene Reaktionsnorm hält, sich nach einer genaueren Analyse als Regulationen durch übergeordnete Systeme erweisen. Dies gilt z. B. für die Bereiche mit niedrigen $\mathrm{Q}_{10}$-Werten in den Abhängigkeitskurven von der VT. Bei ruhenden Reptilien zeigt sich ein Minimum der Atemfrequenz bei der Vorzugstemperatur der Arten; dieses verschwindet in Urethannarkose und nach Entfernung des Vorderhirns (PRECHT, CHRISTOPHERSEN \& HENSEL 1955, p. 24). KeISTER \& Buck (1961) fanden ein Plateau bei der Atmung von Pbormia regina-Larven (nicht bei Puppen und Imagines) im VTBereich von $10^{\circ}$ bis $15^{\circ} \mathrm{C}$, das nach Dekapitierung verschwindet. Nach FIscher \& Sullivan (1958) weist die Häufigkeit der Spontanbewegungen bei Forellen zwei Maxima auf. Das erste ist nach bestimmten Gehirndefekten nicht mehr vorhanden; die Kurve steigt dann bis zum zweiten Maximum regelmäßig an. Bei einigen Carabiden kommt ein Plateau oder sogar ein Minimum der Temperaturkurve für den Sauerstoffverbrauch dadurch zustande, daß (vermutlich durch verstärkte Ventilation) die Atmung bei VT's unter diesem "Regulationsintervall“ überhöht ist; nach dieser Zone steigt der Sauerstoffverbrauch besonders steil an (Sснмпт 1956). BENTHE maß die Erregbarkeit des isolierten Fußes von Lymnaea stagnalis (k-Werte nach BLArr). Er fand eine Leistungsadaptation nach Typ 3, doch waren die $Q_{10}$-Werte bei den Abhängigkeitskurven von der VT für Präparate verschieden adaptierter Schnecken unterschiedlich, je nachdem die Pedalganglien entfernt wurden oder nicht (PrEchr in Prosser 1958, p. 57). Natürlich kann auch eine veränderte Aktivität der Tiere ein Plateau bei den Stoffwechselkurven bedingen (vgl. Gromysz-KaLKowsKa $\&$ STOJALowsKa 1966). 
Es ist fraglich, ob die für den Stoffwechsel von Landpulmonaten von Nopp (1965) gefundenen niedrigen $Q_{10}$-Werte bei relativ hohen VTs als Regulationen zu bezeichnen sind, zumal die Gewebsatmung gleiche Erscheinungen zeigt (Nopp \& FarAHAт 1967), doch konnte dieses Phänomen bei einigen Arten z. B. während der Fortpflanzungszeit oder nach einer Ruhepause nicht beobachtet werden.

Ist der Zeitfaktor als Unterschiedsmerkmal zwischen Regulationen und Adaptationen geeignet? Man muß damit rechnen, daß auch die Regulationen, die nach der Temperaturänderung einsetzen, Zeit bis zu ihrem Einsetzen bzw. bis zu ihrem Wirksamwerden benötigen, wie das auch bei der erwähnten Volumenregulation nach Salzgehaltsänderungen der Fall ist (p. 504). Die Leistungsadaptation ist meist ein länger dauernder Prozeß, doch dürfen wir nicht unterstellen, daß dies immer so ist. Selbst wenn an iht Syntheseprozesse beteiligt sind, können diese relativ schnell verlaufen. Bei Musca domestica wird z. B. die RNS-Synthese durch eine plötzliche Senkung der VT weniger beeinträchtigt als die RNS-Passage durch die Kernmembran. Bereits im Laufe von einigen Stunden findet eine normale Proportionierung der Synthese- und Ausschleusrate statt, hier wahrscheinlich durch eine schnelle Adaptation (BIER 1965). Für die Synthese eines Submoleküls des Hämoglobins, das eine Peptidkette von etwa 150 Aminosäuren darstellt, nimmt man heute eine Dauer von etwa 1,5 min an.

So können wir auch bei folgendem Problemkreis allein auf Grund des Zeitfaktors nicht einwandfrei entscheiden, ob man von einer Regulation oder Adaptation sprechen soll; eine scharfe Trennung ist ohne Kenntnis des Mechanismus kaum möglich. Der sogenannte endogene circadiane Rhythmus ist bekanntlich weitgehend temperaturunabhängig; er wird durch äußere Zeitgeber einreguliert (vgl. PRECHT 1964a, REMMERT 1965 u. a.). In diesem Zusammenhang ist oftmals die Aktivität von wechselwarmen Tieren untersucht worden. Die Aktivitätsdauer ist temperaturabhängig, nicht jedoch die Periodenlänge (vgl. LoHMann 1967 u. a.). Die Unabhängigkeit von der Temperatur ist eine Vorbedingung für das zuverlässige Funktionieren einer inneren Uhr. Rasche Temperaturänderungen können bei wechselwarmen Tieren zu einer vorübergehenden Beeinflussung des endogenen Rhythmus im Sinne einer Beschleunigung bzw. Verlangsamung führen (Literatur bei PREcht et al. 1966). Wenn z. B. eine rasche Leistungsadaptation nach diesen Temperaturänderungen einsetzen würde, so muß sie zur Richtigstellung der Uhr etwa dem später erörterten Typ 2 entsprechen; kleine Abweichungen nach den Typen 1 und 3 könnten durch Zeitgeber ausgeglichen werden. Eine solche Adaptation käme dann nur der Uhr zu, nicht den anderen Lebensprozessen. Es wird noch erörtert, daß sich im Hinblick auf die Leistungsadaptation die einzelnen Organfunktionen und Zellstoffwechselprozesse sehr unterschiedlich verhalten können. Die Anpassung der Uhr versagt vielfach bei sehr tiefen Temperaturen, was den Gedanken an ein "Einfrieren" des Regulations- bzw. Adaptationsmechanismus nahelegt. Eine weitgehende Temperaturunabhängigkeit besteht auch für andere Rhythmen wie die Jahresuhr. Eine derart einfache Deutung mag nicht allen Beobachtungen gerecht werden; bei einigen Pflanzen kann es auf die Phase des Zyklus ankommen, in der die Temperaturänderung vorgenommen wird.

Es sei erwähnt, daß die Temperatur auch als Zeitgeber funktionieren kann. Selbst Temperaturzyklen von geringer Schwankungsbreite können die circadiane Aktivität synchronisieren (z. B. bei Eidechsen nach HorfMANN 1968). Bei feldbewohnenden 
Carabiden ist dieser Zeitgeber wirksamer als bei waldbewohnenden Arten (vgl. THIELE 1968).

Das Abschätzen kurzer Zeitintervalle durch Goldfische hängt nach RozIN (1965) nicht von der Temperatur ab, wohl aber die Höhe der Antwortrate, die ähnliche $\mathrm{Q}_{10^{-}}$ Werte aufweist wie der Stoffwechsel.

\section{AKKLIMATISATIONEN (ADAPTATIONEN)}

\section{Stoffliche Veränderungen}

Bei der Messung von Lebensprozessen (z. B. von Fermentaktivitäten) kann man von unterschiedlich adaptierten Organismen ausgehen und Abhängigkeitskurven von der $\mathrm{VT}^{t}$ aufzeichnen und dadurch klären, ob eine Leistungsadaptation vorhanden ist, und diese dann einem Typ zuordnen. Mit der AT dürften sich nicht nur die im allgemeinen gemessenen Fermentaktivitäten ändern, sondern auch die Fermentmengen (vgl. Precht, Christophersen \&. Hensed 1955, p. 31, Freed 1965). Man kann bei Mengenänderungen von Substanzen jeder AT nur eine zugehörige Quantität zuordnen bzw. feststellen, ob die Menge mit steigender AT zu- oder abnimmt; eine Zuordnung $\mathrm{zu}$ den später erörterten Typen der Leistungsadaptation ist nicht möglich. Natïrlich kann man auch die Geschwindigkeit einer Synthese oder die des Einbaus einer markierten Substanz untersuchen, insofern also wieder eine Reaktionsgeschwindigkeit in Abhängigkeit von der VT bei unterschiedlich adaptiertem Versuchsmaterial. So ist nach MEws (1957b) die Einbaugeschwindigkeit von eingespritztem Glykokoll bei kaltadaptierten Fröschen (Rana temporaria) größer als bei warmadaptierten (vgl. JANKoWSKY 1960, ferner DAs 1967). Bei einer V'T von $15^{\circ} \mathrm{C}$ ist nach DAs \& Prosser (1967) eine Std. nach der Injektion von Leucin die Einbaurate bei warmadaptierten Goldfischen in Leber und Kieme größer als bei kaltadaptierten, bei einer VT von $25^{\circ} \mathrm{C}$ jedoch kleiner, ebenfalls beim Muskel bei allen VTs. Ein erhöhter Einbau in die Eiweiße kann auf einer vermehrten Synthese beruhen oder auf einem verminderten Abbau.

Eine mit der A'T veränderte Substanzmenge kann für den normalen Temperaturbereich eine Bedeutung haben, aber auch für die Resistenzadaptation an extreme Temperaturen, was z. B. für das Glycerin und Sorbit bei Insekten gilt (vgl. SALT in DuLL et al. 1964), doch ist die Entscheidung nicht immer eindeutig zu fällen. Bei Meerestieren kann eine Vermehrung des osmotischen Drucks der Körperflüssigkeiten ein Mittel zur Erhöhung der Kälteresistenz sein (vgl. Scholander et al. 1957, RAschack 1967); ein hoher Zuckergehalt kann bei Insekten eine Beziehung zur Kälteresistenz haben (WYATT 1967).

Eine weitere Schwierigkeit kann sich daraus ergeben, daß eine Temperaturänderung relativ schnell eine neue Gleichgewichtseinstellung bewirkt, die in der Folgezeit kaum verändert wird, also auch kaum als Anpassung aufgefaßt werden kann. Als Beispiel sei die Wasseraufnahme bei Fröschen ( $R$. temporaria) nach einer Senkung der AT genannt. Das Wasser wird in die Körperflüssigkeiten aufgenommen, weniger in das Gewebe (Grainger 1961, 1964). Kaltadaptierte Frösche kann man durch einen mäßigen 
Druck auf den Unterleib zur Entleerung der Harnblase veranlassen, nicht warmadaptierte Tiere (Kasbohm 1967). Für die Leistungsadaptation des Sauerstoffverbrauchs haben diese Wassergehaltsänderungen nach JANKowsKY (1960) keine Bedeutung.

Auch bei diesen stofflichen Veränderungen muß man genetis che und $\mathrm{n}$ ichtgen et is che Adaptationen trennen. Zur Unterscheidung beider Möglichkeiten müßte man wiederum Tiere verwandter Arten oder derselben Art aus unterschiedlich temperierten Wohngebieten (soweit möglich) längere Zeit unter gleichen Bedingungen halten. Unter anderen Aspekten untersuchten DEAN \& GoodNIGHT (1964) 4 Parameter (Blutglukose, Blutmilchsäure, Muskel- und Leberglykogen) von 4 Fischarten mit und ohne Muskeltätigkeit (jedoch kaltadaptierte Tiere gemessen im Winter, warmadaptierte im Sommer). Sie fanden deutliche Unterschiede und gleichzeitig, daß z. B. Pomoxis annularis bessere Leistungen in Wohngebieten mit niedrigen Temperaturen vollbringen kann, Micropterus salmonides bessere in wärmeren Wohngebieten (eine genauere Analyse ist notwendig, da z. B. auch temperaturunabhängige jahreszeitliche Einflüsse hinzukommen können; vgl. Hammond \& Hrckman 1966).

Im allgemeinen sind nur nichtgenetische Adaptationen untersucht worden, wobei das gleiche Versuchsmaterial längere Zeit bei unterschiedlichen ATs gehalten wurde. $\mathrm{Ob}$ diese Zeit immer lang genug war, ist fraglich, da, wie erwähnt, Temperaturänderungen relativ langfristige, aber dennoch vorübergehende Veränderungen zur Folge haben können; auch aus diesem Grunde sei auf diese Probleme relativ kurz und ohne Vollständigkeit eingegangen. Jahreszeitliche Anderungen, die oftmals nicht oder nicht nur mit der AT zusammenhängen, sollen nicht behandelt werden.

\section{Wassergebalt}

Eine Möglichkeit, die Intensität der Zellstoffwechselprozesse anzupassen, besteht in einer Änderung des Gehaltes an freiem Wasser und damit der Größe des Lösungsraumes. Bei der Hefe Torulopsis kefyr kann die Kompensation der Succinodehydrogenaseaktivität und deren Änderung mit dem Alter der Kulturen durch Wassergehaltsänderungen erklärt werden (Precht, Christophersen \& Hensel 1955, p. 32 ff.); dieses eine Prinzip muß allerdings schon bei diesem Einzeller zur Erklärung der fermentativen Adaptation versagen, da z. B. die Peroxydaseaktivität eine inverse Kompensation zeigt. Eine Anderung des an die Kolloide gebundenen, z. T. nichtlösenden Wassers muß sich umgekehrt wie die des freien Wassers auswirken.

Wassergehaltsänderungen nach einem Wechsel der AT sind oftmals auch für das Gewebe von Metazoen beobachtet worden, doch dürften sie für das Adaptationsproblem keine generelle Bedeutung haben (vgl. FRY 1958). Verwandte Arten oder sogar Rassen können sich unterschiedlich verhalten. HOAR \& CotTLE (1952) und KANungo \& Prosser (1959) fanden eine Zunahme des Wassergehaltes von Muskel und Leber des Goldfisches mit steigender AT. Murphy (1961, zitiert nach DAs 1967) und DAs konnten dies für die Leber, die Kiemen und den Muskel derselben Art nicht bestätigen (eine geringe Abnahme des Wassergehaltes in Leber und Muskel bei den kaltadaptierten Tieren war nicht abzusichern). SuHRMANN (1955), die wahrscheinlich mit C. gibelio, der Stammform des Goldfisches, arbeitete, konnte keine Abhängigkeit der Menge an 
freiem und gebundenem Wasser des Muskelgewebes von der AT feststellen, während das Lebergewebe der gleichen Art eine Abnahme des Gesamtwassergehaltes mit fallender AT zeigt (Christophersen \& PRECHT 1952).

\section{Salze}

Bei Wassertieren können, wie erwähnt, Temperaturänderungen zu vorïbergehenden oder auch zu bleibenden Wasser- und Salzgehaltsänderungen führen. Die Innenkonzentration kann dabei mit der Temperatur ab- und auch zunehmen (vgl. Remane \& Schlieper 1958, Kinne, Parrey u. a. in Dill et al. 1964). Lockwood (1960) hielt Asellus aquaticus längere Zeit bei verschiedenen Temperaturen, untersuchte aber auch die Wirkung eines Wechsels der AT. Er fand für die Hämolymphkonzentration ein Minimum bei etwa $5^{0} \mathrm{C}$. Die Geschwindigkeit des Na-Verlustes hing nicht von der Temperatur ab, wohl aber die aktive Na-Aufnahme (vgl. p. 504). Auch die aktive Aufnahme von Chlorid kann bei manchen Tieren durch die AT verändert werden (RAO in Prosser 1967, vgl. auch Cordier \& Worbe 1954). Permeabilitätsänderungen mit der AT wirken sich zumeist auf den Elektrolytgehalt des Körpers aus. Nach SMrth (1966a, b) sollen sich im Goldfischdarm nach einer Anderung der AT sogar qualitativ verschiedene Trägermolekïle für den Natriumtransport bilden. Die Serosa-MucosaPotentialdifferenz hängt von der AT ab. Puromycin-Injektionen verhindern die Veränderungen mit der AT (SMith 1966c).

Bei Rana esculenta ändert sich die Zusammensetzung des Blutplasmas mit der AT (Abnahme der Alkalireserve, des $\mathrm{Na}$ - und Chloridgehaltes und des $\mathrm{pH}$ mit steigender AT; Straub 1957, vgl. Gahlenbeck \& Bartels 1968). Nach Rao (1966, in Prosser 1967) und seinen Mitarbeitern soll im allgemeinen eine Adaptation an tiefe Temperaturen begleitet sein von einer Zunahme an Calcium, Kalium und Natrium in den Körperflüssigkeiten, während der Gehalt an Magnesium, Sulphat und Chlorid abnimmt („these changes may result in increased muscle metabolism"); sie fanden jedoch auch Ausnahmen von dieser Regel (z. B. für den Na-Gehalt des Blutes von Etroplus). Bei Lampitio manritii (ATs: $20^{\circ}, 28^{\circ}, 35^{\circ} \mathrm{C}$ ) zeigt der Ca-Gehalt ein Minimum bei der AT von $28^{\circ} \mathrm{C}$, der $\mathrm{Na}$ - und Chloridgehalt ein Maximum (Saroja \& RAO 1965, vgl. auch Parvatheswararao 1967). Nach Selvarajan (1962) nimmt der Chloridgehalt des Blutes und der Gewebeflüssigkeit beim Süßwasserfisch Cirrbina reba mit steigender AT (geringfügig) ab. PLÁTner (1950) beobachtete bei Goldfischen und Schildkröten nach einer starken Senkung der AT einen Anstieg des Mg-Gehaltes im Blutserum; bei Schildkröten nimmt der Mg-Gehalt in Muskel und Haut ab (11 Tage nach der Umadaptation gemessen). Die Arbeit von Hrckman et al. (1964) zeigt eindringlich die Bedeutung des Zeitfaktors. Im Gehirngewebe von Salmo gairdnerii bleibt, wie erwähnt (p. 505), der Chloridgehalt nach einer Senkung der AT stark erhöht, nicht der des Blutplasmas und Muskels.

Auch für terrestrische Tiere können sich besondere Probleme ergeben. Nach einer Blutmahlzeit von Rhodnius prolixus setzt z. B. eine hormonal ausgelöste Diurese ein, bei der die Geschwindigkeit der Exkretion und die Zusammensetzung des Urins von der VT' abhängen: „a fed insect kept at high a temperature will be left at the end of 
diuresis with a relative excess of water and an insect kept at a low temperature with a relative excess of salts" (MADDWELL 1964, p. 172).

\section{Proteine, Fette, RNS, DNS etc.}

Auch die Transportgeschwindigkeit von Aminosäuren (z. B. von Methionin ${ }^{3}$ durch den Goldfischdarm) (SMITH 1967a) kann im Sinne einer Kompensation von der AT abhängen. Es würde zu einer derartigen Leistungsadaptation passen, daß nach RAO (1966) u. a. die freien Aminosäuren in den Körperflüssigkeiten mit fallender AT abnehmen, die an Eiweiße gebundenen Aminosäuren, der gesamte Proteingehalt in den Zellen und Geweben und der RNS-Gehalt dagegen zunehmen. Für eine Anderung einer Fermentaktivität mit der AT braucht allerdings nicht ausschließlich die Fermentmenge bzw. die Apofermentmenge verantwortlich zu sein. Die durch unterschiedliche ATs bedingten Aktivitätsänderungen von Hefe-Transaminasen konnten nach RiNG \& Christophersen (1964) teilweise durch Zugabe von Coferment ausgeglichen werden. Es können ferner Einflüsse des Zellmilieus, die von der AT abhängen, eine Bedeutung für die Fermentaktivität haben.

Senkung der Zudhttemperatur $\left(30^{\circ} \rightarrow 24^{\circ} \rightarrow 15^{\circ} \mathrm{C}\right)$ bewirkt bei Drosophila melanogaster eine Erhöhung der Konzentration an freien Aminosäuren; dabei können sich einzelne Aminosäuren, wie die Glutaminsäure, anders verhalten (ANDErs et al. 1964). Im Muskel von Eriocheier sinensis sinkt von den nicht an Eiweiß gebundenen Aminosäuren besonders der Prolingehalt mit abnehmender AT (DUCHÂTEAU \& FLORKIN 1955, vgl. auch Baslow in Prosser 1967). Beim Skelettmuskel von Bufo boreas wird der gesamte Proteingehalt kaum von der AT beeinflußt (BIsHop \& GoRdon in Prosser 1967).

Ein 10tägiger Kälteaufenthalt von Rana pipiens führt zu einer Vergrößerung der Leberzellkerne, was auf einer Proteinzunahme beruht; der RNS- und DNS-Gehalt bleiben unverändert (Alvarez \& COWDEN 1966). Der DNS-Gehalt wird auch beim Goldfisch nicht mit der AT verändert. Ein Anstieg des Proteingehaltes in Kiemen, Leber und Muskel mit fallender AT führt nicht zu einer entsprechenden Abnahme des Gehaltes an freien Aminosäuren in diesen drei Gewreben. Der gesamte RNS-Gehalt der Kiemen und die RNS-Konzentration in der "nuclear" und der "microsomal" Fraktion nehmen mit der Adaptation an tiefe Temperaturen zu; der "supernatant" RNS-Gehalt verringert sich in Kiemen und Leber, aber vermehrt sich im Muskel mit abnehmender AT (DAS 1967).

Auf etliche andere Substanzen (Glykogen etc.), deren Menge von der AT abhängen kann, soll nicht eingegangen werden (vgl. z. B. DeAN \& Vernberg 1965). Sogar der H-Agglutinintiter kann bei Reptilien von der AT abhängen (Evans \& CowLes 1959).

Bei Daphnien wird die Hämoglobinmenge mit steigender AT vermehrt (Fox 1955). Straub. (1957) fand im Blut von Rana esculenta einen Anstieg der Erythrocytenzahl, eine Abnahme von deren Größe und des Hämoglobingehalts und einen An-

${ }^{3}$ Die Endkonzentration von Methionin auf der Serosaseite hing bei diesen Versuchen nur von der VT (nicht AT) ab. 
stieg im Gesamtvolumen der Blutzellen mit abnehmender AT (vgl. ANTHONY 1961, Huggins \& Percoco 1965, Frankel et al. 1966, Dean \& Vernberg 1966). Beim Karpfen sinkt die Zahl der Lymphozyten nach einer Sekung der AT, wie dies ganz allgemein nach einem Streß der Fall ist (SERFATY \& LAFFONT 1965).

Nach Rao (1966) nimmt das Verhältnis ATP/ADP bei Lampitio etwas mit der AT zu. Nach Christophersen (in Prosser 1967) nimmt der ATP-Spiegel bei Hefen nach einer Erhöhung der AT $\left(20^{\circ} \rightarrow 37^{\circ} \mathrm{C}\right)$ weit mehr ab als der ADP-Gehalt; AMP nimmt anfangs sogar zu. Diese Veränderungen haben nach CHrISTOPHERSEN eine große Bedeutung für die Leistungsadaptation (vgl. Hochachka in Prosser 1967).

Bei vielen wechselwarmen Tieren nimmt der gesamte Lipoidgehalt mit abnehmender Züchtungstemperatur zu. Beim Käfer Dendroctonus pseudotsuga ist andererseits der Fettgehalt bei einer Züchtung bei $13^{\circ} \mathrm{C}$ niedriger als bei $21^{\circ} \mathrm{C}$ (ATKINs 1967). Bei Leberzellen von Salmo gairdnerii nimmt nach BERLIN \& DEAN (1967) die Größe des Golgi-Apparates mit zunehmender AT zu und auch das gespeicherte Material (wahrscheinlich Lipoproteide) in diesen.

Wenn die kaltadaptierten Organismen im allgemeinen verhältnismäßig mehr ungesättigte Fettsäuren enthalten als warmadaptierte, so hängt dies wahrscheinlich mehr mit der Resistenz- als mit der Leistungsadaptation zusammen. JoHNSTON \& ROOTS (1964) und Prosser (1967, p. 367) betonen aber, daß diesbezügliche Unterschiede der Lipoide bedeutsam für Enzymaktivitäten (die von verbundenen Lipoiden abhängen) und für die Permeabilität von Zellmembranen sein können, so auch die von Neuronen, was wichtig für die Acetylcholinfreisetzung ist.

Nach Christophersen \& Kaufmann (1955) kann sich bei Hefen auch die Fettzusammensetzung mit der AT ändern (höherer Anteil niederer Fettsäuren bei tiefer Züchtungstemperatur; vgl, auch Farkas \& Herodek 1959 u. a.). Der Sättigungsgrad der Fettsäuren kann auch durch die Photoperiode beeinflußt werden (HARwood \& Takata 1965). KNIPPRATH \& MEAD (1966) verfolgten die zeitliche Anderung des Sättigungsgrades nach einer Senkung der AT bei Gambusa affinis und Lebistes reticulatus; die von der Anderung betroffenen Fettsäuren waren bei beiden Arten verschieden.

ROots (1968) untersuchte Phospholipoide des Gehirns unterschiedlich adaptierter Goldfische. „Greater relative unsaturation of C 16 fatty acids at the lower temperatures was mediated by an increase in the amount of palmitoleic acid from 5-10 per cent at $30^{\circ} \mathrm{C}$ to $12-14$ per cent at $5^{\circ} \mathrm{C}$. In contrast the greater degree of unsaturation of the $\mathrm{C} 18$ fatty acids at $5^{\circ} \mathrm{C}$ is due to a decrease in stearic acid from $17-22$ percent at $30^{\circ} \mathrm{C}$ to an average of 12 per cent at $5^{\circ} \mathrm{C}$. The oleic acid remained relatively constant at 24-27 per cent."

\section{Leistungsakklimatisationen (Leistungsadaptationen)}

\section{Genetische Adaptationen}

Unterschiedliche stoffliche Zusammensetzung oder verschiedene Abhängigkeit der Reaktionsgeschwindigkeit eines Lebensprozesses von der VT bei verwandten Arten und Rassen unter sonst gleichen Bedingungen (auch gleicher Vorbehandlung) können gene- 
tisch bedingte Anpassungen an ihren Wohnort darstellen. Die Frage, ob es sich in derartigen Fällen um einen Nutzen im Sinne eines Selektionsvorteils handelt, ist manchmal wiederum schwierig zu beantworten.

\section{Organismen aus unterschiedlich temperierten Wohngebieten}

Es ist früh aufgefallen, daß es in sehr kalten Regionen wie auch in den Tropen lebhafte und träge Tiere gibt. Die Bewegungsintensivät braucht sich auch zu den verschiedenen Jahreszeiten trotz der großen Temperaturunterschiede nicht so erheblich zu unterscheiden, wie man zunächst annehmen möchte. Der Sauerstoffverbrauch von verschiedenen Arten aus sehr unterschiedlichen Wohngebieten kann bei den Temperaturen dieser Gebiete etwa gleich sein (dies gilt z. B. nach Trorson 1952 für Mytiliden; Precht, Christophersen \& Hensel 1955, p. 173, Abb. 43) oder zumindest nicht so unterschiedlich, wie man es bei normalen $Q_{10}$-Werten erwarten sollte (z. B. bei Fischen und Krebsen; vgl. Scholander et al. 1953). Wenn man bei nicht vollständiger Anpassung des Stoffwechsels etwa gleiche Lebhaftigkeit beobachtet, so bleibt die Frage zu klären, ob arktische Formen einen größeren Prozentsatz ihrer Energie für die Lokomotion bereitstellen müssen als südlichere.

WOHLSCHLAG hat mehrfach antarktische Fische untersucht, die mit Ausnahme weniger Wochen in einigen Jahren ständig unter einer dicken Eisdecke leben. Bei dem extrem kaltstenothermen Fisch Trematomus bernacchii nimmt der Sauerstoffverbrauch über $0^{\circ} \mathrm{C}$ ab $(\mathrm{VT}=\mathrm{AT})$; bei $2^{\circ} \mathrm{C}$ stellen die untersuchten Arten ihre Schwimmtätigkeit ein (größte Schwimmaktivität bei der niedrigsten verwandten Temperatur von $-1,8^{\circ} \mathrm{C}$ ). Zumindest 2 von 4 untersuchten Trematomus-Arten besitzen einen relativ hohen Stoffwechsel, der von Rbigopbila dearbomi ist geringer; deses Tier gehört zu einer Fischgruppe, die auch außerhalb der Antarktis vorkommt. Im Sommer untersuchte $T$. bernaccbii aus tieferem Wasser haben einen geringeren Stoffwechsel als Tiere aus flachem Wasser; $T$. lönnbergi und $R$. dearborni aus $680 \mathrm{~m}$ Tiefe haben ebenfalls einen niedrigeren Stoffwedhsel als andere Trematomus-Arten aus flacheren Wohngewässem. Bei den von WoHLScHLAG untersuchten Fischen handelt es sich zumeist um träge Formen. Es gibt weitere demonstrative Fälle, wo Tiere noch bei sehr tiefen Temperaturen (z. B. $0^{\circ} \mathrm{C}$ ) aktiv sind und dabei einen relativ hohen Stoffwechsel zeigen, wie z. B. Isotoma saltans. Dieses Tier soll auf dem Gletschereis bei Sonnenschein herumhüpfen, bei Nacht an der Unterlage anfrieren, um nach dem Auftauen wieder auf Nahrungssuche zu gehen (Precht, Christorhersen \& Hensel 1955, p. 53, Schaller \& ZINKLER 1963). Winterfliegen (Cbionea araneoides) liefen noch bei - $6^{\circ} \mathrm{C}$ munter auf dem Schnee herum (Precht, Christophersen \& Hensel 1955, p. 53).

Diese Arten mïssen natürlich an so extreme Wohngebiete angepaßt sein. ScHoLANDER et al. (1953) vermißten Anpassungen bei artischen Landinsekten. Diese können ungünstigen Temperaturen ausweichen und bessere mikroklimatische Bedingungen aufsuchen. Anpassungen können auch bei marinen Arten fehlen (THorson 1952, Bullock 1955).

In diesen Fällen einer Anpassung und besonders beim zwischen- oder innerartlichen Vergleich ist stets zu prüfen, inwieweit erbliche Anpassungen vorliegen und in- 
wieweit sie durch Außenfaktoren (hier speziell die AT) bedingt werden. Sehr eingehend sind Arten und Rassen der Gattung $U c a$ aus unterschiedlich temperierten Wohngebieten untersucht worden. VerNBERG \& CostLow (1966) fanden z. B. bei jungen $U$. pugilator die höchsten Stoffwechselwerte bei allen VTs für Tiere aus Massachusetts, niedrigere für solche aus North Carolina und die niedrigsten für Tiere aus Florida $\left(A T=25^{\circ}\right.$ C). W. B. VernBERg \& F. J. VERnberg (1966) untersuchten den Sauerstoffverbrauch verschiedener Gewebe einer tropischen Form (U. rapax) und von $z$ wei Arten der gemäßigten Zone (U. pugilator und $U$. pugnax von Beaufort), wobei die Tiere an zwei AT's angepaßt und bei verschiedenen V'T's gemessen wurden. U. pugnax ergab die höchsten Werte; diese Art dringt weniger weit nach Süden vor als $U$. pugilator.

Nach RAo \& Bullock (1954) weisen Tiere aus kalten Lebensräumen nicht nur meist einen relativ hohen Stoffwechsel auf, sondern auch kleinere $\mathrm{Q}_{10}$-Werte der $\mathrm{Ab}$ hängigkeitskurven von der VT als ihre Verwandten aus wärmeren Biotopen, wenn auch Ausnahmen existieren. Es wurde schon erwähnt (p. 492), daß niedrige $\mathrm{Q}_{10}$-Werte verschiedene Ursachen haben können. Bei Pachygrapsus crassipes z. B. war die Abhängigkeit der Leistungs- und $\mathrm{Q}_{10}$-Werte von der geographischen Breite des Fundorts lediglich durch eine nichtgenetische Leistungsadaptation bedingt (ROBERTS 1957). Bei diesbezüglichen Versuchen müssen die Tiere lange genug an die ATs angepaßt werden. SEgal et al. (1953) måßen z. B. für den Herzschlag von Acmaea limatula für Populationen aus größeren Tiefen höhere Frequenzen als für Tiere aus flacherem Wasser der Gezeitenzone. Dieser Unterschied blieb bestehen, als man die Tiere für einige Wochen im Laboratorium unter gleichen Bedingungen hielt; in langfristigen Feldexperimenten erwies sich das Phänomen jedoch als reversibel, wobei allerdings auch andere Faktoren als die Temperatur eine Rolle mitgespielt haben können (vgl. SEGAL 1961). Nach TASHIAN (1956) und DÉmEusy (1957) zeigt der Sauerstoffverbrauch von geographischen Rassen von Uca pugnax (Ausnahme: Tiere von Florida) bzw. U. pugilator $\mathrm{Q}_{10}{ }^{-}$ Werte, die mit zunehmender Breite abnehmen. Démeusy hielt die Rassen yon $U$. pugilator 7 bis 8 Wochen unter gleichen Bedingungen, so daß die Unterschiede genetisch bedingt sein dürften (vgl. auch VERNBERG 1959, 1962). Im allgemeinen hat ein Anstieg der VT von $15^{\circ}$ auf $20^{\circ} \mathrm{C}$ und von $30^{\circ}$ auf $35^{\circ} \mathrm{C}$ einen größeren Effekt auf den Stoffwechsel yon tropischen Zoea-Larven und $U c a-A r t e n$ als bei solchen der gemäßigten Zone (Ausnahme $U$. pugilator aus Florida). Bei jungen Krebsen haben VerNBERG $\&$ Costlow (1966) die höchsten $\mathrm{Q}_{10^{-}}$Werte (bei $15^{\circ}$ bis $20^{\circ} \mathrm{C}$ ) für die mehr nördliche Form von $U$. pugilator erhalten. Die beiden Warmwasserpopulationen (U. rapax und $U$. pugilator aus Florida) weisen die höchsten $\mathrm{Q}_{10}$-Werte zwischen $20^{\circ}$ bis $25^{\circ} \mathrm{C}$ auf. Werte unter 2 sind typisch für $U$. pugilator bei hohen VTs, nicht jedoch für $U$. rapax (AT $=25^{\circ} \mathrm{C}$, vgl. VERnBERg \& VERnBERg 1964, MoRris 1961).

Wie schwierig bisher ein Vergleich von Daten mehrerer Autoren und damit auch die Postulierung von Regeln ist, zeigt z. B. die Abbildung 7 von WoHlschlag (1964), in der die Temperaturabhängigkeit des Sauerstoffverbrauchs von tropischen Fischen, solchen der gemäßigten Zone, der Arktis und Antarktis zusammenfassend dargestellt wird. In den Fällen, wo von stenothermen Arten die Haltung bei gleichen ATs nicht vertragen wird, hat man zum Zwecke des Artvergleichs (z. B. mit Hilfe der KRoGHschen Normalkurve) zu extrapolieren versucht. 
Man kann diese Untersuchungen auch auf Fermentaktivitäten ausdehnen. STEINвасн (1949) maß beispielsweise die Apyrase-Aktivität von Muskelhomogenaten von

4 Fischarten, Spatzen, Mäusen, Schildkröten und Fröschen. Er konnte die $\mathrm{Q}_{10}$-Werte Gruppen zuordnen, die am niedrigsten $(1,4$ bis 1,7$)$ bei Fischen waren und am höchsten $(2,0$ bis 2,2) bei Spatzen und Schildkröten; Frösche und Mäuse ergaben Zwischenwerte. Eine Beziehung zu den Temperaturen der Wohngebiete ergab sich nicht (vgl. Bastow \& Nigreli 1964). Davison \& Richards (1954) fanden die höchsten Werte der Apyrase-Aktivität bei Elritzen, die niedrigsten bei einer Schabe und mittlere Werte für den Flußkrebs; die höchsten $Q_{10}$-Werte ergab die Schabe, die niedrigsten die Elritze (vgl. Abrahamson \& Maher 1967). Auch bei diesen Versuchen ist auf eine konstante und gleiche Vorbehandlung der zu vergleichenden Arten zu achten. Der Sauerstoffverbrauch des Gewebes (Kiemen, Gehirn) des antarktischen Fisches Trematomus bernacchii ist hoch und weist relativ hohe $Q_{10}$-Werte im natürlichen VT-Bereich auf; er ist unabhängig von der AT. Die Succinodehydrogenaseaktivität der Kiemenmitochondrien ist durch einen geringen $\mu$-Wert ausgezeidhnet (SOMERo et al. 1968).

Steno- und eurytherme Formen

Die Ausdrücke steno- und eurytherm sind wenig scharf gefaßt. Eine Art wäre als eurytherm zu bezeichnen, wenn sie in Wohngebieten mit sehr unterschiedlichen Temperaturen vorkommt; es bleibt zu untersuchen, ob sie nicht in stenothermere erbliche Rassen zerfällt. Ferner kann eine Art dadurch ausgezeichnet sein, daß sie große jahreszeitliche Schwankungen der Temperatur verträgt, was durch temperaturunabhängige Faktoren oder durch besondere Ruhezustände mitbedingt sein kann. Schließlich ist die Fähigkeit zu betrachten, Temperaturschwankungen zu derselben Jahreszeit zu ertragen. Erbliche Anpassungen wird man eher bei stenothermen Arten oder Rassen erwarten, nichterbliche bei eury thermen.

Schlieper zog aus Versuchen $\left(V^{\prime} T^{\prime}=A T^{\prime}\right.$ ) an Planarien und Fischen den Schluß, daß im allgemeinen stenotherme Arten höhere $Q_{10}$-Werte aufweisen als eurytherme. Dies kann nach Untersuchung seiner Mitarbeiter (Precht, Christophersen \& Hensel 1955, p. 37) erbliche Ursachen haben, doch ist auch damit zu rechnen, daß eurytherme Arten eher über eine nichtgenetische Leistungsadaptation verfügen oder über eine solche größeren Ausmaßes als stenotherme. Palaemonetes vulgaris als eurytherme Form zeigt für den Sauerstoffverbrauch niedrige $\mathrm{Q}_{10}$-Werte (zumeist $<2$ ); eine nichtgenetische Leistungsadaptation fehlt (McFarland \& Pickens 1965).

\section{Nichtgenetische Adaptationen}

Von einer nichtgenetischen Adaptation sprechen wir dann, wenn bei dem gleichen oder demselben Versuchsmaterial die Abhängigkeitskurve von der VT durch die AT beeinflußt wird. Diese Anpassungen sind besonders eingehend untersucht worden, und sie sind der Einfachheit halber gemeint, wenn von einer Leistungsadaptation (capacity adaptation) ohne den Zusatz nichtgenetisch gesprochen wird. 
Versuchsausführung und Typeneinteilung

Abbildung 4 gibt die Typeneinteilung von Precht (1949, in Prosser 1958, 1964, Precht, Christophersen \& Hensez 1955, p. 26 f.) wieder (die Einteilung von Prosser wurde schon auf p. 500 erwähnt). Kaltadaptierte Tiere ( $A T=t_{1}$ ) liefern die Abhängigkeitskurve von der VT $A_{1} A_{2}$. Nach der Umadaptation an die höhere AT to kann man

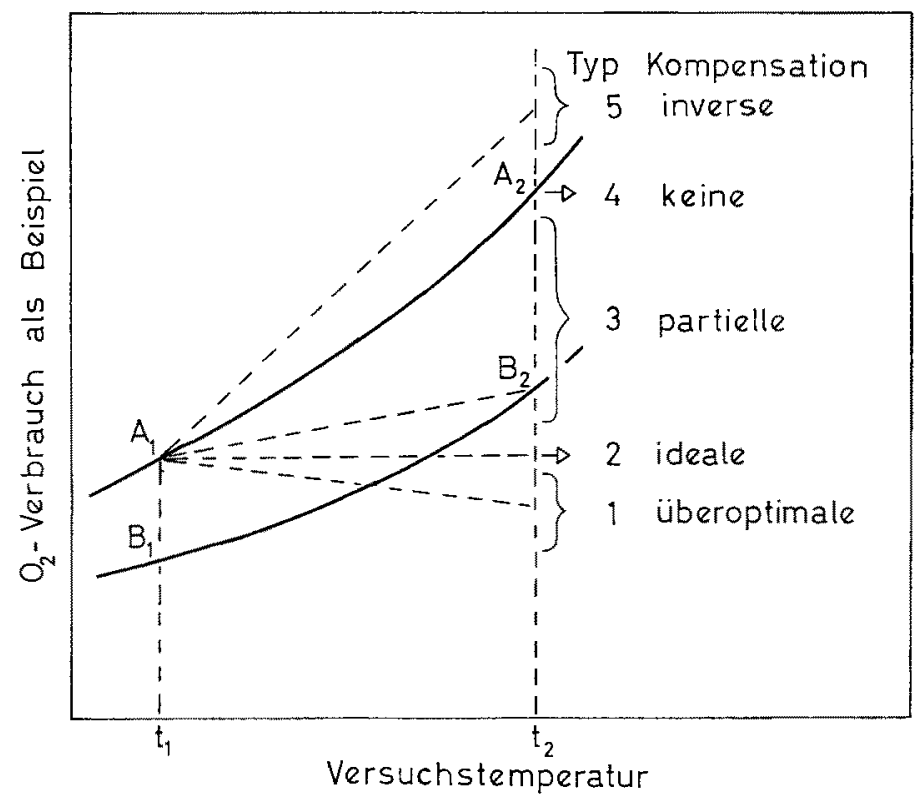

Abb. 4: Typen der Leistungsadaptation (nach Precht 1949). AT bei der Kurve $A_{1} A_{2}: t_{1}$, bei $B_{1} B_{2}: t_{2}$

für $V^{\prime} T=t_{2}$ den Wert $A_{2}$ (bzw. für mehrere VTs die Kurve $A_{2} A_{1}$ ) erhalten, dann fehlt eine Leistungsadaptation (Typ 4). Oder man erhält einen niedrigeren Wert, dann liegt eine Kompensation vor (Typ $3=$ partielle Kompensation, Typ $2=$ ideale Kompensation, gleiche Leistungswerte $A_{1}$ und $B_{2}$, Typ $1=$ überoptimale Kompensation). Die eingezeichnete Kurve $B_{2} B_{1}$ mit entsprechenden $Q_{10}$-Werten wie $A_{1} A_{2}$ entspricht Typ 3; in anderen Fällen sind die Temperaturkoeffizienten nicht gleich (p. 499). Schließlich gibt es Fälle, bei denen $B_{2}$ über $A_{2}$ liegt (Typ 5 , inverse Kompensation).

Diese Einteilung geht jeweils von den (beiden) ATs aus, also den Temperaturen, bei denen die zu vergleichenden Organismengruppen wirklich gelebt haben und denen deshalb besondere Bedeutung zukommt. Schwierigkeiten ergeben sich für die Typeneinteilung dann, wenn sich die Kurven zwischen den V'Ts $t_{1}$ und $t_{2}$ schneiden, was selten vorkommt (p. 499). Jenes gilt auch für den Fall, wenn die Umkehrpunkte der Abhängigkeitskurven von der VT bei relativ tiefen Temperaturen liegen, so daß der abfallende Kurventeil oberhalb desselben noch zum "normalen “ Temperaturbereich gehört, wie dies oft für Bewegungsvorgänge der Fall ist (Abb. 3). Bei Fischen zeigt die Abhängigkeitskurve der Maximalgeschwindigkeit (cruising speed, p. 496) von der VT oft ein Maxi- 
mum etwa bei der jeweiligen AT (vgl. FRY in DiLl et al. 1964, p. 722). Für einen VTBereich links vom Schnittpunkt zweier solcher Kurven würde man eine Kompensation (Typen 1 bis 3) messen, für jede VT rechts vom Schnittpunkt den Typ 5.

Man paßt (besonders bei der Untersuchung von Fermentaktivitäten) die Organismen sehr oft an eine hohe und eine niedrige AT an und mißt dann den Leistungswert der Einfachheit halber bei einer (oft mittleren) VT. Wenn die Werte der kaltadaptierten Organismen größer sind als die der warmadaptierten, so liegt eine Kompensation vor, wobei zwischen den Typen 1 bis 3 nicht unterschieden werden kann; im umgekehrten Fall handelt es sich um den Typ 5. Hierbei unterstellt man, daß diese Typeneinteilung in jedem Fall sinnvoll ist. Ein Beispiel, wo hierbei wiederum die V'T wichtig sein kann, geben OHNEsorge \& Schmrtz (1968) für die Kontraktionshöhen der quergestreiften Darmmuskulatur von Tinca tinca (nach Acetylcholinzusatz); bei einer VT von $10^{\circ} \mathrm{C}$ fanden sie eine Abnahme und bei $30^{\circ} \mathrm{C}$ eine Zunahme mit steigender AT.

LemManN (1968a) hat sehr zahlreiche Fermente der Muskulatur von Idus idus nach Adaptation an viele ATs zwischen $0,5^{\circ}$ und $37^{\circ} \mathrm{C}$ gemessen (VT stets $25^{\circ} \mathrm{C}$ ). Wenn man von den hohen Extremtemperaturen absieht, so zeigen etliche Fermente des Citratcyclus einen Abfall der Aktivität bis zu einer AT' von etwa $21^{\circ} \mathrm{C}$, darüber hinaus aber wieder einen Anstieg (der über $29^{\circ} \mathrm{C}$ in einen Abfall übergeht). Bei den Fermenten der Glycolyse macht sich eine Tendenz zur Aktivitätszunahme mit ansteigender AT bemerkbar. Insgesamt betrachtet wird aber bei etlichen Fermenten eine jede Typeneinteilung fragwiirdig, da man sonst jeden kleineren Kurvenabschnitt gesondert charakterisieren müßte (Abb. 5). Nach den bisherigen Erfahrungen scheinen derartige Komplikationen bei der Ganztieratmung und bei Organfunktionen intakter Tiere weniger aufzutreten. Bei den Messungen des Sauerstoffverbrauchs intakter Tiere kann die Leistungsadaptation zwar auf biologisch wichtige AT-Bereiche beschränkt bleiben, doch ergibt sich dadurch eine sinnvolle Unterteilung in wenige Temperaturbereiche. Der Sauerstoffverbrauch des Gewebes ist selten von Tieren gemessen worden, die man bei mehreren ATs hielt. Prosser (in Troshrn 1967) benutzte bei Goldfischen 4 ATs und fand für den Sauerstoffverbrauch und die Glukoseaufnahme der Leber ein Minimum bei mittleren ATs, was nicht für den Sauerstoffverbrauch der Ganztiere gilt. Bei einer $\mathrm{AT}$ von $10^{\circ} \mathrm{C}$ zeigt jedoch der Sauerstoffverbrauch intakter Limax flawus ein Maximum (SEGAL 1961).

Bei Benutzung von Hungertieren zum Versuch sei auf folgende Fehlerquelle aufmerksam gemacht. Wenn man die Tiere in den verschiedenen AT's von dem Versuch gleich lange aufbewahrt und der Hunger wie des öfteren ein Absinken der Meßwerte bedingt, so kann eine Kompensation dadurch vorgetäuscht werden, daß der Hungereffekt bei hohen ATs stärker ist als bei tieferen. Dem kann man dadurch begegnen, daß man die Hungerzeiten je nach Höhe der A'T verschieden lang wählt, oder dadurch, daß man zunächst alle Tiere an die höhere $A T$ anpaßt, und alle bzw. einige anschließend an die tiefere (und zum Schluß eventuell nochmals an die Ausgangs-AT). Bei einer Senkung der AT laufen sich bei der Kompensation Hunger- und Adaptationseffekt entgegen, bei einer Erhöhung steigern sich beide Effekte. Es kann dann bei einer Senkung der AT eine Adaptation wohl in ihrem Ausmaß verändert, aber nicht vorgetäuscht werden (vgl. Prosser in Hannon \& VIERECK 1962, p. 9). Wenn die warmadaptierten Tiere Nahrung aufnehmen, die kaltadaptierten diese aber verweigern, 
was gelegentlich vorkommt, so kann dies den Typ 5 vortäuschen, da auch die Nahrungsaufnahme durch einen Sauerstoffverbrauch gekennzeichnet ist (WIESER 1963). Besonders wenn noch andere Faktoren als die Temperatur einen Einfluß haben können, ist die Durchführung einwandfreier Versuche erschwert (vgl. z. B. PICKENs 1965, Kasвонм 1967).

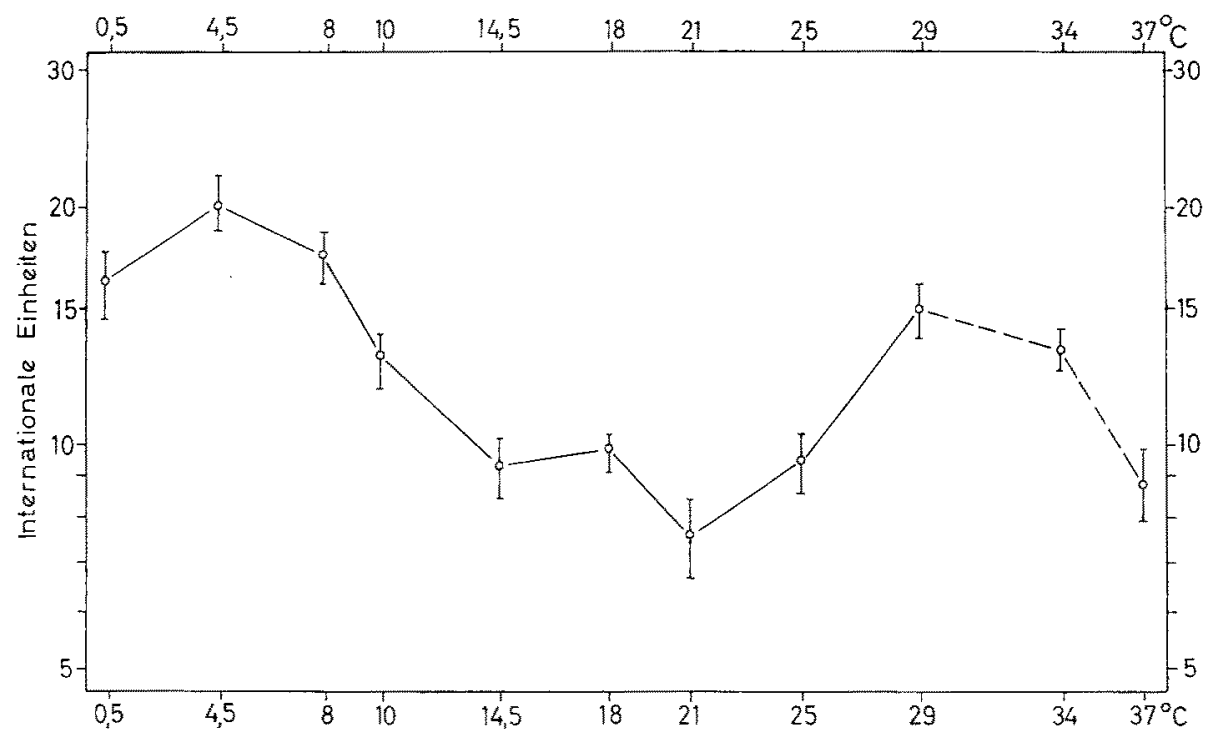

Abb. 5: Fumarase-Aktivität der Seitenrumpfmuskulatur von Idus idus in Abhängigkeit von

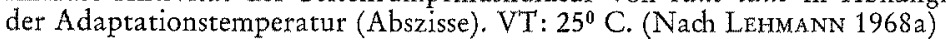

\section{Bedeutung und Vorkommen einer Leistungsakklimatisation}

Die biologische Bedeutung einer Kompensation nach Typen 1 bis 3 besteht zweifellos darin, daß die Organismen in die Lage versetzt werden, trotz wechselnder Körpertemperatur einen Standardleistungswert mehr oder weniger ideal einzuhalten, was die Warmblüter durch Konstanthaltung der Körpertemperatur erreichen. Es handelt sich um Claud Bernards "fixité du milieu intérieur" oder um eine "metabolic homoio-

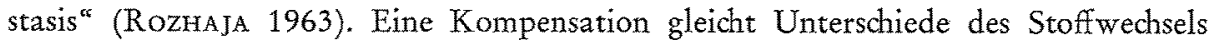
während länger dauernder Temperaturunterschiede zur gleichen Jahreszeit und, allein oder zusammen mit den schon erwähnten von der AT unabhängigen Mechanismen, eventuell auch den Jahreswechsel der Temperatur aus. Die nichtgenetische Adaptation kann neben einer genetischen Komponente das Leben von Tieren in verschieden temperierten Biotopen erleichtern bzw. ermöglichen.

Schwieriger deutbar ist der Typ 5. Bei der Peroxydaseaktivität der Hefe wurde dessen Auftreten mit der Schutzfunktion des Fermentes in Verbindung gebracht, die bei hohen ATs besonders wichtig sein mag (Precht, Christophersen \& Hensel 1955, p. 38). Es sind auch Anpassungen der Fermentaktivitäten an eine erhöhte Muskeltätigkeit bekannt (vgl. Precht, Christophersen \& Hensel 1955, p. 32, Glick 
8x Bronk 1964, Heath \& Pritchard 1962). So lag der Gedanke nahe, daß der Typ 5 in diesen Fällen mit der vermehrten Aktivität der warmadaptierten Tiere zusammenhängt, wie dies z. B. CARLSEN (1953) für die Zunahme des Cocarboxylasegehaltes der Aalmuskulatur mit der AT für gegeben hält. Bei all diesen Deutungen ist jedoch zu berücksichtigen, daß durch jede Steigerung der AT die Reaktionsgeschwindigkeit der Lebensprozesse für gewöhnlich schon zunimmt. Nur wenn darüber hinaus noch ein weiterer Effekt (z. B. hinsichtlich der Schutzfunktion eines Fermentes oder der Bewegung) erzielt werden soll, kommt es zum Typ 5. Allerdings kann er speziell bei Fermentaktivitäten bei der willkürlichen Wahl von zwei ATs einfach aus der Unregelmäßigkeit der Abhängigkeitskurven resultieren. Aber auch für den Sauerstoffverbrauch intakter Tiere ist mehrfach der Typ 5 gemessen worden (vgl. z. B. Pocrnjic 1965), ohne daß wohl in jedem Fall der erwähnte Einwand von WIESER (1963) als Ursache angenommen werden darf.

Alle Typen sind bereits früher durch Beispiele belegt worden (PRECHT, CHRIstoPHERSEN \& HENSEL 1955), etliche weitere sind in dem bisher Erörterten schon erwähnt worden. Inzwischen sind (insbesondere für Typ 3) so viele Beispiele für Funktionen intakter Organismen, für Organ- und Zellfunktionen bekanntgeworden, daß es nicht mehr darum geht, neues Beweismaterial zu sammeln, sondern ganz allgemein darum, Gesichtspunkte für das Vorkommen der Leistungsadaptation zu gewinnen und ihren Mechanismus zu klären, wobei die Tiere tunlichst an weit mehr ATs anzupassen sind als dies bisher üblich war (zusammenfassende Literatur: PRECHT 1961a, 1964b, SEgaL 1961 [Mollusken], Kinne 1963, 1964a, b, 1965, in Dill et al. 1964 [Krebse], Prosser in Hannon \& Viereck 1962, in Troshin 1967 [Fermentaktivitäten], Fry 1958, in Rose 1967, Christophersen in Prosser 1967 [Mikroorganismen], I. Precht 1967 [Insekten], Gelrneo in DrLu et al. 1964 u. a.). Hier sollen nur einige besondere Fälle einer Leistungsadaptation erwähnt werden.

Die Dissoziationskurve des Blutes wird bekanntlich durch eine Erhöhung der V'T nach rechts verlagert. Nach einer Adaptation der zunächst kaltgehaltenen Frösche (Rana esculenta) an eine höhere AT wird diese Verschiebung $z$. T. wieder rückgängig gemacht (Precht, Christophersen \& Hensel 1955, p. 29, Straub 1957, vgl. GaHLENBECK \& BARTEls 1968). Dieser Adaptationseffekt wird nicht durch das Blutplasma verursacht, da er nach einem Austausch des Plasmas durch physiologische Salzlösung erhalten bleibt. Er hängt jedoch von der Unversehrtheit der Erythrocyten ab und fehlt in reinen Hämoglobinlösungen, hergestellt aus dem Blut unterschiedlich adaptierter Frösche (G. KRÜGER 1961). Ein Adaptationseffekt braucht sich nicht bei allen Arten zu zeigen (vgl. BLACK et al. 1966). Die AT kann auch die Schnelligkeit der Blutgerinnung beeinflussen (z. B. bei Ligia, Precht, Christophersen \& Hensel 1955, p. 29). Kaltadaptierte $U_{c a}$ pugilator haben eine längere Blutgerinnungszeit als warmadaptierte (Dean \& Vernberg 1966); Entsprechendes gilt nach eigenen Beobachtungen für den Karpfen (vgl. auch ZaIN-UL-ABEDIN \& KABORSKI 1966). Von der AT kann auch der kritische Punkt abhängen, bis zu dem der Sauerstoffverbrauch unabhängig von Sauerstoffpartialdruck ist (Precht, Christophersen \& Hensel 1955, p. 29).

Die Abhängigkeit des Stoffwechsels von der Größe der Tiere wird zumeist in $\mathrm{b}$-Werten ausgedrückt ( $\mathrm{b}=1$ : gewichts-, $\mathrm{b}=0,67$ : oberflächenabhängig). Diese Werte nehmen z. B. für den Sauerstoffverbrauch des Skorpions Heterometrus fulvipes mit 
steigender VT ab (was nicht immer der Fall ist, vgl. Davies 1967), jedoch mit steigender AT im allgemeinen zu (Vijayalakshmo in Rao 1966, ferner Tsukuda \& OHSAWA 1958, Istenic 1963). Die Größe der Tiere kann bei Hemigrapsus sowohl das Ausmaß der Leistungsadaptation als auch eventuell ihren Typ beeinflussen (DeHNel 1960).

Bei der Goldfischatmung ist anscheinend das Ausmaß der Adaptation größer und die Zeit einer Umadaptation länger bei einer Steigerung der AT $\left(15^{\circ} \rightarrow 30^{\circ} \mathrm{C}\right)$ als bei einer Senkung $\left(30^{\circ} \rightarrow 15^{\circ} \mathrm{C}\right)$, doch können bei diesen Versuchen von KuIcKA (1965), bei denen die VT mitverändert wurde, auch andere Phänomene eine Rolle mitgespielt haben (vgl. p. 504).

Die Komponenten eines Fermentsystems (untersucht von SMrTH 1967b an der Adenosintriphosphatase des Goldfischdarmes) können in entgegengesetzter Weise von der AT beeinflußt werden. "Acclimatization to different environmental temperatures might involve one form of adenosine triphosphatase changing to another" (SMrrH et al. 1967, p. 691).

Es ist, wie erwähnt, zu erwarten, daß eine Kompensation bzw, eine solche größeren Ausmaßes eher bei eurythermen Tieren als bei stenothermen vorkommt (vgl. Precht in Prosser 1958, Roberts in Prosser 1967). Segal (1961) stellt die umgekehrte Frage: "are the animals eurytherm because they can acclimate?" Als Ausmaß der Adaptation kann man die prozentuale Anderung der ursprünglichen Werte nach der Umadaptation bezeichnen (in Abb. 4 ist z. B. der Leistungswert $\mathrm{B}_{2}$ etwa $43 \%$ kleiner als $\mathrm{A}_{2}$ ). Hat die Kurvenschar wie in Abbildung 4 gleiche $\mathrm{Q}_{10}$-Werte, so ist das Ausmaß der Adaptation für alle Kurvenpunkte gleich, bei ungleichen $Q_{10}$-Werten für jede VT unterschiedlich. Als Ausmaß kann man auch die Anderung der $\mathrm{Q}_{10}$-Werte durch die Adaptation ansehen, so die Differenz der Temperaturkoeffizienten der Kurven $\mathrm{A}_{1} \mathrm{~A}_{2}$ und $A_{1} B_{2}$ in Abbildung 4 (EDNEY 1964). Bisher wurde von $Q_{10}-$ Werten nur in Verbindung mit Abhängigkeitskurven von der VT (bei konstanter AT) gesprochen, doch kann man solche Werte auch für VT=AT-Kurven oder Abhängigkeitskurven von der AT (bei konstanter VT) berechnen (wenn nichts vermerkt ist, so sind nur Kurven des ersten Typs gemeint).

Es wurde die Vermutung geäußert (Precht, Christophersen \& Hensel 1955, p. 40), daß eine Kompensation sich phylogenetisch dort entwickelt hat, wo ein wichtiger Bedarfsstoff bei dem raschen Stoffwechsel bei hoher Temperatur leicht zum Mangelfaktor wird. So findet sich eine derartige Leistungsadaptation bei vielen im Wasser oder amphibisch lebenden Tieren; der verbrauchte Sauerstoff kann wegen der langsamen Diffusion im Wasser bei hohen Temperaturen leicht zum Mangelfaktor werden. Es kommt hinzu, daß bewegliche Wassertiere ungünstigen Temperaturen weniger ausweichen können als terrestrische, doch sind andererseits die Temperaturschwankungen großer Wassermengen gedämpt, so daß aus diesem Grunde eine Adaptation weniger notwendig erscheint (vgl. WILBER und FrY in Dill et al. 1964, p. 661 ff., 715 ff.).

Eine Kompensation kommt jedoch auch bei terrestrischen Tieren vor und kann bei Wassertieren fehlen (z. B. bei Eriocheir sinensis, Precht, Christophersen \& Hensel 1955 , p. 36). Von den von TEAL (1959) untersuchten Uca-Arten zeigt z. B. U. pugnax eine Kompensation, nicht jedoch $U$. minax, obwohl beide Arten in gleicher Weise im Wasser und außerhalb des Wassers aktiv sind. Nach F. J. Vernberg \& W. B. Vernserg (1966b) können sich hinsichtlich der Leistungsadaptation selbst geographische Rassen 
der Winkerkrabben unterscheiden, obwohl ihre Biotope ähnliche oder sogar gleiche Temperaturbedingungen aufweisen. Einige Insekten zeigen eine Kompensation, andere Arten nicht; eine Regel ist nicht zu erkennen (I. PrECHT 1967). Es ist dabei zu berücksichtigen, daß bewegliche Insekten ungünstigen Temperaturen einfach ausweichen können, ein Verhalten, das eine Kompensation ersetzen kann. Nach HUNTER (1964-1966) sollen eurytherme Drosopbila-Arten eine ausgeprägtere Kompensation zeigen als stenotherme, doch stößt die Erklärung ihres Befundes, daß Weibchen von $D$. melanogaster hinsichtlich des Sauerstoffverbrauchs im Gegensatz zu den Männchen eine Kompensation zeigen, schon auf Schwierigkeiten. Eine Kompensation fand EDNEY (1964) bei Porcellio laevis und Armadillidium vulgare; Porcellio adaptiert mehr im Hinblick auf den Herzschlag als den Standardstoffwechsel, der bei Armadillidium eine deutlichere Kompensation zeigt. Bei $P$. scaber fehlt nach Wreser $(1965 a, b)$ im Gegensatz dazu eine Leistungsadaptation.

Als Mangelfaktor sind auch die Reservestoffe bei Ruhestadien anzusehen, da sie bei hohen Temperaturen leicht aufgebraucht werden, ohne daß ein Nachschub erfolgt. Zwei Chrysomeliden zeigen eine Kompensation des Sauerstoffverbrauchs nur während der Ruheperiode, und zwar am ausgeprägtesten bei der Art mit der längsten Ruhephase; für Chrysomela baemoptera gilt diese Regel jedoch nicht. Auch bei Diapauselarven von Cephalaia abietis weisen der Sauerstoffverbrauch und die Succinodehydrogenaseaktivität keine Leistungsadaptation auf (PRECHT, Christophersen \& Henser 1955 , pp. 40 bis 41 ). Weinbergschnecken zeigen nicht nur während des Winterschlafs eine Kompensation des Stoffwechsels, sondern auch während der Fraßzeit (PRECHT, Christophersen \& Hensel 1955, p. 28, Gelineo \& Kolendic 1953, Blažka 1955, Mews 1957a).

Man könnte vermuten, daß sich langsam bewegende Tiere, die ungünstigen Temperaturen weniger ausweichen können, eher über eine Kompensation verfügen als schnell bewegliche. Es zeigen jedoch auch einige Eidechsen eine Kompensation des Sauerstoffverbrauchs (Schmidt-Nielson \& Dawson und Gelineo in Dill et al. 1964). SEGAL (1961) konnte für Mollusken keine Korrelation zwischen dem Vorkommen einer Adaptation und dem Wohngebiet der Arten feststellen. Nach Roberts (in Prosser 1967) besteht bei Fischen eine Beziehung der Adaptationsfähigkeit zu bestimmten systematischen Gruppen; sie ist bei Centrarchiden, Ameiuriden und Cypriniden vorhanden, weniger bei Salmoniden. Es können sich jedoch verwandte Arten, wie erwähnt (p. 521), unterschiedlich verhalten. Die von SuHRManN (1955) benutzten Karauschen zeigten (wie dies für den Goldfisch bekannt ist) eine partielle Kompensation des Sauerstoffverbrauchs; wahrscheinlich handelte es sich um die wilde Stammform des Goldfisches (C. gibelio); die sehr verwandte Art C. carassius weist nach v. BudDenBROCK (1960) und RoBERTs (1966) eine inverse Kompensation auf (vgl. PRECHT 1961a).

\section{Beschränkung der Leistungsakklimatisation auf bestimmte Bereiche der Adaptationstemperatur}

Das Ausmaß der Leistungsadaptation kann in den einzelnen AT-Bereichen sehr verschieden sein und sich, wie erwähnt, sogar im Typ unterscheiden. Hier sollen nur die 
Fälle interessieren, bei denen eine Beschränkung der Adaptation auf bestimmte Bereiche deutbar erscheint, nicht die schwer erklärbaren Abhängigkeitskurven der Fermentaktivitäten von der AT (p. 518, vgl. auch FreED 1965). Beim Sauerstoffverbrauch von Lumbriculus variegatus und der Erregbarkeit des Fußes von Lymnaea stagnalis (Precht, Christophersen \& Hensel 1955, p. 29 f.) nimmt das Ausmaß der Kompensation z. B. mit steigender AT zu (vgl. EDNEy 1964, SMIT 1967), beim Sauerstoffverbrauch von Pachygrapsus crassipes nach RoBERTs (1957) jedoch ab. Werden die Tiere

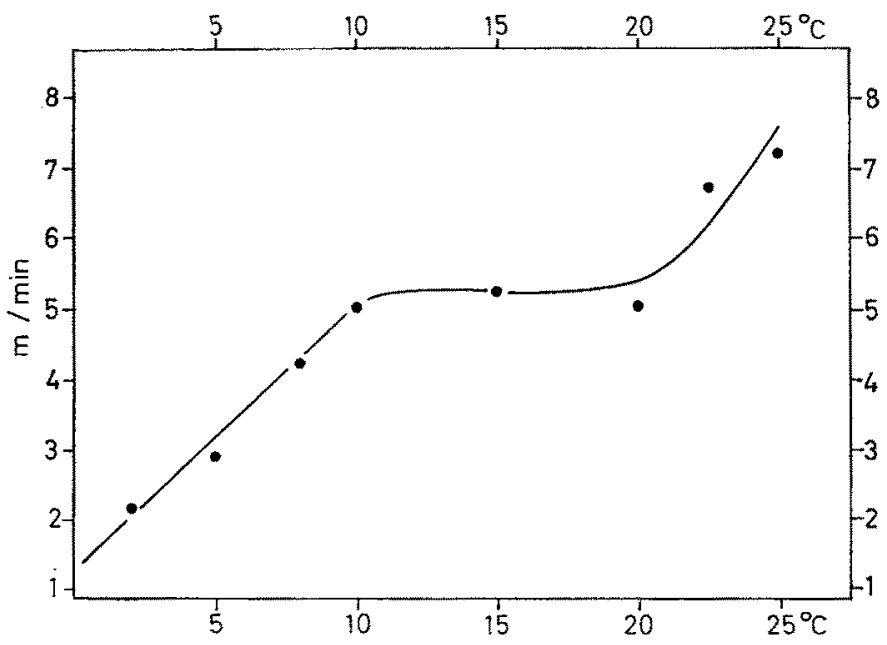

Abb. 6: Ein durch eine Leistungsadaptation bedingtes Konstanzintervall bei der Bewegungsgeschwindigkeit von Homarus americanus. Ordinate: Bewegungsgeschwindigkeit in $\mathrm{m} / \mathrm{min}$; Abszisse: $\mathrm{AT}^{\prime}(-\mathrm{VT})$ in ${ }^{\circ} \mathrm{C}$. (Verändert nach McLeEse \& WILDER 1958)

bei mehreren ATs gehalten, so können sich Bereiche mit einer stärkeren Adaptation z. T. mit Typ 2) als Plateaus abzeichnen, die, wie erwähnt, auch durch eine angeborene Reaktionsnorm oder durch eine Regulation zustande kommen können. Diese Plateaus scheinen bei den Temperaturen aufzutreten, die für das Tier, biologisch betrachtet, wichtig sind. MCLEESE \& WILDER (1958) fanden $z$. B. ein solches durch eine Kompensation bedingtes Konstanzintervall beim Hummer (Abb. 6).

Für den Beweis, daß ein Plateau auf eine Leistungsadaptation zurückführbar ist, genügt, wie erwähnt, die Aufstellung von VT =AT-Kurven nicht. Es ist jedoch wahrscheinlich, daß solche Bereiche z. B. bei Fischen, bei denen eine Kompensation des Stoffwechsels häufig vorkommt, oft auch durch eine solche bedingt ist (vgl. SERFATY \& Waitzenegger 1964, Grigg 1965 u. a.). Nach Meuwis \& Heuts (1957, VT=ATKurven) tritt ein Plateau beim Stoffwechsel der Karpfen mit deren Heranwachsen immer weniger in Erscheinung. RoberTs (in PROsser 1967, VT = AT) gibt Anhaltspunkte dafür, daß sich der Homeostasis-Bereich bei Lepomis gibbosus aus Beaufort gegenüber dem von nördlicheren Tieren aus Amherst zu höheren Temperaturen hin verlagert; sein Auftreten hängt von der Photoperiode und damit der Jahreszeit $a b$ „and has been discussed as adaptive means for meeting the greater physiological and competitive demand of reproductive, compared with postbreeding animals". Nach 
SCHMEING-ENGBERDING (1953) soll das Konstanzintervall des Sauerstoffverbrauchs einiger Süßwasserfische (VT=AT-Kurven) bei narkotisierten Tieren fortfallen, was für eine Regulation spricht; rein theoretisch bleibt natürlich die Möglichkeit einer Adaptation der übergeordneten Zentren, die bei Narkose fortfällt, doch wäre dies zu untersuchen.

Der hervorgehobene Bereich der Adaptation kann anscheinend für verschiedene Funktionen des Tieres unterschiedlich sein. Konishi \& Hickman (1964) überführten Regenbogenforellen von einer $\mathrm{AT}^{\top}=10^{\circ}$ in $4^{\circ} \mathrm{bzw} .16^{\circ} \mathrm{C}$. Die Antworten des Mittelhirns auf eine direkte elektrische Retinareizung zeigen eine Kompensation nur bei der Umsetzung in $4^{\circ}$, die Gewebsatmung des Gehirns weist sie viel vollkommener zwischen $10^{\circ}$ und $16^{\circ} \mathrm{C}$ als zwischen $10^{\circ}$ und $4^{\circ} \mathrm{C}$ auf.

\section{Der zeitliche Verlauf der Leistungsakklimatisation}

Eine Leistungsadaptation des Stoffwechsels dürfte im allgemeinen mit einer Änderung der Proteinsynthese verbunden sein; es wurde schon erwähnt, daß eine solche Anderung auch relativ rasch verlaufen kann (p. 508). Im allgemeinen nimmt eine Umadaptation bei Metazoen jedoch eine längere Zeit (meist mehrere Tage) in Anspruch (Precht, Christophersen \& Hensel 1955, p. 41, Precht et al. 1966). Es handelt sich dann um eine Anpassung an einen länger dauernden Temperaturwechsel, nicht an die kurzfristigen Tagesschwankungen. Bei sich rasch vermehrenden Einzellern dürfte die Anpassung im allgemeinen schneller verlaufen. Die Änderung der Peroxydaseaktivität der Hefe Torulopsis kefyr ist nach Erhöhung der Züchtungstemperatur $\left(20^{\circ} \rightarrow 40^{\circ} \mathrm{C}\right)$ in etwa einem halben Tag abgeschlossen; sie dauert bei einer Senkung der AT $\left(40^{\circ} \rightarrow 20^{\circ} \mathrm{C}\right.$ ) länger (Precht, ChristophrRsen \& Hensel 1955, p. 41). Die Adaptation ist hier wie in anderen Fällen selbst temperaturabhängig.

Bei der Resistenzadaptation hat man die Frage geprüft, ob eine Umadaptation auch an sehr tiefe Temperaturen möglich ist oder ob dann der Adaptationsmechanismus "einfriert" (vgl. PкEcht et al. 1966, p. 391). Der Schlag der Rankenfüße von Balanus crenatus weist nach unveröffentlichten Versuchen von HeLFENSTELLER eine Kompensation (fast Typ 2) und eine sinnvolle Hitzeadaptation auf. Bei einem Umadaptationsversuch von $15^{\circ}$ in $10,4^{\circ}, 5,2^{\circ} \mathrm{bzw} .-1,3^{\circ} \mathrm{C}$ zeigt die Anpassung der Hitzeresistenz einen normalen Verlauf, wobei die Endwerte nach 4,6 bzw. 8 Tagen erreicht werden. Die Umadaptation bei der Leistungsadaptation dauert länger; zunächst erfolgt eine sich über 6 Tage erstreckende Verlangsamung der Schlagfrequenz, die besonders ausgeprägt bei den $-1,3^{0}$-Tieren ist, bis diese nach etwa 3 Wochen den höchsten Endwert erreichen (VT stets $10^{\circ} \mathrm{C}$, alle Tiere wurden nur einmal gemessen).

Hier sei noch ein Beispiel einer relativ langen Adaptationszeit erwähnt. Weibchen von Xiphophorus belleri waren langfristig an $19,5^{\circ}, 25^{\circ} \mathrm{bzw} .31^{\circ} \mathrm{C}$ angepa $3 \mathrm{t}$ (PreCHT et al. 1966). Die VT wurde, ausgehend von $25^{\circ} \mathrm{C}$, langsam geändert $\left(0,3^{\circ} \mathrm{C} / \mathrm{min}\right)$ und so die ganze Abhängigkeitskurve der Kiemendeckelbewegungen von der VT registriert. Wird die AT erhöht $\left(19^{\circ} \rightarrow 31^{\circ}\right)$, so ist die Umadaptation im oberen Bereich der VT nach 13 Tagen abgeschlossen, jedoch noch nicht im unteren (unter $19^{\circ} \mathrm{C}$ ); für diesen Bereich werden etwa 12 weitere Tage benötigt. Bis zum 3. Tag nach der Umsetzung 
bleiben die Meßwerte im VT-Bereich von $19^{\circ}$ bis $30^{\circ} \mathrm{C}$ ziemlich unverändert auf der Höhe der Werte der $19^{\circ}$-C-Tiere. Bei einer Anderung der AT von $25^{\circ} \rightarrow 31^{\circ} \mathrm{C}$ ergibt sich schon am 2. Tage eine Verschiebung der Kurve über den ganzen VT-Bereich. Am 7. Tag ist die Umadaptation noch nicht vollständig, was wiederum besonders für den unteren VT-Bereich gilt. Beim Senken der AT $\left(31^{\circ} \rightarrow 19^{\circ} \mathrm{C}\right)$ ist nach einem Tag schon über den ganzen VT-Bereich ein deutlicher Effekt sichtbar. Vom 30. bis 37. Tag ist die Umadaptation im oberen Bereich abgeschlossen, jedoch noch nicht im unteren. Auch hier ist der Prozeß der Adaptation selbst temperaturabhängig. Es kommt hinzu, daß sich die verschiedenen VT-Bereiche unterschiedlich verhalten. Wenn das Ausmaß der Adaptation für verschiedene AT-Bereiche verschieden ist, so muß sich dies auch auf den zeiclichen Verlauf der Anpassung auswirken (vgl. z. B. KLICKA 1965).

G. KRüger (1962) maß bei Rhodeus amarus die Ganztieratmung, den Sauerstoffverbrauch des Muskelgewebes (mit Succinatzusatz) und die Succinodehydrogenaseaktivität (Thunbergmethode). In allen Fällen zeigt sich eine Kompensation, am ausgeprägtesten bei der Ganztieratmung. Bei einer Anderung der AT $\left(8^{\circ} \rightarrow 24^{\circ} \mathrm{C}\right)$ ist die Umadaptation in allen 3 Fällen etwa am 10. Tag beendet, jedoch entsprechen sich die zeitlichen Abläufe nicht. Nach F. J. Vernberg \& W. B. Vernberg (1966a) besteht zwischen der Leistungsadaptation des Stoffwechsels der Ganztiere ( $U c a$-Arten) und der der Gewebe (Kiemen, Mitteldarmdrüse, Typ 3, z. T. Typ 5) hinsichtlich des Ausmaßes und des zeitlichen Verlaufs kein Zusammenhang. Nach Prckens (1965) ist für den Herzschlag von Mytilus californicus die Zeit der Umadaptation bei kleineren Tieren kürzer als bei größeren.

Bei der Kompensation der Transportgeschwindigkeit von Partikeln auf den Frontalcilien isolierter Kiemenstücke von Anodonta sind bei Umadaptationsversuchen (AT $5^{\circ} \rightarrow 21^{\circ} \mathrm{C}$ ) 7 bis 8 Wochen für die vollständige Angleichung notwendig, jedoch nur 4 Tage, um die sinnvolle Hitzeadaptation derselben Funktion zum Abschluß zu bringen (Lagerspetz \& Dubitscher 1966). Wie bei Balanus crenatus verläuft die Resistenzadaptation schneller als die Leistungsadaptation.

\section{Leistungsakklimatisation auf verschiedenen Ebenen}

Die bisher erwähnten Beispiele zeigen, daß man die Leistungsadaptation auf verschiedenen Ebenen verfolgen kann, beim Ganztier, bei einzelnen Organfunktionen oder auch beim Zellstoffwechsel, wo sich die einzelnen Fermentaktivitäten ganz unterschiedlich verhalten können, ohne daß es bisher möglich ist, diese Veränderungen schon zu erklären. Boycort et al. (1961) fanden bei Eidechsen von der AT abhängige histologische Besonderheiten des Zentralnervensystems; JANKOwSKY (1968) erwähnt histologische Veränderungen der Fischmuskulatur.

Wir haben mehrfach den Sauerstoffverbrauch des Ganztieres und den des Muskelgewebes besonders bei Fischen untersucht; durch den Succinatzusatz wird im wesentlichen die Aktivität der Succinodehydrogenase erfaßt, also eines Fermentes, das in den Mitochondrien gelagert ist und ein Maß für die Kapazität des Citratcyclus abgibt (vgl. PRECHT 1964b). MalesSA (1968) untersuchte gleichzeitig die Aktivität der Cytochromoxydase, die als Maß für die Leistungsfähigkeit der Atmungskette verwandt wird. 
Das Verhältnis beider Parameter der oxydativen Kapazität kann sich im Muskelgewebe des Aales mit der AT ändern. Dies triff auch für die Zahl der Mitochondrien des Muskelgewebes von Idus idus zu (JANkowsky \& Korn 1965, vgl. auch BочкотT et al. 1961). Da sich nach LEHMANN (1968a) die Aktivitäten der einzelnen mitochondrialen Fermente von Idus idus unterschiedlich mit der AT ändern können ( $\mathrm{z}$. B. der Succino- und Glutaminsäuredehydrogenase), dürfte nicht nur die Mitochondrienzahl betroffen sein (vgl. hierzu Siminovitch et al. in Prosser 1967, p. 29).

Im wesentlichen haben wir deshalb mit Muskelgewebe gearbeitet, weil es im allgemeinen dominiert; bei den Fischen wurde allerdings bei früheren Arbeiten übersehen, $\mathrm{daß} z$ wischen einer äußeren roten Muskelschicht (mit mehr tonischer Funktion) und einer inneren weißen (mit Bewegungsfunktion) unterschieden werden muß (vgl. WITtenberg \& Diaciuc 1965 u. a.). Bei den von Precht (1961), Schultze (1965) und Prosser et al. (1965) durchgeführten Messungen des Sauerstoffverbrauchs des Aalmuskelgewebes wurden noch beide Schichten vermischt. Mißt man bei diesem Fisch beide getrennt, so ist der Adaptationseffekt bei der roten, äußeren Schicht hinsichtlich der Succinodehydrogenase- und Cytochromoxydaseaktivität gegenüber der weißen Schicht verstärkt (Malessa 1968, vgl. Jankowsky 1968). Es wird z. Z. geprüft, ob sich auch die Schichtdicke der roten Muskulatur mit der AT ändert. Man kann somit bei Fischen nicht von einem einheitlichen dominierenden Muskelgewebe sprechen.

Bei überwinternden Helix pomatia (KIRBERger 1953), Lenciscus rutilus (AuerBACH 1957), Rhodeus amarus (G. KRüGER 1962) und Idus idus (PRECHT 1964c) weisen der Sauerstoffverbrauch der intakten Tiere und der des Muskelgewebes eine stärkere Kompensation auf. Bei dunkel gehaltenen Fröschen (Rana esculenta u. Rana temporaria, im Gegensatz zu hell gehaltenen; vgl. KasвoHM 1967) und dem Wurm Lumbriculus variegatus (KIRBRRgER 1953) zeigt der Sauerstoffverbrauch des Muskelgewebes (bzw. des gesamten Gewebes) im Gegensatz zu dem des Ganztieres keine Adaptation. GRAINGER \& GOLDSPINK (1964) vermißten bei ebenfalls dunkel gehaltenen $R$. temporaria eine Adaptation von Muskelfunktionen (vgl. auch BARILlot et al. 1965). Bei Karauschen können sich endlich in bezug auf den Sauerstoffverbrauch Ganztier und Muskelgewebe entgegengesetzt verhalten, d. h. im ersten Fall zeigte sich Typ 3, im zweiten Typ 5 (Suhrmann 1955). Bei all diesen Versuchen haben wir die Tiere nur an wenige ATs angepaßst.

Bei Bufo boreas weisen der Sauerstoffverbrauch und die $\mathrm{CO}_{2}$-Abgabe eine starke Abhängigkeit von der AT auf, nicht der respiratorische Quotient und der Herzschlag (Bishop \& Gordon in Prosser 1967).

Kanungo \& Prosser (1959) maßen den Sauerstoffverbrauch (bezogen auf N) und das $\mathrm{P} / \mathrm{O}-$ Verhältnis von isolierten Lebermitochondrien von Goldfischen. Die Atmung der Mitochondrien ist je nach dem verwendeten Substrat bei den kalt- oder warmadaptierten Fischen etwas höher; das P/O-Verhältnis nimmt mit der AT zu. Der Sauerstoffverbrauch von Leberhomogenaten zeigt eine deutliche Kompensation. „It is concluded that the activities of dehydrogenases associated with the krebs cycle in mitochondria are not significantly altered on acclimation. The phosphorylating system in the mitochondria of cold-acclimated fish is somehow decreased in efficiency so that less ATP is synthesized. "

Es ist stets zu berücksichtigen, daß sich die einzelnen Gewebe desselben Tieres 
unterschiedlich verhalten können. Der Sauerstoffverbrauch des Gehirngewebes von Carassius carassius zeigt nach v. BuddenBrock (1960) eine Adaptation nach Typ 3, der des Kiemengewebes eine solche nach Typ 5 (wie das Ganztier). Evans et al. (1962) maßen bei Salmo gairdnerii den Sauerstoffverbrauch des Ganztieres und den verschiedener Gewebe. Ganztier und Kiemengewebe verhalten sich etwa gleich (Typ 4 bzw. schwach Typ 3); das Gehirngewebe zeigt Typ 2, das Lebergewebe Typ 5 (allerdings erschlossen aus VT=AT-Kurven). Es ist zweifelhaft, ob man aus der idealen Kompensation der Atmung des Gehirns auf dessen Funktion schließen kann. Beim Goldfisch zeigt der Sauerstoffverbrauch der Kiemen eine gute Kompensation, der des Muskels eine geringere, der der Leber eine noch geringere und der von Gehirn und Herz keine (Ekberg 1958, Murphy, zitiert bei Prosser in Troshin 1967; vgl. auch Freeman 1950, Roberts 1957, 1966, W. B. Vernberg \& F. J. Vernberg 1966a, b).

Es wurde schon erwähnt, daß sich die Fermente desselben Gewebes sehr unterschiedlich verhalten können. Sogar das Verhältnis einzelner Isoenzyme kann von der AT abhängen. In der weißen Rumpfmuskulatur von Forellen fand HochachKa (in Prosser 1967) 14 Isoenzyme der Laktatdehydrogenase. „Warmadaptation causes a striking loss in the activity of the LDHs 1-9 (A-B-C-series) in relation to the LDHs 10-14 (D-E-series). The first are located in either the nucleus or the mitochondria or both; the $\mathrm{D}$-E-series is definitely in the soluble fraction ... and can be expected to display properties suited for anaerobic metabolism ... In cold adaptation of trout extramitochondrial is favored over mitochondrial metabolism in both liver and muscle (glycolysis, gluconeogenesis, glycogen synthesis, lipogenesis, and shunt participation); the complexity of the changes was greater in liver than in muscle" (p. 184 f., 179). In der Goldfischleber fand Hоснаснка 5 Isoenzyme der LDH bei kaltadaptierten Tieren, 3 bei warmadaptierten. "In cold adaptation, the isozymes that are being induced are regulatory enzymes and are markedly more sensitive to metabolic control than those that are unchanged during the adaptive process" (HochachKa in Prosser 1967, p. 190).

Schon Versuche an Goldfischen hatten zur Vermutung geführt, daß der Pentosephosphatabbauweg durch eine Senkung der AT verstärkt wird (EKBERG 1958, KAnungo \& Prosser 1959, vgl. jedoch auch Prosser in Hannon \& Viereck 1962 und Bishop \& Gordon in Prosser 1967, ferner HochachKa \& Hayes 1962). Nach G. KRüGER (1962) hängt dies vielleicht mit der Bereitstellung von NADP zusammen; rein energetisch betrachtet ist dieser Weg unrationeller als der Embden-MeyerhofAbbauweg. Brown (1960) fand in Leberhomogenaten von Karpfen nur eine geringe Aktivität zweier Fermente des Pentosephosphatabbauweges (Glukose-6-Phosphat- und 6-Phosphoglukonsäuredehydrogenase), ebenfalls LeHManN (1968a) für beide Fermente in der Seitenrumpfmuskulatur von Idus idus; eine stärkere Aktivität soll die Schwanzmuskulatur bei Fischen aufweisen (ZEBE 1961). Die gemessenen Fermentaktivitäten sind allerdings kein unbedingtes Maß für die Bedeutung eines Stoffwechselweges, zumal es auf die begrenzenden Enzymaktivitäten ankommt. Es kommt hinzu, daß sich nach LANG (vgl. G. KRügER 1962) die Konzentrationen der wesentlichen Fermente der Glykolyse und des Cytochroms c um eine Zehnerpotenz höher liegen können als es für den durchschnittlichen Stoffumsatz erforderlich ist. So dürften sich die Anpassungen oft in einem Fermentüberschuß abspielen (vgl. Ohlenbusch u. Precht 1960). Bei 
Carassius carassius wurde von den beiden oben genannten Fermenten im Kiemengewebe nur das letzte von der AT im Sinne einer Kompensation beeinflußt (2 ATs, EKBERg 1962). LEHMANN (1968a) maß die Abhängigkeit beider Fermentaktivitäten in der Seitenrumpfmuskulatur von Idus idus von der AT nach Anpassung an viele Temperaturen (VT $=25^{\circ} \mathrm{C}$ ). Die Aktivität der $\mathrm{G}_{6} \mathrm{PDH}$ verringert sich von der AT $0,5^{\circ}$ ausgehend bis 14,50 stetig; anschließend steigt sie auf relativ hohe Werte an (Maximum bei $\mathrm{AT}=29^{\circ} \mathrm{C}$ ). Die 6-PGDH hat nur bei niederen ATs relativ hohe Aktivitäten; diese nehmen dann mit steigender AT ab. Die beiden Enzyme des Pentosephosphatabbauweges stimmen bei $I d u s$ somit nur im Aktivitätsverlauf des unteren AT-Bereichs überein. Der Einfluß der AT auf den Stoffwechselweg ist beim Krebs Orconectes virilis für die verschiedenen Entwicklungsstadien unterschiedlich (McWHINNIE \& O'CONNOR 1966).

EKBERG (1962) maß ferner den anaeroben Gewebsstoffwechsel bei C. carassitus, und zwar die $\mathrm{CO}_{2}$-Menge, die vom Gewebe ausgeschieden wird, und die, welche am Anfang und Ende der Messung mit Säure aus den Carbonaten ausgetrieben werden kann; nur die letzte zeigte eine Kompensation, die bei Tieren, welche im Langtag gehalten wurden, deutlicher war als bei Kurztagstieren (vgl. auch BLAžKA 1958). Eine Abhängigkeit des Gewebsstoffwechsels (Gehirn) von der AT (Typ 5) zeigte sich bei Lepomis gibbosus nur nach Hinzugabe von entkoppelnden Substanzen (2,4-Dinitrophenol, RoBERTs 1964),

\section{Inkonstante Vorbehandlung}

Bei den bisher geschilderten Versuchen wurden die Tiere an konstante ATs angepaßt; dies ist insofern unnatürlich, als in der Natur die Temperatur zumeist im Tagesrhythmus schwankt, was man auch im Versuch nachahmen kann. Bei einem $12-$ stündigen Wechsel der AT $\left(15^{\circ} \leftrightarrow 2^{\circ}\right)$ weist Lumbriculus variegatus den gleichen Sauerstoffyerbrauch auf wie nach einer Aufbewahrung bei $19^{\circ} \mathrm{C}$ (KIRBERGER 1953, vgl. auch Birk et al. 1962). Nach BerkHolz (1966) zeigt der Sauerstoffverbrauch von Idus idus, der bei konstant gehaltenen Tieren eine deutliche Kompensation aufweist, aach einer inkonstanten Vorbehandlung der Tiere $\left(15^{\circ} \leftrightarrow 22^{\circ} \mathrm{C}, 12\right.$ stündiger Wechsel) mittlere Werte mit einer (besonders bei kleinen Tieren vorhandenen) Annäherung an die Werte der konstant bei $22^{\circ} \mathrm{C}$ gehaltenen Orfen. Diese Annäherung ist weniger deutlich beim Sauerstoffverbrauch des Muskelgewebes. Grundsätzlich sind derartige Verschiebungen, die besonders deutlich bei der Hitzeadaptation sind, aus der Temperaturabhängigkeit der Adaptationsprozesse zu verstehen. Außerdem muß der zeitliche Ablauf einer Umadaptation berücksichtigt werden. Nimmt bei konstant gehaltenen Tieren die anfangs große Geschwindigkeit der Umadaptation immer mehr ab, d. h., ist die Geschwindigkeit davon abhängig, inwieweit der Endzustand erreicht ist, so wird bei einer inkonstanten Vorbehandlung trotz der oft vorhandenen Temperaturabhängigkeit des Adaptationsvorganges der Wert konstant gehaltener warm gehaltener Tiere nicht erreicht, weil der zweite Effekt dem ersten immer mehr entgegenwirkt, so daß schließlich bei einem nach der Seite der konstant warmgehaltenen Tiere hin verlagerter Endwert erreicht wird. Streß-Phänomene, overshoots usw. mögen hinzukommen und das Bild komplizieren. Es hatte auf die Ganztieratmung von Idus bei 
einem 12stündigen Wechsel der AT keinen Einfluß, ob die höhere Temperatur tags oder nachts herrschte. Bei Tieren, die normalerweise sehr großen Temperaturschwankungen ausgesetzt sind, müßte sich die Verlagerung der Leistungswerte im normalen Temperaturbereich und der Resistenzwerte eigentlich nachteilig auswirken; wir prüfen z. Z., ob die Verlagerung bei solchen Tieren weniger ausgeprägt ist.

Untersuchungen über den Mechanismus der Leistungsakklimatisation

Die bisher erörterten Befunde machen es deutlich, wie schwierig eine Analyse der Mechanismen der Leistungsadaptation ist, zumal kaum eine einheitliche Erklärung gegeben werden kann, da Einzeller eine solche Anpassung zeigen können und auch Metazoen, bei denen zu prüfen ist, inwieweit übergeordnete Systeme (Zentralnervensystem, Hormone etc.) beteiligt sind, und ob das Gewebe sich auch direkt anpassen kann, was wir zur Zeit durch Züchtung von Geweben bei verschiedenen ATs zu klären versuchen.

Man könnte daran denken, besonders die ideale Kompensation als Regelkreis darzustellen, bei der ein konstanter Sollwert durch einen sich über Tage erstreckenden Prozeß nach jeder Veränderung der AT wieder eingestellt wird, oder die Regulationen als Regelkreise und die Adaptationen als Sollwertverstellungen, doch führt eine solche Betrachtungsweise kaum weiter, da wesentliche Glieder (Fühler, Art der Rückmeldung usw.) noch weitgehend unbekannt sind.

Prosser (in Troshin 1967) glaubt, daß bei der Kompensation eventuell durch eine Stoffakkumulation eine Enzyminduktion über den Kern ausgelöst wird. Als Möglichkeiten für das Zustandekommen einer solchen Akkumulation werden angegeben: „if there are alternate and cross-linked pathways having different temperature characteristics, one may slow more than another in the cold... It can be suggested that the action of an intermediate or product of a biochemical reaction may show feedback control by direct inhibition, by repression of the synthesis of a particular messenger RNA or by induction as by a substrate. The concentration of the controlling products or substrates would be dependent on the temperature characteristics of the particular steps" (p. 382). HochachKa (in Prosser 1967) schreibt: "It appears that, in the control of protein synthesis, two kinds of processes are operating under conditions of thermal adaptation: (1) control of the amount (activity) of enzymes, as in goldfish muscle, by classical enzyme induction, probably related to changes in rate functions that occur during thermal adjustments; and (2) control of the kind of enzyme responsible for a particular catalytic activity, which, presumably, is a case of isozyme induction and is more likely to be involved in the regulation of participation of different metabolic systems" (p. 189 f.). Entscheidend für die zuletzt erwähnten Kontrollmechanismen ist nach Носнаснка, daß die bei neuen ATs gebildeten Enzyme allosterisch beeinflußbar sind; Hemmungen und Aktivierungen enzymatischer Vorgänge erfolgen von besonderen Enzymorten aus, die nicht mit den aktiven Wirkorten der Fermente identisch sind, sie aber in ihrer Aktivität beeinflussen.

Sind übergeordnete Systeme beteiligt, so muß man Nacheffekte von Direkteffekten unterscheiden. Die ersten sind auch beim isolierten Organ oder Gewebe meßbar, die letzten nicht. Hormone können, wie erwähnt, z. B. über Gene die Protein- 
synthese beeinflussen (Nacheffekte) oder auch in Form von Direkteffekten die Fermentaktivitäten stimulieren oder hemmen oder auf Membranpermeabilitäten einwirken (KARLSON 1961).

Beispiel einer Untersuchung (Versuchsobjekt: Anguilla vulgaris): Das Verhältnis von Haut- und Kiemenatmung des Aales ist mehrfach untersucht worden; LEICHT (1968) fand in neueren Versuchen für die VTs $17^{\circ}, 21^{\circ}$ und $25^{\circ} \mathrm{C}$ $\left(\mathrm{AT}=21^{\circ} \mathrm{C}\right)$ folgende Prozentwerte für den Anteil der Haut- an der Gesamtatmung: $37,2,32,2$ und $27,7 \%$. Wurde das Rückenmark der Aale (Durchschnittslänge $56 \mathrm{~cm}$ ) $4 \mathrm{~cm}$ hinter dem Brustflossenansatz durchtrennt bzw. von der Schnittstelle ab bis zur Schwanzspitze hin ausgebohrt, so ergaben sich folgende Prozentwerte: $32,5,27,5$ und $24,0 \%$ bzw. 29,0, 24,2 und 21,4\%.

Der Sauerstoffverbrauch des Aales zeigt nach Precht (1951) eine partielle Kompensation, die Aktivität der Katalase des Lebergewebes eine inverse; die der Katalase des Muskelgewebes ist kaum von der AT abhängig. Die Aktivität der Schilddrüse nimmt schwach (nicht gesichert) mit steigender AT ab (Olivereau 1955, vgl. Precht in Prosser 1958, p. 66, Leloup \& FontaINe 1960). Auch der Sauerstoffverbrauch des Muskelgewebes (mit Succinatzusatz) weist eine Kompensation auf; dies gilt besonders für die äußere rote Schicht (p. 526). Die zwischen Vorder- und Hinterende stets zu berücksichtigenden Unterschiede in der Gewebsatmung sollen hier nicht erörtert werden.

Wenn man Vorder- und Hinterende des Aales längere Zeit unterschiedlichen Temperaturen aussetzt, so wirken sich diese auf die Succinatatmung des Muskelgewebes des jeweiligen Endes in demselben Sinne aus wie bei der Verwendung von einheitlichen ATs für die ganzen Tiere (Precht 1961b, Schultze 1965, Prosser et al. 1965). Schultze fand darüber hinaus, daß der Sauerstoffverbrauch des Ganztieres nur von der Vorbehandlung des Kopfendes abhängt; es ist dafür gleichgültig, ob das Muskelgewebe des Hinterendes durch eine Anpassung an hohe ATs einen relativ niedrigen oder durch eine solche an niedrige ATs einen relativ hohen Sauerstoffverbrauch (in vitro) aufweist.

Es ergibt sich die Frage, ob die Adaptation des Gewebes durch eine direkte Einwirkung der AT auf das Gewebe zustande kommt oder indirekt über das Rückenmark, das ja bei den vorn und hinten unterschiedlich adaptierten Tieren miterfaßt wird. Daß auch mit der letzten Möglichkeit gerechnet werden muß, ergibt sich daraus, daß die vom Rückenmark an die Muskulatur gesandten Spikefolgen bei derart vorbehandelten Aalen auch eine Kompensation zwischen vorn und hinten aufweisen (Prosser et al. 1965). Wir versuchen zur Zeit, dies durch die Untersuchung von Aalen mit teilweise zerstörtem Rückenmark zu klären.

Besondere Probleme wirft die Steuerung des Sauerstoffverbrauchs des Ganztieres vom Kopfende auf. Nach Jankowsky $(1966,1968$, vgl. auch Carlsen 1953) weisen Atem- und Herzfrequenzen bei leicht narkotisierten Aalen eine Leistungsadaptation im Sinne einer Kompensation auf. Die Frequenz des Caudalherzens wird zum Teil auch vom Kopf her bestimmt, was Mistin (1960) durch unterschiedliche Erwärmung von Vorder- und Hinterenden der Aale feststellte. Der Sauerstoffdruck des venösen Blutes ist nach JANKOwSKY bei kaltadaptierten Aalen niedriger als bei warmadaptierten, wenn die Messungen (durch künstliche Beeinflussung) bei übereinstimmender Atemfrequenz und VT vorgenommen werden; der $\mathrm{pO}_{2}$ im Blut der caudalen Aorta unter- 
scheidet sich dann nicht. Werden veränderte VTs eine gewisse Zeit beibehalten, so ist bei kaltadaptierten Aalen der $\mathrm{pO}_{2}$ des venösen Blutes weitgehend konstant $\left(8^{\circ}\right.$ bis $21^{\circ} \mathrm{C}$ ), bei warmadaptierten Tieren trift dies nur für den Bereich $8^{\circ}$ bis $13^{\circ} \mathrm{C} \mathrm{zu}$ (höhere VTs bewirken Anstieg). Ordnet man die venösen $\mathrm{pO}_{2}$-Werte nach der Höhe der Atemfrequenz, so sind im VT-Bereich $10^{\circ}$ bis $21^{\circ} \mathrm{C}$ die höheren Werte jeweils bei den warmadaptierten Aalen zu finden. Der $\mathrm{pO}_{2}$ ist in der weißen Muskulatur bei warm- und kaltadaptierten Aalen stets niedrig. Der $\mathrm{pO}_{2}$ im arteriellen Blut wird relativ gering gehalten (STEEN \& KRUYSSE 1964).

Aus diesen Daten geht hervor, daß unter vergleichbaren experimentellen Bedingungen die Gewebe kaltadaptierter Aale den angebotenen Blutsauerstoff stärker ausnützen als die Gewebe warmadaptierter, was in Ubereinstimmung mit der Kompensation der Gewebsatmung in vitro steht. Anderungen der VT beeinflussen den $\mathrm{pO}_{2}$ des venösen Blutes (bei kaltadaptierten Tieren) kaum, da Angebot (durch beschleunigte Atem- und Herzfrequenz) und Verbrauch sich die Waage halten.

Es ist zu beriicksichtigen, daß bei den Versuchen von Schultze (1965) das Kopfende, das etwa ${ }^{1 / 3}$ des Körpers ausmachte, wichtige, stark atmende Organe enthält, dagegen die weiße Muskulatur des Hinterendes, die den größten Teil ausmacht, einen relativ geringen Sauerstoffverbrauch aufweist. Wenn wir jedoch nicht unterstellen wollen, daß dadurch Änderungen der Gewebsatmung durch eine unterschiedliche Adaptation des Hinterendes bei der Messung der Gesamtatmung des Aales schwer erfaßbar sind, so ist die von ScHultze postulierte Steuerung der Gesamtatmung durch das Kopfende wohl nur so verständlich, daß von dort die Durchblutung der Muskulatur geregelt wird, sei es hormonal oder nervös (eine nervöse Beeinflussung über den Vagus fanden z. B. Pequignot et al. 1967 bei Tinca tinca). Es käme dann nicht auf die in vitro gemessene Succinatatmung der Muskulatur an, da man diese ja im Hinterende durch die AT ändern kann, ohne daß dies die Gesamtatmung beeinflußt. Der Fermentbesatz des Gewebes scheint somit keine Bedeutung zu haben. Entscheidend wäre danach nur die Steuerung des Angebots durch das Kopfende, die durch die Adaptation des Kopfendes an unterschiedliche $A T s$ verändert wird. Im Gewebe sinkt der $\mathrm{pO}_{2}$ sowohl bei kaltals auch bei warmadaptierten Aalen weitgehend ab; das Angebot wird fast vollkommen ausgenutzt. Eine verminderte Durchblutung bei den warmadaptierten Tieren bedingt vermutlich, daß der $\mathrm{pO}_{2}$ im venösen Blut bei ihnen höher ist. Die erwähnte unterschiedliche Abhängigkeit von der VT beruht wahrscheinlich auf einer Anderung der $\mathrm{Q}_{10}$-Werte durch die AT, wodurch bewirkt wird, daß bei warmadaptierten Tieren bei höheren V'Ts der Verbrauch weniger zunimmt als das Angebot.

Eine lokale Erhöhung des Verbrauchs kommt normalerweise durch eine Muskeltätigkeit zustande. Man kann sie im Versuch auch dadurch erzeugen, daß man während des Versuchs die Temperatur im Vorder- oder Hinterkörper des Aales erhöht. LEICHT (1968) führte derartige Versuche durch (Ausgangsbedingungen vorn und hinten $21^{\circ} \mathrm{C}$; eine Anderung der VT um $4^{0} \mathrm{C}$ ergab mehrere Kombinationen; AT stets $21^{\circ} \mathrm{C}$ ). Wenn $21^{\circ}-21^{\circ} \mathrm{C}$ gleich $100-100$ gesetzt wird, so ergab sich z. B.: $17^{0}-21^{\circ} \mathrm{C}: 79,8-97,4$; $21^{0}-17^{\circ} \mathrm{C}: 84,9-92,7 ; 25^{0}-21^{\circ} \mathrm{C}: 120,9-103,9 ; 21^{0}-25^{\circ} \mathrm{C}: 111,9-110,8 ; 17^{0}-25^{\circ} \mathrm{C}$ : $91,0-107,7 ; 25^{\circ}-17^{\circ} \mathrm{C}: 102,7-95,4$.

Wenn das Hinterende eine andere Temperatur hat als das Vorderende, so beeinflußt dies nicht über das Blut die Temperatur des Gehirns. Dennoch wirkt sich eine 
Temperaturänderung des Hinterendes (auf noch unbekannte. Weise) auf die Kiemenatmung aus und eine solche des Kopfendes auf die Hautatmung des Hinterendes (weitere Einzelheiten in der Originalarbeit).

Zentralnervöse Einflüsse: Beim Aal dürfte dem Kopf (Gehirn) eine große Bedeutung für die Leistungsadaptation zukommen. Die Kiemendeckelbewegung, deren Kompensation THIEDE (1965) bei Xiphopborus helleri untersuchte, werden vom Atemzentrum gesteuert (vgl. PRecht 1959). Eine Funktion kann an sich schon eine Kompensation aufweisen, die jedoch verstärkt wird, wenn zentralnervöse Einflüsse hinzukommen. Dies fand BENTHE (1954) für die Erregbarkeit des isolierten Fußes von Lymnaea stagnalis. Die Kompensation war größer, wenn er das Pedalganglion an den Präparaten beließ, als wenn er es entfernte.

Wie erwähnt (p. 527), hat man versucht, aus der Messung der Abhängigkeit der Atmung und von Fermentaktivitäten des Gehirngewebes von der AT speziell bei Fischen Rückschlüsse auf Funktionen der Ganztiere zu ziehen, doch ist deren Tragweite wohl meist begrenzt (vgl. hierzu auch JoHnston \& Roors 1964, Hickman et al. 1964, Konishi \& Hickman 1964, Baslow in Prosser 1967).

Einflüsse der Körperflüssigkeiten: Direkteffekte können auch von den Körper- und Blutflüssigkeiten ausgehen. Extrakte oder Blut von kaltadaptierten Tieren (Lampitio mauritii, Heterometrus swammerdami, H. fulvipes, Etroplus maculatus) stimulieren den Sauerstoffverbrauch von Geweben aus normal- oder warmadaptierten Individuen, selbst wenn sie bei in vitro-Versuchen in kleinen Mengen zugefügt werden. Extrakte oder Blut von warmadaptierten Tieren haben den entgegengesetzten Effekt (RAo in Troshin 1967). Jankowsky (1964a) und Precht (1964c, 1965) konnten diese Befunde der indischen Autoren für Tinca tinca und Idus idus (und Karpfenblut) bestätigen. Bei $I d u s$ treten die steigernden Effekte durch das Serum kaltadaptierter Karpfen nur dann auf, wenn der Sauerstoffverbrauch des Muskelgewebes nicht schon (wie beim Gewebe kaltadaptierter Orfen) durch die eigene Adaptation sehr hoch ist. Das Blutserum warmadaptierter Karpfen senkt dagegen gerade den hohen Sauerstoffverbrauch des Muskelgewebes kaltadaptierter $I d u s$ und beeinflußt kaum den geringeren von Tieren aus hohen ATs. Es wurde erwähnt, daß sich die einzelnen Gewebe eines Tieres sehr unterschiedlich verhalten können; durch Direkteffekte von seiten der Körperflüssigkeiten mag wieder eine gewisse Konformität erreicht werden, doch bleibt dies zu untersuchen.

Hormonale Einflüsse: RAo und seine Schüler haben die soeben besprochenen Wirkungen der Körperflüssigkeiten weiter untersucht. Lampitio besitzt neurosekretorische Zellen im Ober- und Unterschlundganglion. Die Tätigkeit der letzten hängt von der AT ab (Minimum bei $28^{\circ} \mathrm{C}$ nach SAROJA \& RaO 1965), mit der sogar der aktive Zelltyp wechseln soll. Ein Schüler von RAO untersuchte den Einfluß von injizierten Nervenextrakten von kalt- und warmadaptierten Würmern bei $28^{\circ}$-Tieren. Drei Stunden nach der Injektion mit Extrakt aus kaltadaptierten Lampitio war ein. Anstieg der Atmung, der RNS, der Lipaseaktivität, der Ungesättigtheit der Fettsäuren und des Gehaltes an Magnesium zu verzeichnen, also der Symptome, die bei einer Senkung der AT auftreten. Extrakte aus warmadaptierten Würmern hatten den entgegengesetzten Effekt. Auch Skorpione sollen Entsprechendes zeigen. Aus dem Nervengewebe der unterschiedlich adaptierten Würmer extrahierte Sterol-Fraktionen sol- 
len in gleicher Weise gewirkt haben. Bei den von uns durchgeführten Versuchen haben wir das Blutserum kurz vor der Messung des Sauerstoffverbrauchs dem Muskelgewebe im Warburgtrog zugefügt.

Beim Fisch Etroplus fand Rao eine Zunahme der Schilddrüsenaktivität mit fallender AT. Hiermit ist ein Problem berührt, das zwar oft untersucht, aber wenig geklärt ist. Es lag nahe, die Beteiligung von stoffwechselaktiven Hormondrüsen von Wirbeltieren und auch Wirbellosen an der Leistungsadaptation zu untersuchen, wobei die Arten sich natürlich unterschiedlich verhalten können. Das verschiedene Verhalten der Fermente eines Gewebes und das der gleichen Fermente in unterschiedlichen Geweben zeigt schon, daß man die Probleme nicht $z$ u sehr vereinfachen darf, wenn auch bekannt ist, daß dasselbe Hormon die Aktivität eines Fermentes stimulieren, die eines anderen senken kann (vgl. Precht 1961a). Nach Tishler (1963) wird beim Frosch-Myocard die Oxydation von Succinat in vitro durch L-Thyroxin erhöht, die von Malat gehemmt. Logische Schwierigkeiten ergeben sich für die Beteiligung von Hormonen auch bei der Deutung der Ergebnisse russischer Autoren (vgl. Precht in Troshin 1967, p. 261).

Das Interesse hat sich vor allem auf die Beteiligung des Hypophysen-Schilddrüsen-Systems der Wirbeltiere an der Leistungsadaptation gerichtet, doch soll darüber nur kurz berichtet werden, da trotz zahlreicher Arbeiten unsere Kenntnisse noch lückenhaft sind (vgl. Precht in Prosser 1958, 1961a, 1964d, Prosser in Hannon \& ViereCK 1962, JANKOWSKY 1964a, b).

Es ist zunächst zu berücksichtigen, daß die den Stoffwechsel beeinflussende Wirkung der Schilddrüsenhormone bei wechselwarmen Tieren nicht immer so klar nachweisbar ist wie bei den Säugetieren. Man kann den Sauerstoffverbrauch von Ganztieren nach Hormoninjektionen oder nach einer Exstirpation bzw. Reimplantation der Drüsen messen, den Sauerstoffverbrauch verschiedener Gewebe oder einzelne Fermentaktivitäten. Besonders umstritten ist die Frage, ob die Schilddrüsenhormone auch bei in vitro-Versuchen den Stoffwechsel aktivieren. PRECHT (1965) konnte die oft zitierten Befunde von HAARMANN (1936) an Karpfen nicht bestätigen, doch liegen auch neuere positive Befunde bei anderen Tieren vor (z. B. für isolierte Harnblasen von Kröten nach Thorndurn \& Matty 1966, vgl. auch Marusic et al. 1966, Taylor \& Barker 1967). Dies Problem ist für unsere Betrachtungen weniger wichtig, weil es nur die Art der Wirkung der Schilddrüsenhormone berührt, so das Problem der Direkt- und Nacheffekte. Es ist zu berücksichtigen, daß die einzelnen Gewebe unterschiedlich auf die Hormone ansprechen können und daß sich die Ansprechbarkeit jahreszeitlich ändern kann. Die Wirkung von Hormoninjektionen hängt bei Eidechsen (MaHER 1965, WILHOFF 1966) und Goldfischen (ThornbuRN \& MATTY 1963) von der Umgebungstemperatur der Tiere $a b$, ebenfalls bei Rana pipiens im Gegensatz zu Bufo woodhousii (MAHER 1967).

Hormone können auch die Größe der $\mu$-Werte beeinflussen; z. B. erniedrigt Vasopressin-Injektion diese für die Wasseraufnahme von Bufo melanoticus um 4000 cal (die Tiere befanden sich bereits über Nacht bei den VT's, Dicker \& Eltrot 1967).

Im Vordergrund der Untersuchungen steht die Frage, ob die Schilddrüsenaktivität durch die AT beeinflußt wird. Leider führen verschiedene Methoden (histologische Untersuchungen, ${ }^{131} \mathrm{~J}$-Aufnahme etc.) nicht immer $\mathrm{zu}$ den gleichen Resultaten (vgl. HOAR 
\& Eales 1963, EALEs 1965). Es wäre auch hier von Vorteil, die Tiere bei unterschiedlichen ATs zu halten, und dann bei gleichen VTs eine Funktionsprüfung der Drüsenaktivität vorzunehmen (über die möglichen Schlußfolgerungen aus solchen Versuchen und über die Befunde, die für bzw. gegen die Beeinflussung der Funktion des Hypophysen-Schilddrüsen-Systems durch die AT sprechen, vgl. Prechr 1964d).

Für Fische hat man bei diesen Untersuchungen ein sehr wechselndes Bild erhalten; die Aktivität der Schilddrüse kann mit der AT ansteigen, abfallen oder von ihr ziemlich unabhängig sein. Kaltadaptierte Amphibien zeigen sehr oft eine höhere Drüsenaktivität als warmadaptierte, das Umgekehrte gilt für etliche Reptilien (vgl. LYNN et al. 1965; Literaturübersicht bei Precht 1964d). Ein Unterschied zwischen den Arten (Goldfisch, Forelle) zeigt sich auch beim Thyroxineinfluß auf die $\mathrm{NH}_{3}$-Erzeugung (Thorndurn \& Matty 1963). Oft sind jahreszeitliche Anderungen der Drüsenaktivität, die mit der Laichzeit oder Wanderung der Fische in Beziehung stehen können, beobachtet worden, doch wirken hier neben der Temperatur auch andere Faktoren mit.

Beim Goldfisch zeigt die auffallend inaktive Schilddrüse keine Abhängigkeit von der AT; dennoch reagiert sie auf eine TSH-Behandlung, was besagen würde, daß die Produktion dieses Hypophysenhormons auch nicht von der AT abhängt (ForTunE 1956, 1958, Delsol \& Flatin 1956). Klicka (1965) konnte keinen Hinweis für eine Beteiligung der Schilddrüse an der Leistungsadaptation des Goldfisches finden.

Positive Befunde stammen von SuHrManN (1955) für den Sauerstoffverbrauch yon Karauschen und von JankowsKY (1960) für die Beteiligung des HypophysenSchilddrüsen-Systems an der Kompensation der Atmung von Rana temporaria. Durch Ausschaltung der Hormonproduktion durch Thioharnstoff bzw. durch Drüsenexstirpation konnte die Kompensation unterdrückt bzw. in ihrem Ausmaß erheblich reduziert werden (vgl. JANKOW/SKY 1964b). Thyreostatica können natïrlich auch unerwünschte Nebenwirkungen haben. Weitere Arten müßten untersucht werden (vgl. AuerBACH 1957, KasBoHm 1967).

\section{ZUSAMMENFASSUNG}

1. Das Stoffgebiet wird (trotz mancher Utbergänge und Schwierigkeiten der Zuordnung) in (a) Reaktionen, (b) Regulationen und (c) Akklimatisationen (Adaptationen) aufgegliedert. Das Problem des Nutzens im Sinne eines Selektionsvorteils wird ausgeklammert. Es wird bei dieser zusammenfassenden Darstellung besonders die nach 1955 erschienene Literatur berücksichtigt.

2. Zur Charakterisierung der Abhängigkeit der Lebensprozesse von der Versuchstemperatur (VT) pflegt man $Q_{10}$ - oder (wenn möglich) $\mu$-Werte anzugeben, die jedoch große Unterschiede zeigen können, z. B. für verschiedene Organfunktionen, für Teilfunktionen eines Organs, bei unterschiedlichem Funktionszustand eines Organs, für gleiche Organfunktionen verschiedener Rassen und Arten etc. Biologisch bedeutsame Kurvenbereiche können durch besonders niedrige Temperaturkoeffizienten ausgezeichnet sein, was nicht immer auf angeborene Reaktionsnormen zurückzuführen ist, sondern auch durch Regulationen oder Adaptationen zustande kommen kann. 
3. Die Abhängigkeitskurven von der VT können von der Körpergröße in unterschiedlicher Weise abhängen, wobei man verschieden große Rassen oder verwandte Arten bzw. unterschiedliche Wachstumsstadien derselben Art untersuchen kann.

4. Die Temperaturkoeffizienten können von der Adaptationstemperatur (AT) abhängen, und zwar in unterschiedlicher Weise auch bei demselben Typ der Leistungsadaptation.

5. Jahreszeitliche Einflüsse auf die Abhängigkeitskurven von der VT werden nur kurz behandelt; es können dabei mehrere Faktoren eine Rolle spielen (die Adaptationstemperatur, die Photoperiode, endogene Rhythmen).

6. Bei relativ raschen Temperaturänderungen können over- und undershoots das Bild komplizieren. Es kann sich hierbei um Reaktionen (Einschwingprozesse) handeln, doch sind auch länger dauernde Nachwirkungen zu beobachten, wobei z. B. Streßphänomene vorliegen können, die Gegenreaktionen des Körpers auslösen und eine exakte Versuchsausführung sehr erschweren, oder auch Schädigungen, die Reparationen notwendig machen. Die Streßphänomene kann man auch auf der Fermentebene beobachten oder an Änderungen des RNS-Gehaltes ablesen.

7. Es werden einige Beispiele für Regulationen durch übergeordnete Systeme angegeben und die Möglichkeiten geschildert, diese von Reaktionen und Adaptationen $z u$ unterscheiden.

8. Es muß zwischen genetisch bedingten und den (weit besser untersuchten) nichtgenetischen Adaptationen unterschieden werden. Mit der AT können sich Substanzmengen (Wasser- und Salzgehalt, Proteine, Fette, RNS, DNS etc.) ändern oder die Abhängigkeitskurven von der VT. Hierfür können mehrere Typen angegeben werden, doch stößt eine solche Einteilung in manchen Fällen auf Schwierigkeiten (z. B. bei einigen Fermentaktivitäten).

9. Die Bedingungen für eine exakte Versuchsausführung zur Erfassung einer Leistungsadaptation werden dargelegt.

10. Eine nichtgenetische Leistungsadaptation kann auf allen Ebenen (Funktionen intakter Tiere oder isolierter Organe, bei Zellstoffwedıselprozessen etc.) beobachtet werden. Selbst für ihr Vorkommen beim Stoffwechsel intakter Tiere sind schwer Regeln anzugeben; sie findet sich anscheinend bei im Wasser lebenden Tieren häufiger als bei terrestrischen. Die Organfunktionen oder die Gewebe eines Tieres oder verschiedene Zellstoffwechselprozesse desselben Gewebes können sich im Ausmaß der Adaptation oder sogar im Adaptationstyp unterscheiden. Auch der Stoffwechselweg kann yon der AT abhängen.

11. Obwohl eine solche Leistungsadaptation in einigen Fällen auch relativ rasch verlaufen kann, handelt es sich im allgemeinen doch um eine Anpassung an langfristige Temperaturänderungen. Der Adaptationsmechanismus ist oft selbst temperaturabhängig; er kann aber noch bei Temperaturen unter dem Nullpunkt funktionsfähig sein.

12. Es ist bisher nur ungenügend gelungen, den Mechanismus der nichtgenetischen Leistungsadaptation zu klären. Erörtert werden zentralnervöse Einflüsse und solche der Körperflüssigkeiten und der Hormone. An einem Beispiel (der Atmung des Aales) wird ein Versuch zur Erforschung des Mechanismus geschildert. 


\section{ZITIERTE LITERATUR}

A.bramamson, Y. \& Maher, M., 1967. The effects of temperature upon pancreatic amylase in selected reptiles and an amphibian. Can. J. Zool.45, 227-232.

Alvarez, M. R. \& CowDEN, R. R., 1966. Karyometric and cytophotometric study of hepatocyte nuclei of frogs exposed to cold and prolonged starvation. Z. Zellforsch. mikrosk. Anat. 75, 240-249.

Anders, F., Drawert, F., Anders, A. \& Reuther, K. H., 1964. Über kausale Zusammenhänge zwischen der Zuchttemperatur, dem Aminosäure-Pool und einigen quantitativen Phänen bei Drosopbila melanogaster. Z. Naturf. 19b, 495-499.

ANTHONY, E. T., 1961. The oxygen capacity of goldfish (Carassius auratus L.) blood in relation to the thermal environment. J. exp. Biol. 38, 93-107.

ArmitAGe, K. B., 1962. Temperature and oxygen consumption of Orchomonella chilensis (Heller) (Amphipoda: Gammaroidea). Biol. Bull. mar. biol. Lab., Woods Hole 123, 225-232.

AtKins, M. D., 1967. The effect of rearing temperature on the size and fat content of the Douglas-fir beetle. Can. Ent. 99, 181-187.

Averbach, M., 1957. Hat die Schilddrüse für die Temperaturadaptation der Fische eine Bedeutung? Z. Fisch. (N. F.) 6, 605-620.

Autrum, H. \& Hamdorf, K., 1964. Der Sauerstoffverbrauch des Bienenauges in Abhängigkeit von der Temperatur bei Belichtung und im Dunkeln. Z. vergl. Physiol. 48, 266-269.

Barrllot, J. C., Maphlippect, F. \& Gargoul, Y. M., 1965. Influence de la température et de la durée de conservation sur quelques caractéristiques physiologiques de Rana esculenta L. C. r. Séanc. Soc. Biol. 158, 2445-2448.

Baslow, M. H. \& Nigrelli, R. F., 1964. The effect of thermal acclimation on brain cholinesterase activity of the killifish, Fundulus heteroclitus. Zoologica, N.Y. 49, 41-51.

Beamsh, F. W. H., 1964. Respiration of fish with special emphasis on standard oxygen consumption. II. Can. J. Zool. 42, 177-188.

- 1966. Swimming endurance of some Northwest Atlantic fishes. J. Fish. Res. Bd Can. 23, 341-347.

- \& MookneRjIr, P. S., 1964. Respiration of fishes with special emphasis on standard oxygen consumption. I. Can. J. Zool. 42, 161-175.

Benthe, H.-F., 1954. Über die Temperaturabhängigkeit neuromuskulärer Vorgänge. $Z$. vergl. Physiol. 36, 327-351.

Berg, K., Jónasson, P. M. \& Ockelmann, K. W., 1962. The respiration of some animals from the profundal zone of a lake. Hydrobiologia 19,1-39.

Berkrolz, G., 1966. Ober die Temperaturadaptation des Nerflings (Idus idus L., Pisces) nach inkonstanter Vorbehandlung. Z. wiss. Zool. 174, 377-399.

BerLin, J. D. \& Dean, J. M., 1967. Temperature-induced alterations in hepatocyte structure of rainbow trout (Salmo gairdnerii). J.exp. Zool. 164, 117-132.

BIER, K., 1965. Uber den Transport zelleigener Makromoleküle durch die Kernmembran. I. Chromosoma 16, 58-69.

BrRCH, L. C., 1947. The oxygen consumption of the small strain of Calandra oryzae L. and Rhizopertha dominica FAB. as affected by temperature and humidity. Ecology 28, 17-25.

Brrk, Y., Harpaz, I., IshaAyA, I. \& Bondi, A., 1962. Studies on the proteolytic activity of the beetles Tenebrio and Tribolium. J. Insect. Physiol. 8, 417-429.

Black, E. C., KrrkPatrick, D. \& Tucker, H. H., 1966. Oxygen dissociation curves of the blood of brook trout (Salvelinus fontinalis) acclimated to summer and winter temperature. J. Fish. Res. Bd Can. 23, 1-13.

BŁAŽKA, P., 1955. Temperaturadaptation des Gesamtmetabolismus bei der Weinbergschnecke Helix pomatia L. Zool. Jb. (Abt. allg. Zool. Physiol. Tiere) 65, 357-504.

- 1958. The anaerobic metabolism of fish. Physiol. Zoöl. 31, 117-128.

Boxcotr, B. B., Gray, E. G. \& GullezRY, R. W., 1961. Synaptic structure and its alternation with environmental temperature: a study by light and electron microscopy of the central nervous system of lizards. Proc. R. Soc. (B) 154, 151-172. 
BRETT, J. R., 1964. The respiratory metabolism and swimming performance of young sockeye salmon. J. Fish. Res. Bd Can. 21, 1183-1226.

- 1965. The relation of size to rate oxygen consumption and sustained swimming speed of sockeye salmon (Oncorbynchus nerka). J. Fish. Res. Bd Can. 22, 1491-1501.

- 1967. Swimming performance of sodkeye salmon (Oncorbynchus nerka) in relation to fatigue time and temperature. J. Fish. Res. Bd Can. 24, 1731-1741.

Brown, W. D., 1960. Glucose metabolism in carp. J. cell. comp. Physiol. 55, 81-84,

Buck, J. \& CASE, J. F., 1961. Control of flashing in fire flies. I. Biol. Bull. mar. biol. Lab., Woods Hole 121, 234-250.

BudDENBRock, E. V, 1960. Ubber die Temperaturabhängigkeit der Narkosewirkung bei wechselwarmen Tieren. Z. wiss. Zool. 164, 173-187.

Bullock, T. H., 1955. Compensation for temperature in the metabolism and activity of poikilotherms. Biol. Rew. 30, 311-342.

Burkfardt, D., 1959. Die Erregungsvorgänge sensibler Ganglienzellen in Abhängigkeit von der Temperatur. Biol. Z bl. 78, 22-62.

Busner, M. C., 1953. Contribution à l'étude des émissions acoustiques des Orthoptères. I. Annls Épiphyt. (C) 4, 333-421.

Carlsen, H., 1953. Der Cocarboxylasegehalt des Aales (Anguilla vulgaris L.).Z. vergl. Physiol. 35, 199-208.

Christophersen, J. \& KAUfMANN, W., 1955. Spektraloptische und papierchromatographische Untersuchungen an Lipoiden und Fetten von Hefezellen bei verschiedenen Züchtungstemperaturen. Kieler milchw. ForschBer. 39, 323-335.

- \& PRecht, H., 1952. Untersuchungen zum Problem der Hitzeresistanz. 1. 2. Biol. Zbl. $71,313-326,585-601$.

CORDIER, D. \& WORBE, J. F., 1954. Influence de la température du milieu et de l'acclimatement préalable sur la perméabilité du gardon (Leuciscus rutilus) à l'éthanol. C. r. Séanc. Soc. Biol. 148, 1253-1256.

Dalton, J. C. \& Hendrix, D. E., 1962. Effects of temperature on membrane potentials of lobster giant axon. Am. J. Physiol. 202, 491-494.

Danielli, J. F., 1954. Morphological and molecular aspects of active transport. Symp. Soc. exp. Biol. 8, 502-516.

Das, A. B., 1967. Biochemical changes in tissues of goldfish acclimated to high and low temperatures. II. Comp. Biochem. Physiol. 21, 469-485.

- \& Prosser, C. L., 1967. Biochemical changes in tissues of goldfish acclimated to high and low remperatures. I. Comp. Biochem. Pbysiol. 21, 469-467.

Davres, P. S., 1966/67. Physiological ecology of Patella. I. II. J. mar. biol. Ass. U. K. 46, $647-658,47,61-74$.

- \& WALKEY, M., 1966. The effect of body size and temperature upon oxygen consumption of the cestode Schistocephalus solidus (Müller). Comp. Biochem. Physiol. 18, 415-425.

Davison, J. A. \& Richards, A. G., 1954. Muscle apyrase activity as a function of temperature in the cockroach, crayfish, and minnow. Archs Biochem. Biophys. 48, 485-486.

Dawson, W. R. \& Templeton, J. R., 1966. Physiological response to temperature in the alligator lizard, Gerrhonotus multicarinotus. Ecology 47, 759-765.

Dean, J. M. \& Goodnight, C. J., 1964. A comparative study of carbohydrate metabolism in fish as affected by temperature and exercise. Physiol. Zoöl. 37, 280-299.

- \& Vernberg, F. J., 1965. Effects of temperature acclimation on some aspects of carbohydrate metabolism in decapod crustaceae. Biol. Bull. mar. biol. Lab., Woods Hole 129, 19-22.

- - 1966. Hypothermia and blood of crabs. Comp. Biochem. Physiol. 17, 19-22.

DeHNel, P. A., 1960. Effect of temperature and salinity on the oxygen consumption of two intertidal crabs. Biol. Bull. mar. biol. Lab., Woods Hole 118, 215-249.

- \& McCaughran, D. A., 1964. Gill tissue respiration in two species of estuarine crabs. Comp. Biochem. Pbysiol. 13, 233-259. 
Delsol, M. \& Flatin, J., 1956. Action de la température sur l'activité de l'hormone thyreotrope chez deux vertébrés intérieurs: Rana esculenta L. et Carassius auratus L. C. r. Séanc. Soc. Biol. 150, 938-940.

Démeusy, N., 1957. Respiratory metabolism of the fiddler crab Uca pugilator from two different latitudinal populations. Biol. Bull. mar. biol. Lab., Woods Hole 113, 245-253.

Dicker, S. E. \& Elliot, A. B., 1967. Water uptake by Bufo melanoticus as affected by osmotic gradients, vasopressin and temperature. J. Physiol., Lond. 190, 359-370.

Dill, D. B., AdolPy, E. F. \& WILBER, C. G. (Eds), 1964. Adaptation to the environment. In: Handbook of physiology. Section 4. American Physiological Society, Washington, D. C., $1056 \mathrm{pp}$.

Duchâteau, G. \& Florkin, M., 1955. Influence de la température sur l'état stationnaire du pool des acides aminés non protéiques des muscles d' Eriocheir sinensis MrLNE-EDwards. Archs int. Physiol, Biochim. 63, 213-221.

Eales, J. G., 1965. Factors influencing seasonal changes in thyroid activity in juvenile steelhead trout, Salmo gairdneri. Can. J. Zool. 43, 719-729.

Edmunds, L. N., jr., 1963. The relation between temperature and flashing intervals in adult mate fireflies, Photinus pyralis. Ann. ent. Soc. Am. 56, 716-718.

EDney, E. B., 1964. Acclimation to temperature in terrestrial isopods. I. II. Pbysiol. Zoöl. 37, $364-377,378-394$.

EKBERG, D. R., 1958. Respiration in tissues of goldfish adapted to high and low temperatures. Biol. Bull. mar. biol. Lab., Woods Hole 114, 308-316.

- 1962. Anaerobic and aerobic metabolism in gills of the crucian carp adapted to high and low temperatures. Comp. Biochem. Physiol. 5, 123-128.

Evans, E. E. \& Cowles, R. B., 1959. Effect of temperature on antibody synthesis in the reptile, Dipsosaurus dorsalis. Proc. Soc. exp. Biol. Med. 101, 482-483.

Evans, R. M., Purdie, F. C. \& Hrckman, C. P., jr., 1962. The effect of temperature and photoperiod on the respiratory metabolism of rainbow trout (Salmo gairdnerii). Can. J. Zool. 40, 107-118.

FAgerlund, U. H. M., 1967. Plasma cortisol concentration in relation to stress in adult sockeye salmon during the freshwater stage of their life cycle. Gen. comp. Endocr. 8, 197-207.

Farkas, T. \& Herodex, S., 1959. Paperchromatographic studies in the fatty acid composition of some fresh water crustaceans. Acta biol. hung. 10, 85-90.

Farmanfarmatan, A. \& Giese, A. C., 1965. Thermal tolerance and acclimation in the western purple sea urchin Strongylocentrotus purpuratus. Pbysiol. Zoöl. 36, 237-243.

Fisher, K. C. \& Sullivan, CH. M., 1958. The effect of temperature on the spontaneous activity of speckled trout before and after various lesions of the brain. Can. J. Zool. 36, 49-63.

FlöRKE, M., KEIZ, G. \& Wangorsch, G., 1954. Uber die Temperatur-Stoff wechsel-Relation und Wärmeresistenz einiger Süßßwasserfische und des Flußkrebses. Z. Fisch. (N.F.) 3, 241-310.

Fortune, P. Y., 1956. An inactive thyroid gland in Carassius auratus. Nature, Lond. 178, 98.

- 1958. The effect of the temperature changes on the thyroid-pituitary relationship in teleosts. J. exp. Biol. 35, 824-831.

Fox, H. M., 1955. L'hémoglobine de la daphnie et les problèmes qu'elle soulève. Bull. Soc. zool. France 80, 288-298.

Frankel, H. M., Steinberg, G. \& Gordon, J., 1966. Effects of temperature on blood gases, lactate, and pyruvate in turtles, Pseudemys scripta elegans, in vivo. Comp. Biochem. Physiol. 19, 279-283.

FREED, J., 1965. Changes in activity of cytochrome oxidase during adaptation of goldfish to different temperatures. Comp. Biochem. Physiol. 14, 656-659.

FreEMAN, J. A., 1950. Oxygen consumption, brain metabolism and respiratory movements during temperature acclimatisation, with special reference to lowered temperatures. Biol. Bull. mar. biol. Lab., Woods Hole 99, 416-424.

Frings, H. \& Frings M., 1957. The effects of temperature on chirp rate of male cone-headed grasshoppers Neoconocephaltus ensiger. J. exp. Zool. 134, 411-425. 
FRX, F. E. J., 1958. Temperature compensation. A. Rev. Physiol. 20, 207-224.

GAHLENBECK, H. \& Bartels, H., 1968. Temperaturadaptation der Sauerstoffaffinität des Blutes von Rana esculenta L. Z. vergl. Physiol. 59, 232-240.

Gr̈RDEFors, D., 1964. The influence of rapid temperature changes on the activity of Chorthippus albomarginatus DE GEER (Acrididae, Orthoptera). Entomologia exp. appl. 7, 71-84.

Gezrneo, S. \& Kolendrc, M., 1953. Influence du milieu thermique d'adaptation sur la dépense chez l'escargot Helix pomatia. Glas srp. Akad. Nauka (Prirod.mat. nanka) 6 (208), 19-23.

GLICK, J. L. \& Bronk, J. R., 1964. The effect of exercise on the rate of oxygen uptake by ratliver mitochondria. Biochim. biophys. Acta 82, 165-167.

Grainger, J. N. R., 1960. The early phasis in the adjustment of respiratory rates of unicellular organisms to new temperatures and the simulation of these in a model. $Z$. wiss. Zool, 163, 317-341.

- 1961. The early stages in the adaptation of the frog Rana temporaria to higher temperatures. Zool. Anz. (Suppl. Bd) 24, 60-72.

- 1964. The effect of temperatures on weight changes and water fluxes in the common frog Rana iemporaria. Proc. R. Ir. Acad. 64 B, 25-32.

- \& Goldspink, G., 1964. The effect of adaptation temperature on the properties of nerve muscle preparations and on the performance of the frog Rana temporaria L. Helgoländer wiss. Meeresunters. 9, 420-427.

Grigg, G. C., 1965. Studies on the Queensland lungfish, Neoceratodus forsteri (KreffT). II. Austr. J. Zool. 13, 407-411.

Gromysz-Kalkowska, K. \& Stojalowska, W., 1966. Respiratory metabolism in Orthomorpha gracilis C. L. KoCH (Diplopoda) as a function of temperature and body size. Folia Biol., Kraków 14, 379-389.

Hammond, B. R. \& Hickman, C. P., jr., 1966. The effect of physical conditioning on the metabolism of lactate, phosphate, and glucose in rainbow trout, Salmo gairdnerii. J. Fish. Res. Bd Can. 23, 65-83.

Hane, S., Robertson, O. H., Wexler, B. C. \& Krupp, M. A., 1966. Adrenocorrical response to stress and ACTH in pacific salmon (Oncorbynchus tshawytscba) and steelhead trout (Salmo gairdnerii) at successive stages in the sexual cycle. Endocrinology 78, 791-800.

HANNON, J. P. \& VIERECK, E. (Eds), 1962. Comparative physiology of temperature regulation. Arctic Aeromed. Lab., Fort Wainwright, Alaska, 455 pp.

Harwoon, R. F. \& Takata, N., 1965. Effect of photoperiod and temperature on fatty acid composition of the mosquito Culex tarsalis. J. Insect. Physiol. 11, 711-716.

Hasan, R. \& QAsim, S. Z., 1961. Studies on fish metabolism. I. Proc. Indian Acad. Sci. (B) 53, $230-239$.

Heath, A. G. \& Pritchard, A. W., 1962. Changes in the metabolism rate and blood lactic acid of bluegill sunfish, Lepomis macrochirus RAF, following severe muscular activity. Pbysiol. Zoöl. 35, 323-329.

HeEt, W. H. D. van, 1956. Pitch discrimination in the minnow (Phoxinus laevis) at different temperature levels. Experientia 12, 75-77.

Hennicke, E. A. \& Houston, A. H., 1965. Effect of thermal acclimation and sublethal heat shock upon ionic regulation in the goldfish, Carassius auratus. J. Fish. Res. Bd Can. 22, $1455-1476$.

Hickman, C. P., jr., McNabB, R. A., Nelson, J. S., Breemen, E. D. van \& Comport, D., 1964. Effect of cold acclimation on electrolyte distribution in rainbow trout (Salmo gairdnerii). Can. J. Zool. 42, 577-597.

HoAr, W. S. \& COTTLE, M. K., 1952. Some effects of temperature acclimation on the chemical composition of goldfish tissues. Can. J. Zool. 30, 49-54.

- \& Eales, J. G., 1963. The thyroid gland and low-temperature resistance of goldfish. Can. J. Zool. 41, 653-669.

HochachK., P. W. \& HaXes, F. R., 1962. The effect of temperature acclimation on pathways of glucose metabolism in the trout. Can. J. Zool. 40, 261-270.

Hoffmann, K., 1968. Synchronisation der circadianen Aktivitätsperiodik von Eidechsen durch Temperaturcyclen verschiedener Amplitude. Z. vergl. Pbysiol. 58, 225-228. 
HÜLSEN, J. \& ZERBST, E., 1964. Untersuchungen zur kurzzeitigen Temperaturanpassung der Froschherzfrequenz. Pflügers Arch. ges. Physiol. 279, R 40.

Hugger, H., 1959. Experimentelle Untersuchungen über Autonomie, Temperaturabhängigkeit und die Arbeit des embryonalen Fischherzens; unter besonderer Berïcksichtigung der Salmoniden und Scyliorhiniden. Z. vergl. Physiol. 42, 63-102.

- 1961. Zur Morphologie der Herzbildung bei den Salmoniden und Scyliorhiniden. Revue suisse Zool. 68, 111-119.

- Kleinhaus, A. \& Hamzehpour, M., 1963. Composition du sang de Salmo gairdnerii irideus et Squalus cepbalus. Revue suisse Zool. 70, 286-290.

Huggrns, S. E. \& Percoco, R. A., 1965. Blood volume in alligators during prolonged hypothermia. Proc. Soc. exp. Biol. Med.119, 678-682.

Hughes, G. M. \& Shelton, G., 1962. Respiratory mechanisms and their nervous control in fish, Adv. comp. Physiol. Biochem. 1, 275-364.

Hunter, A. S., 1964-1966. Effects of temperature on Drosophila. I. II. III. Comp. Biochem. Pbysiol. 11, 411-417; 16, 7-12; 19, 171-177.

Istenic, L., 1963. Rate of oxygen consumption of larvae Perla marginata Pz. in relation to body size and temperature. Raspr. slov. Akad. Znan. Umet. - Diss. Acad. scient. art. slov. (Cl. 4: Hist. nat.) 7, 201-236.

JANKOWskx, H.-D., 1960. Uber die hormonale Beeinflussung der Temperaturadaptation beim Grasfrosch (Rana temporaria L.). Z. vergl. Physiol. 43, 392-410.

- 1964a. Der Einfluß des Blutes auf den Sauerstoffverbrauch des isolierten Muskelgewebes von Schleien (Tinca tinca L.). Zool. Anz. 172, 233-239.

- 1964b. Die Bedeutung der Hormone für die Temperaturanpassung im normalen Temperaturbereich. Helgoländer wiss. Meeresunters. 9, 412-419.

- 1966. The effect of adaptation temperature on the metabolic level of the eel Anguilla vulgaris L. Helgoländer wiss. Meeresunters. 13, 402-407.

- 1968. Versuche zur Adaptation der Fische im normalen Temperaturbereich. Helgoländer reiss. Meeresunters. 18, 317-362.

- \& KorN, H., 1965. Der Einfluß der Adaptationstemperatur auf den Mitochondriengehalt des Fischmuskels. Naturwissenschafien 52, 642-643.

Joв, S. V., 1957. The routine-active oxygen consumption of the milk fish. Proc. Indian Acad. Sci. 45, 302-303.

Johnston, P. V. \& Roots, B. I., 1964. Brain lipid fatty acids and temperature acclimation. Comp. Biochem. Physiol. 11, 303-309.

KanemisA, K, 1965. Effect of temperature on the isolated hindgut movements of American codkroach Periplaneta americana L. Jap. J. appl. Ent. Zool. 9, 301-302.

Kanungo, M. S. \& Prosser, C. L., 1959. Physiological and biochemical adaptation of goldfish to cold and warm temperatures. I. II. J. cell. comp. Physiol. 54, 259-263, 265-274.

Kanwisher, J. W., 1966. Tracheal gas dynamics in pupae of the Cecropia silkworm. Biol. Bull. mar. biol. Lab., Woods Hole 130, 96-105.

Karger, W., 1962. Oscillatorische Phänomene des elektrischen Potentials an der isolierten Froschhaut nach Temperaturwechsel. Pflügers Arch. ges. Physiol. 274, 331-339.

KarLson, P., 1961. Biochemische Wirkungsweise der Hormone. Dt. med. Wschr. 86, 668-672.

Kasbohm, P., 1967. Der Einfluß des Lichtes auf die Temperaturadaptation bei Rana temporaria. Helgoländer wiss. Meeresunters. 16, 157-178.

KeIster, M. \& BucK, J, 1961. Respiration of Phormia regina in relation to temperature and oxygen. I. Insect. Physiol. 7, 51-72.

KEnNEDY, J. S., 1939. The behaviour of the desert locust Schistocerca gregaria (FonsK.) (Orthopt.) in an outbreak centre. Trans. R. ent. Soc. Lond. 89, 385-540.

Kennedy, J. W. \& Richards, A. G., 1955. Differences between leg and flight muscle of the giant water bug, Lethocerus americanus. Ent. News 66, 29-36.

Keppler, E., 1958. Uber das Richtungshören von Stechmücken. Z. Naturf. 13b, 280-284; 285-286.

Kerkut, G. A. \& RuDge, A. P., 1961. The effect of temperature changes on the resting potential of crab, insect and frog muscle. Comp. Biochem. Physiol. 3, 64-70. 
- \& TAYLOR, B. J. R., 1958. The effect to temperature changes on the activity of poikilothermes. Behaviour 13, 259-279.

Kinuchi, R., Naito, K. \& Minagawa, S., 1961. Effect of temperature on the retinal slow potential of the horseshoe crab. Nature, Lond. 190, 1011-1012.

KrnNE, O., 1963. The effects of temperature and salinity on marine and brackish water animals. 1. Temperature. Oceanogr. mar. Biol. A. Rev. 1, 301-340.

- 1964a. ...2. Salinity and temperature salinity combinations. Oceanogr. mar. Biol. A. Rev. $2,281-339$.

- 1964b. Non-genetic adaptation to temperature and salinity. Helgoländer wiss. Meeresunters. 9, 433-458.

- 1965. Physiologische und ökologische Aspekte des Lebens in Astuarien. Helgoländer wiss. Meeresunters. 11, 131-156.

KirberggR, CH., 1953. Untersuchungen über die Temperaturabhängigkeit von Lebensprozessen bei verschiedenen Wirbellosen. Z. vergl. Physiol. 35, 175-198.

Kitching, J. A., 1954. The physiology of contractile vacuoles. IX. J. exp. Biol. 31, 68-75.

KLICKA, J., 1965. Temperature acclimation in goldfish: lack of evidence for hormonal involvement. Physiol. Zoöl. 38, 177-189.

Kniprath, W. G. \& Mead, J. F., 1966. Influence of temperature on the fatty acid pattern of mosquito-fish (Gambusia affinis) and guppies (Lebistes reticulatus). Lipids 1, 113-117.

Konisfi, J. \& HrсKman, C. P., jr., 1964. Temperature acclimation in the centre nervous system of rainbow trout Salmo gairdnerii. Comp. Biochem. Pbysiol. 13, 433-442.

KRÜGER, F., 1963. Versuche einer mathematischen Analyse der Normalkurve von KRoGH. Helgoländer wiss. Meeresunters. 8, 333-356.

- 1966. Zur mathematischen Struktur der lebenden Substanz, dargelegt am Problem der biologischen Temperatur- und Wachstums-Funktion. Helgoländer wiss. Meeresunters. 14, 302-325.

KRüGer, G., 1961. Der Einfluß der Temperatur auf die Sauerstoffbindung des Froschblutes. Zool. Anz. (Suppl. Bd) 24, 80-83.

- 1962. Uber die Temperaturadaptation des Bitterlings (Rhodeus amarus BLOCH). Z. wiss. Zool. 167, 87-104.

Lagerspetz, K. Y. H. \& Dubitscher, I., 1966. Temperature acclimation of the ciliary activity in the gills of Anodonta. Comp. Biochem. Physiol. 17, 665-671.

- \& TAlo, A., 1967. Temperature acclimation of the functional parameters of the giant nerve fibres in Lumbricus terrestris L. 1. J. exp. Biol. 47, 471-480.

Laget, P., Gúḱrin, J. \& VANNier, J., 1955. Effets de l'ion calcium et du gaz carbonique sur l'excitabilité des nerfs de Batraciens soumis à des variations lentes de température. C. $r$. Séanc. Soc. Biol. 149, 2160-2162.

LARMmer, J. L., 1967. The effects of temperature on the activity of the caudal photoreceptor. Comp. Biochem. Physiol. 22,683-700.

Legay, J. M. \& Coulon, J., 1965. Vers une définition du métabolisme de base chez les insectes. C. r. hebd. Séanc. Acad. Sci., Paris 261, 1908-1909.

LeHManN, J., 1968a. Ober die Abhängigkeit der Enzymaktivitäten von der Vorbehandlungstemperatur im Rumpfmuskel der Goldorfe (Idus idus). Int. Rev. ges. Hydrobiol. (im Drudk).

- 1968b. Ober Veränderungen der Enzymaktivitäten nach einem Wechsel der Adaptationstemperatur, untersucht am Seitenrumpfmuskel des Goldfisches. Int. Rev. ges. Hydrobiol. (im Druck).

Leicht, R., 1968. Der Sauerstoffverbrauch von Anguilla vulgaris L. in seiner Abhängigkeit von Temperaturdifferenzen zwischen Kopfbereich und Rumpf. Mar. Biol, 2 (im Druck).

Leloup, J. \& Fontaine, M., 1960. Jodine metabolism in lower vertebrates. Amm. N. Y. Acad. Sci. 86, 316-353.

LOCKER, A., 1958a. Die Gewebsatmung poikilothermer Wirbeltiere in Abhängigkeit von Körpergröße und Temperatur. Z. vergl. Physiol. 41, 249-266.

- 1958b. Zur Temperaturaktivierung der Substratatmung tierischer Gewebe. Experientia 14, 407. 
- 1959. Zur unterschiedlichen Temperaturabhängigkeit der Gewebsatmung von Leber und Haut bei Amphibien. Biol. Zbl. 78, 383-390.

- \& Wersh, P., 1965. Stoffwechselunterschiede zwischen Kalt- und Warmblütern bei der Kälteadaptation. Zool. Anz. (Suppl. Bd) 28, 365-378.

LockwOOD, A. P. M., 1960. Some effects of temperature and concentration of the medium on the ionic regulation of the isopod Asellus aquaticus (L.). J. exp. Biol. 37, 614-630.

LÖRCHER, K., 1966. Einfluß der Wassertemperatur auf die Paarungsrufe der Unken. Naturwissenschaften 53, 559-560.

Lohmann, M., 1967. Zur Bedeutung der lokomotorischen Aktivität in circadianen Systemen. Z. vergl. Physiol. 55, 307-332.

Loosanofr, V. L., 1958. Some aspects of behavior of oysters at different temperatures. Biol. Bull. mar, biol. Lab., Woods Hole 114, 57-70.

LüdtKe, A.-H. \& OHNEsorge, F.-K., 1966. Charakterisierung der Cholinesterasen in verschiedenen Geweben der Schleie (Tinca tinca) und des Kaninchens. Z. vergl. Physiol. 52, 260-275.

LynN, W. G., MCCormick, J. J. \& Gregorek, J. C., 1965. Environmental temperature and thyroid function in the lizard, Anolis carolinensis. Gen. comp. Endocr. 5, 587-595.

McFarland, W. N. \& Prckens, P. E., 1965. The effects of season, temperature, and salinity on standard and active oxygen consumption of the grass shrimp, Palaemonetes vulgaris (SAY). Can. J. Zool. 43, 571-585.

McLeese, D. W. \& WILDER, D. G., 1958. The activity and catchatibity of the lobster (Homarus americanus) in relation to temperature. J. Fish. Res. Bd Can. 15, 1345-1354.

McW finnie, M. A. \& O'Connor, J. D., 1966. Metabolism and low temperature acclimation in the temperate crayfish, Orconectes virilis. Am. Zool. 6, 349 (Abstr. 232).

Maddwell, S. H. P., 1964. Excretion in the blood-sudking bug Rhodnius prolixus STÅL. II. J.exp. Biol. 41, 163-176.

Maher, M. J., 1965. The role of the thyroid gland in the oxygen consumption of lizards. Gen. comp. Endocr, 5, 320-325.

- 1967. Response to thyroxine as a function of environmental temperature in the toad, Bufo woodhousii, and the frog, Rana pipiens. Copeia 1967, 361-365.

Mahon, E. F., Hoar, W. S. \& Tabata, S., 1962. Histophysiological studies of the adrenal tissue of the goldfish. Can. J. Zool. 4, 449-464.

MalessA, P., 1968. Beiträge zur Temperaturadaptation des Aales (Anguilla vinlgaris L.). III. Mar. Biol. 2 (im Druck).

Marusic, E., Martinez, R. \& Toretri, J., 1966. Unresponsiveness of the adult toad to thyroxine administration. Proc. Soc. exp. Biol. Med. 122, 164-167.

Meuwis, A. L. \& Heuts, M. J., 1957. Temperature dependance of breathing rate in carp. Biol. Bull. mar. biol. Lab., Woods Hole 112, 97-107.

Mews, H.-H., 1957a. Uber die Temperaturadaptation der Sekretion von Verdauungsfermenten und deren Hitzeresistenz. Z. vergl. Physiol. 40, 345-355.

- 1957b. Ober die Temperaturadaptation der eiweißspaltenden und -synthetisierenden Zellfermente von Fröschen. Z. vergl. Physiol. 40, 356-362.

Milstead, W. W. (Ed.), 1967. Lizard ecology; a symposium, Univ. of Missouri Press, Kansas City.

Mrnamori, S., 1957. Physiological isolation in cobitidae. VI. J. Sci. Hirosbima Univ. (Ser. B 1) 17, 65-119.

Misurn, H., 1960. Zur Funktionsanalyse des lymphatischen Kaudalherzens beim Aal (Anguilla anguilla L.). Revue suisse Zool. 67, 262-269.

MORAWSKA, B. \& ZALESKA, A., 1958. The influence of the temperature of tadpoles and metamorphosed individuals of Xenopus laevis D., Rana temporaria L. and $R$. esculenta $L$. Acta Biol. exp., Vars. 18, 39-53.

MorRIs, R. W., 1961. Distribution and temperature sensitivity of some eastern Pacific cottid fishes. Physiol. Zoöl. 34, 217-227.

- 1962. Body size and temperature sensibility in the cichlid fish, Aequidens postalegrensis (HeNSEL). Am. Nat. 96, 35-50. 
- 1965a. Thermal acclimation in metabolism of the yellow bullhead, Ictalurus natalis (LE Sueur). Physiol. Zoöl. 38, 219-227.

- 1965b. Thermal acclimation in an eleotrid fish, Carassiops compressus KREFFT. Am. Nat. 99, 81-87.

Munday, K. A. \& Blane, G. F., 1961. Cold stress of the mammal, bird and reptile. Comp. Biochem. Physiol. 2, 8-21.

Newelt, R. C. \& NorthCroft, H. R., 1967. A re-interpretation of the effect of temperature on the metabolism of certain marine invertebrates. J. Zool., Lond. 151, 277-298.

Nopp, H., 1965. Temperaturbezogene Regulationen des Sauerstoffverbrauchs und der Herzschlagrate bei einigen Landpulmonaten. $Z$, vergl. Physiol. 50, 641-659.

- \& Farahat, A. Z., 1967. Temperatur und Zellstoff wechsel bei Heliciden. Z. vergl. Physiol. $55,103-118$.

O'Connor, J. M., 1960. The action of fatty acids on oxidative metabolism. Proc. R. Ir. Acad. 61B, 187-200.

- 1964. The nature of the influence of fatty acids, glucose, and insulin on the respiratory quotient of animal tissues. Proc. R. Ir. Acad. 63B, 201-215.

OnLExbusch, H.-D. \& PRECHT, H., 1960. Ober den Umkehrpunkt von Atmungskurven bei hohen Temperaturen. II. Z. wiss. Zool. 164, 364-373.

Ohnesorge, F.-K. \& Schmitz, G., 1968. Einfluß der Badtemperatur und der Adaptationstemperatur auf die Kontraktionen des isolierten Darmes der Schleie (Tinca vulgaris). Z. vergl. Physiol. 58, 171-184.

Oufvereau, M., 1955. Température et fonctionnement thyroïdien chez les poissons. J. Physiol., Paris 47, 256-258.

Parry, G., 1966. Osmotic adaptation in fishes. Biol. Rev. 41, 392-444.

Parvatheswararao, V., 1967. Some mechanisms underlying thermal acclimation in a freshwater fish Etroplus maculatus (Teleostei). Comp. Biochem. Physiol, 21, 619-626.

Pequignot, J., Serfaty, A. \& Labat, R., 1967. Variations de salinité chez la Tanche (Tinca tinca L.): effet de la vagotomie sur l'intensité respiratoire et la teneur en eau et cations $\left(\mathrm{Na}+\right.$ et $\left.\mathrm{K}^{+}\right)$du tissu hépatique. Experientia 23, 264-265.

Perrte, D., 1965. Plan und Muster im zellulären Stoffwechsel. Naturwissenscbaften 52, 597-616.

Pickens, P. E., 1965. Heart rate of mussels as a function of latitude, intertidal height, and acclimation temperature. Physiol. Zoöl. 38, 390-405.

Platner, W. S., 1950. Effects of low temperature on magnesium content of blood, body fluids and tissues of goldfish and turtle. Am. J. Physiol. 161, 399-405.

Platzer, I., 1967. Untersuchungen zur Temperaturadaptation der tropischen Chironomidenart Chironomus strenzkei FitTkau (Diptera). Z. vergl. Physiol. 54, 58-74.

PocrNJić, Z., 1965. Influence de l'adaptation thermique sur la consommation d'oxygène chez les tritons. Arb. biol. Nauka 17, 139-148.

PRECFT, H., 1949. Die Temperaturabhängigkeit von Lebensprozessen. Z. Naturf. 4b, 26-35.

- 1951. Der Einfluß der Temperatur auf die Atmung und auf einige Fermente beim Aal (Anguilla vulgaris L.). Biol. Zbl. 70, 71-85.

- 1956. Einige Versuche zur Temperaturabhängigkeit von Lebensprozessen der Hefe Torulopsis kefyr. Biol. Zbl. 75, 689-705.

- 1959. Untersuchungen über die Resistenzadaptation einiger Organfunktionen von Warmwasserfischen gegenüber extremen Temperaturen. $Z$. vergl. Physiol. 42, 365-382.

- 1961a. Temperaturanpassungen bei wechselwarmen Tieren. Zool. Anz. (Suppl. Bd) 24, $38-60$.

- 1961b. Beiträge zur Temperaturadaptation des Aales (Anguilla vulgaris L.). I. Z. vergl. Physiol. 44, 451-462.

- 1962. Uber die Temperaturadaptation des Schwertträgers Xiphophorus helleri HeCKeL (Poeciliidae, Pisces). Z. wiss. Zool. 167, 73-86.

- 1964a. Gibt es biologische "Langzeituhren" bei wechselwarmen Tieren? Einige Versuche zum Problem der Beendigung von Diapausen bei Tieren. Zool. Anz. 172, 87-95.

- 1964b. Anpassungen wechselwarmer Tiere im normalen Temperaturbereich und ihre Ursachen. Naturw. Rdsch., Stuttg. 17, 438-442. 
- 1964c. Uber die Bedeutung des Blutes für die Temperaturadaptation von Fischen. Zool. Jb. (Abt. allg. Zool. Physiol. Tiere) 71, 313-327.

- 1964d. Uber die Resistenzadaptation wedselwarmer Tiere an extreme Temperaturen und ihre Ursachen. Helgoländer wiss. Meeresunters. 9, 392-411.

- 1965. Ergänzende Versuche zur Bedeutung des Blutes für die Temperaturadaptation bei Fischen. Zool. Anz. 175, 301-310.

- Basedow, T., Bereck, R., Lange, F., Thiede, W. \& Wilke, L., 1966. Reaktionen und Adaptationen wechselwarmer Tiere nach einer Knderung der Anpassungstemperatur und der zeitliche Verlauf, Helgoländer wiss. Meeresunters. 13, 369-401.

- \& Christophersen, J, 1965. Temperaturadaptation des Cilienepithels isolierter Kiemen und Fühlerspitzen von Mollusken. Z. wiss. Zool. 171, 197-209.

- - \& Hensel, H., 1955. Temperatur und Leben. Springer, Heidelberg, 514 pp.

- \& LINDNER, E., 1966. Reaktionen, Regulationen und Adaptationen der Tiere nach Veränderung der Temperatur und des Salzgehaltes. Versuche mit Zoothamninm biketes (Ciliata, Peritridha). Helgoländer wiss. Meeresunters. 13, 354-368.

PRECHT, I., 1967. Untersuchungen über Diapause, Leistungsadaptation und Temperaturresistenz einiger Insekten und Schnecken. Z. wiss. Zool. 176, 122-172.

Prosser, C. L. (Ed.), 1958. Physiological adaptation. A symposium held ... at the Mar. Biol. Lab., Woods Hole, Mass., Sept. 5-6, 1957. Soc. of Gen. Physiologists Washington, DC, $185 \mathrm{pp}$.

- (Ed.), 1967. Molecular mechanisms of temperature adaptation. Publ. Am. Ass. Advmt Sci. 84, $1-390$.

- \& BRown, F. A., jr., 1961. Comparative animal physiology. 2nd ed. Saunders Philadelphia, $\mathrm{Pa}, 688 \mathrm{pp}$.

- Precht, H. \& J JNkowsky, H.-D., 1965. Nervous control of metabolism during temperature acclimation of fish. Natureissenschaften 52, 168-169.

Punt, A., 1945. The influence of temperature upon gas-exchange in fish. Archs néerl. Zool. 7, 205-212.

RAFFY, A., 1954. Influence des variations de la température sur l'osmorégulation de quelques Téléostéens marins. C. r. Séanc. Soc. Biol. 148, 1796-1798.

RAO, K. P., 1966. Some aspects of the biochemical basis of metabolic adaptation. Helgoländer wiss. Meeresunters. 14, 439-450.

- \& BuLlock, T. H., 1954. Q10 as a function of size and habitat temperature in poikilotherms. Am. Nat. 88, 33-44.

Raschack, M., 1967. Osmoregulation und Kälteresistenz mariner Knochenfische. Naturwissenschaflen 54,97 .

Rasmussen, R. A. \& Rasmussen, L. E., 1967. Some observations on the protein and enzyme levels and fractions in normal and stressed elasmobranchs. Trans. N. Y. Acad. Sci. (Ser. 2) 29, 397-413.

Remane, A. \& Schlieper, C., 1958. Die Biologie des Brackwassers. Schweizerbart, Stuttgart, 348 pp. (Binnengewässer 22).

RemmerT, H., 1965. Biologische Periodik. In: Handbuch der Biologie. Hrsg. von F. Gessner. Akad. Verl. Ges. Athenaion, Frankfurt a. M., 5, 335-411.

Richards, A. G., 1963. The effect of temperature of heart-beat frequency in the cockroach, Periplaneta americana. J. Insect. Physiol. 9, 597-606.

RiNG, K. \& ChRistopherien, J, 1964. Untersuchungen über den Einfluß der Adaptationstemperatur auf die Resistenz und Aktivität der Transaminasen von Hefezellen. Arch. Mikrobiol. 48, 50-65.

Roberts, J. L., 1957. Thermal acclimation of metabolism in the crab Pachygrapbus carassipes Randal L. I. II. Physiol. Zoöl. 30, 232-242, 242-255.

- 1961. The influence of photoperiod upon thermal acclimation by the crucian carp Carassius carassius L. Zool. Anz. (Supp. Bd) 24, 73-78.

- 1964. Metabolic responses of fresh-water sunfish to seasonal photoperiods and temperatures. Helgoländer wiss. Meeresunters. 9, 459-473. 
- 1966. Systemic versus cellular acclimation to temperature by poikilotherms. Helgoländer wiss. Meeresunters. 14, 451-465.

Roots, B. I., 1968. Phospholipids of goldfish (Carassius auratus L.) brain: the influence of environmental temperature. Comp. Biochem. Physiol. 25, 457-466.

Rose, A. H. (Ed.), 1967. Thermobiology. Acad. Press, London, 653 pp.

RozhajA, D., 1963. The physiological meaning of thermal adaptation phenomena, Recl. Trav. Fac. Lett. Sci., Pristina 1, 257-263.

Rozin, P., 1965. Temperature independence of an arbitrary temporal discrimination in the goldfish. Science, N. Y. 149, 561-563.

RuHLAND, M. L. \& HeussneR, A., 1959. Chambre respiratoire pour la détermination simultanée de l'activité et la consommation d'oxygène par une méthode manométrique chez les Poissons de 3-10 g. C. r. Séanc. Soc. Biol. 153, 161-164.

Saroja, K. \& RaO, K. P., 1965. Some aspects of the mechanism of thermal acclimation in the earthworm Lampitio manritii. Z. vergl. Pbysiol. 50, 35-54.

SAUnders, R. L., 1963. Respiration of the atlantic cod. J. Fish. Res. Bd Can. 20, 373-386.

SChaller, F. \& ZINKLER, D., 1963. Atmungsphysiologische Untersuchungen am Gletscherfloh. Naturwissenschaften $\mathbf{5 0}, 385$.

Schenck, E., Luschnat, K.-D. \& Brune, H. F., 1956. Einfluß der Temperatur auf neuromuskuläre Bahnung und Hemmung beim Flußkrebs. Pflügers Arch. ges. Physiol. 263, 476-491.

SCHLIEPER, C., 1966. Genetic and nongenetic cellular resistance adaptation in marine invertebrates. Helgoländer wiss. Meeresunters. 14, 482-502.

Schmeing-Engrerding, F., 1953. Die Vorzugstemperaturen einiger Knochenfische und ihre physiologische Bedeutung. Z. Fisch. (N.F.) 2, 125-155.

ScrmidT, G. H., 1956. Der Stoffwechsel der Caraben (Ins., Coleopt.) und seine Beziehung zum Wasserhaushalt. Zool. Jb. (Abt. allg. Zool. Physiol. Tiere) 66, 273-294.

- 1968. Einfluß der Temperatur und Luffeuchtigkeit auf die Energiebilanz während der Metamorphose verschiedener Kasten von Formica polyctena FoersT. (Hym.). Z. angere. Ent. 61, 61-109.

Schneider, G., 1964. Untersuchungen zur Analyse der retinalen Flimmerpotentiale von Carausius morosus. Z. vergl. Physiol. 49, 195-269.

Scholander, P. F., Dam, L. van, Kanwisher, J. W., Hammel, H. T. \& Gordon, M. S., 1957. Supercooling and osmoregulation in arctic fish. J. cell. comp. Physiol. 49, 5-24.

- Flagg, W., Walters, V. \& Irving, L., 1953. Climatic adaptation in arctic and tropical poikilotherms. Physiol. Zoöl. 26, 67-92.

Schultze, D., 1965. Beiträge zur Temperaturadaptation des Aales (Angrilla vulgaris L.). II. Z. wiss. Zool. 172, 104-133.

SChWARTzKopfF, J., 1955. Vergleichende Untersuchungen der Herzfrequenz bei Krebsen. Biol. Zbl. 74, 480-497.

SEGAL, E., 1961. Acclimation in molluscs. Am. Zool. 1, 235-244.

- 1962. Initial response of the heart-rate of a gastropod, Acmaea limatula, to abrupt changes in temperature. Nature, Lond. 195, 674-675.

- RAO, K. P. \& JAMES, T. W., 1953. Rate of activity as a function of intertidal height within populations of some littoral molluscs. Nature, Lond. 172, 1108-1109.

SEIBT, U., 1967. Der Einfluß der Temperatur auf die Dunkeladaptation von Apis mellifica. Z. vergl. Physiol. 57, 77-102.

Selvarajan, V. R., 1962. Chloride regulation in a freshwater fish, Cirrbina reba, under heterosmotic conditions and high temperature. Proc. Indian Acad. Sci. 55, 91-98.

Serfaty, A. \& Laffont, J., 1965. Influence de l'abaissement de la température sur la valeur de la fréquence respiratoire et taux lymphocytaire du milieu sanguin chez la Carpe commune (Cyprinus carpio L.). Hydrobiologia 26, 409-420.

- \& Wattzenegger, M., 1964. Influence des variations du facteur thermique sur l'intensité du reflex aero-cardiaque chez la Carpe commune (Cyprinus carpio L.). Hydrobiologia 23, 281-286. 
Smir, H., 1965. Some experiments on the oxygen consumption of goldfish (Carassius auratus L.) in relation to swimming speed. Can. J. Zool. 43, 623-633.

- 1967. Influence of temperature on the rate of gastric juice secretion in the brown bullhead, Ictalurus nebulosus. Comp. Biochem. Pbysiol. 21, 125-132.

SMiTH, M. W., 1966a. Sodium-glucose interactions in the goldfish intestine. J. Pbysiol, Lond. $182,559-573$.

- 1966b. Time course and nature of temperature induced changes in sodium-ghucose interactions. J. Pbysiol., Lond. 183, 649-657.

- 1966c. Puromycin inbibition of changes in glucose-evoked potentials recorded in goldfish intestine after periods of temperature acclimatization. Experientia 22, 252.

- 1967a. Methionine transfer across goldfish intestine acclimatized to different temperatures. Experientia 23, 548-549.

- 1967b. Influence of temperature acclimatization on the temperature-dependence and ouabain-sensitivity of goldfish intestinal adenosine triphosphatase. Biochem. J. 105, 65-71.

- Colombo, V. E. \& MunN, E. A., 1968. Influence of temperature acclimatization on the ionic activation of goldfish intestinal adenosine triphosphatase. Biochem. J. 107, 691-698.

- \& Morris, D., 1966. Temperature acclimatization and protein synthesis in the goldfish mucosa. Experientia 22, 678-679.

Somero, G. N., Giese, A. C. \& Wohtschl.ag, D. E., 1968. Cold adaption of the antarctic fish Trematomus bernacchii. Comp. Biochem. Physiol. 26, 223-233.

Steen, J. B. \& KruYsse, A., 1964. The respiratory function of teleostean gills. Comp. Biochem. Physiol. 12, 127-142.

Steinbach, H. B., 1949. Temperature coefficients of muscle apyrase systems. J. cell. comp. physiol. 33, 123-131.

Streve, H., 1963. Das Belichtungspotential der Retina des Einsiedlerkrebses in Abhängigkeit von der Temperatur. Z. vergl. Physiol. 46, 249-275.

Straub, M., 1957. Weitere Untersuchungen zur Temperaturadaptation der Sauerstoffbindung des Blutes von Rana esculenta L. Z. vergl. Physiol. 39, 507-523.

Suhrmann, R., 1955. Weitere Versuche über Temperaturadaptation der Karauschen (Carassius vulgaris Nus.). Biol. Zbl. 74, 432-448.

TALO, A. \& Lagerspetz, K. Y. H., 1967. Temperature acclimation of the functional parameters of the giant nerve fibres in Lumbricus terrestris L. II. J. exp. Biol. 47, 481-484.

TAsHian, R. E., 1956. Geographic variation in the respiratory metabolism and temperature coefficient in tropical and temperate forms of the fiddler crab, Uca pugnax. Zoologica, N. Y. 41, 39-47.

- \& VERnBerg, F. J,, 1958. The specific distinctness of the fiddler crabs Uca pugnax (SMrTH) and Uca rapax (SMrTH) at their zone of overlap in northeastern Florida. Zoologica, N. Y. 43, 89-93.

TAYLOR, R. E, jr., \& BARKER, S. B., 1967. Absence of an in vitro thyroxine effect on oxygen consumption and sodium or water transport by anuran skin and bladder. Gen. comp. Endocr. 9, 129-134.

T'EAL, J. M., 1959. Respiration of crabs in Georgia salt marshes and its relation to their ecology. Physiol. Zoöl. 32, 1-14.

ThIEDE, W., 1965. Uber die hormonale Basis der Adaptation an extreme Temperaturen beim Schwertträger Xipbopborus belleri HeCKEL (Poeciliidae, Pisces). Z. wiss. Zool. 172, 305-346.

THIele, H.-U., 1968. Was bindet Laufkäfer an ihre Lebensräume? Naturw. Rdsch., Stuttg. $21,57-65$.

Thornburn, C. C. \& MatTy, A. J., 1963. The effect of thyroxine on some aspects of nitrogen metabolism in the goldfish (Carassius auratus) and the trout (Salmo trutta). Comp. Biochem. Physiol. 8, 1-12.

- - 1966. Effects of long-term treatment and of low concentrations of thyroid hormones on the oxygen uptake of toad tissues. J. Endocr. 36, 221-229.

Thorson, G., 1952. Zur jetzigen Lage der marinen Bodentier-Ókologie. Zool. Anz. (Suppl. Bd) $15,276-327$. 
TrSHLER, P. V., 1963. Effect of thyroxine administered in vitro and in vivo on the succinoxidase and malic dehydrogenase reactions of frog myocardium. Endocrinology 72, 673-676.

TRIBE, M. A. \& BOWLER, K., 1968. Temperature dependence of "standard metabolic rate" in a poikilotherm. Comp. Biochem. Pbysiol. 25, 427-436.

Troshin, A. S. (Ed.), 1967. The cell and environmental temperature. Proceedings of the International Symposium on Cytoecology, Leningrad, 1963. Tr. from the Russian. Engl. ed. by C. L. Prosser. Pergamon Press, Oxford, 462 pp.

TsukUDA, H. \& OHSA WA, W., 1958. The heat and cold coma temperatures in Lebistes reticulatus as determined by raising and lowering water temperature at constant rates. J. Inst. Polytech. Osaka Cy Univ. (Ser. D) 9, 69-76.

VALEN, E., 1958. Oxygen consumption in relation to temperature in some poikilotherms. Acta physiol. scand. 42, 358-362.

VERNBERG, F. J., 1959. Studies on the physiological variation between tropical and temperate zone fiddler crabs of the genus Uca. I. II. Biol. Bull. mar. biol. Lab., Woods Hole 117, $163-184,582-593$.

- 1962. Comparative physiology: Latitudinal effects on physiological properties of animal populations. A. Rev. Physiol. 24, 517-546.

- \& Cosrzow, J. D., jr., 1966. Studies on the physiological variation between tropical and temperate-zone fiddler crabs of the genus Uca. IV. Physiol. Zoöl. 39, 36-52.

- \& Meriney, D. K., 1957. The influence of temperature and humidity on the metabolism of melanistric strains of Drosophila melanogaster. J. Elisha Mitcbell scient. Soc. 73, $351-362$.

- \& Vernberg, W. B., 1964. Metabolic adaptation of animals from different latitudes. Helgoländer wiss. Meeresunters. 9, 476-487.

- 1966a. Studies on the physiological variation between tropical and temperate-zone fiddler crabs of the genus Uca. VI. J. Elisha Mitchell scient. Soc. 82, 30-34.

- 1966b. Studies on the physiological variations between tropical and temperate-zone fiddler crabs of the genus Uca. VII. Comp. Biocbem. Pbysiol. 19, 489-524.

VERNBERG, W. B., 1961. Studies on oxygen consumption in digenetic trematodes. VI. Expl Parasit. 11, 270-275.

- \& Hunter, W. S., 1961. Studies on oxygen consumption in digenetic trematodes. V. Expl Parasit. 11, 34-38.

- \& Vernberg, F. J., 1966. Studies on the physiological variation between tropical and temperate-zone fiddler crabs of the genus Uca. V. Comp. Biochem. Physiol. 17, 363-374.

Vogel, G., John, H. \& Krause, H., 1958. Uber den Einfluß verschiedener Temperaturen auf das Aktionspotential des einzelnen Ranvierschen Schnürringes. Pflügers Arch. ges. Physiol. 267, 414-416.

WALKER, T. J., jr., 1957. Specificity in the response of female tree crickets (Orthoptera, Gryllidae, Oecanthinae) to calling songs of the males. Ann. Ent. Soc. Am. 50, 626-636.

WaLTHER, J. B., 1965. Untersuchungen zur Temperaturabhängigkeit des Generatorpotentials einzelner Sehzellen in Augen von Hirudo medicinalis. Zool. Anz. (Suppl. Bd) 28, 353-358.

Weatherlex, A. H., 1963. Thermal stress and internal tissue in the perch Perca fuviatilis (L.) Proc, zool. Soc., Lond. 141, 527-555.

WIESER, W., 1963. Parameter des Sauerstoffverbrauchs. II. Z. vergl. Physiol. 47, 1-16.

- 1964. Die ökologischen Beziehungen stoff wechselnder Systeme vom Standpunkt der Regelungstheorie. Helgolander wiss. Meereswnters, 9, 356-370.

- 1965a. Untersuchungen über die Ernährung und den Gesamtstoffwechsel von Porcellio scaber (Crustacea: Isopoda). Pedobiologia 5, 304-331.

- 1965b. Die Steuerung von Stoffwechselvorgängen bei Porcellio scaber LATR. durch Temperatur und Licht. Zool. Anz. (Suppl. Bd) 28, 359-364.

- \& Nopp-Pammer, E., 1968. Der Einfluß der Temperatur und des Häutungszyklus auf die Melaninsynthese von Triturus cristatus. Zool. Anz. (Suppl. Bd) 31, 131-139.

WIKGREN, B. J., 1953. Osmotic regulation in some aquatic animals with special reference to the influence of temperature. Acta zool. fenn. 71, 3-102. 
WILHoft, D. C., 1966. The metabolic response to thyroxine of lizards maintained in a thermal gradient. Gen. comp. Endocr. 7, 445-451.

WiNTER, CH., 1967. Untersuchungen über die Temperaturabhängigkeit der Erregung von Mechanoreceptoren. Zool. Anz. (Suppl. Bd) 30, 234-239.

WitTENBERGer, C. \& Diaciuc, I. V., 1965. Effort metabolism of lateral muscles in carp. J. Fish. Res. Bd Can. 22, 1397-1406.

WohlschlaG, D. E., 1963. An antarctic fish with unusually low metabolism. Ecology 44, $557-564$.

- 1964. Respiratory metabolism and ecological characteristics of some fishes in McMurdo sound, Antarctica. In: Biology of the Antarctic seas. Ed. by M. O. Lee. American Geophysical Union, Washington, D. C., 33-62 (Antarctic Res. Ser. 1).

WOYNÁRovich, E., 1963. Sanerstoff verbrauch von frïheren Entwicklungsstadien (Laich, Praelarven, Larven) der Fische in einem Wassertemperaturbereich von $0,5-28^{\circ} \mathrm{C}$. Acta biol. Debrećina 2, 155-168.

WyatT, G. R., 1967. The biochemistry of sugars and polysaccharides in insects. Adv. Insect Physiol. 4, 287-360.

YAMASHITA, S., 1964. Chemoreceptor response in frog, as modified by temperature change. Jap. J. Physiol. 14, 488-504.

YURKIEWICZ, W. J. \& SMYTH, T., jr., 1966. Effect of temperature on oxygen consumption and fuel utilization by the sheep blowfly. J. Insect Physiol. 12, 403-408.

Zain-Ul-ABedin, M. \& KABORSKI, B., 1966. Increased blood clotting time in a hibernating lizard. Can. J. Physiol. 44, 505-507.

ZEBE, E., 1961.Vergleichende Physiologie des Energiestoffwechsels von Muskeln. Ergebn. Biol. 24, $247-286$.

Zerbst, E., 1966. Zur Auswertung biologischer Anpassungsvorgänge mit Hilfe der Fließgleichgewichtstheorie. Untersuchungen zur Temperaturanpassung der Frequenzbildung isolierter Frosch- und Rattenherzen. Berlin, Nat.-math. Habil.-Schr. 